\title{
Psychology and aggression
}

\section{ELTON B. MCNEIL}

\section{University of Michigan}

In man's attempt to apply the scientific method to human affairs, the study of aggression has commanded an inordinate amount of the energy of social scientists. Although recent events have expanded the scale on which human destructiveness can be expressed and have multiplied the urgency of the need for a solution to the riddle of hostility, the primary source of anxiety about aggressive behavior is still highly personal and quite mundane. The parent whose belligerent child is rejected by playmates, the schoolteacher whose ire is provoked by negativism, the policeman whose dignity is outraged by the defiance of a delinquent, and the average citizen whose rights have been trampled on-all experience an anguish that they cannot summon up when they consider the possibility that man may one day be the instrument of his own mass extinction.

Personal frustration is woven tightly into the fabric of the life of each of us, making aggressive feelings an inevitable human experience. The paradox which aggression presents is that, in all its abundance and despite the massive scrutiny it has endured since the beginning of time, it remains as enigmatic as if its presence had not yet been detected by man. An apt analogy might be to liken visible aggressive acts to a tree that is able to resist man's efforts to uproot it because he is only dimly aware of the meaning of the concept "roots." In many respects, the labors of the last forty years resemble such primitive efforts in our attempt to comprehend the notion of the roots of man's emotional life-roots which twist and turn in a seemingly incomprehensible fashion and plunge to depths to which man has seldom ventured. It is not surprising, then, that an account of this toil will inevitably contain murky observation, fanciful speculation, and valid as well as irrelevant and trivial fact. It is man's inability to distinguish between the momentous and the meaningless that constrains him from discarding what looks trivial but may, in fact, be vital.

This description of the current status of theory and fact in the psychological study of aggression is designed to be representative of the progress being made in exploring the many facets of hostility. Research in which the essential findings teeter precariously on an imposingly elaborate, but shaky, structure of premise, assumption, or faith have been excluded from consideration. A similar fate was accorded to experimental programs describable only in language unique to the experimenter and without suitable synonyms or referents in the experience of the educated person. Finally, conclusions at the far reaches of offshoots of branches of theory were omitted if they were meaningful only in the complicated context of a matrix of previous specialized work. To be sure, one man's esoterica is another man's universal truth, but the search here is for the core conclusions in the study 
of aggression. The variety of topics which must be touched upon in considering the effects of man's anger is perhaps an appropriate measure of the degree to which aggression is a concomitant of human activity.

\section{Aggression in Animals}

The survey of our knowledge of aggression might well begin with the study of animals, for it has been said that man is an animal who is distinguishable from other animals only by his incredible capacity for making trouble for himself. Certainly no species other than man has achieved such richness, variety, deviousness, and sophistication in the expression of hostility. It is this very simplicity of infrahuman forms of life which makes them a compelling object of research and which robs findings in animal work of everything but an oblique application to human problems. The unique difficulty of Homo sapiens is that he is capable of experiencing nuances of feeling and of attaching this feeling to symbols. Without this encumbrance, the experience of aggressiveness becomes one-dimensional.

Findings gained from animal research must possess certain qualities if they are to be translated into human terms. They must be such general laws that they fit, with equal ease, all organisms capable of learning, or they must issue from conditions that match the human situation with some exactness. There are some developmental conditions which are similar for human children and the young of infrahuman mammals. In the earliest stages of a child's development, the influence of culture is relatively small, and many of the reactions peculiar to human beings have yet to mature. An undeveloped capacity for logic and language renders the child as ineffective as his less promising and distant relations. In these instances, generalizations concerning subhu- man aggressive responses may properly be extended to children. All too frequently, human-animal analogies do not respect these limits and furnish false and confusing leads to theorists. A comparable analogical error can occur when theorists attempt to draw a parallel between the responses of children and the reactions of "primitive" adults in preliterate societies. Suffering from the romantic conviction that such things as guileless, "childlike" societies exist, some enthusiastic speculators ignore the maxim that only under certain circumstances does a child react to his environment as does the primitive adult. Reasoning by analogy is a useful device if it is employed to stimulate new hypotheses; it is not a device free from risk.

Animals make convenient subjects for study because the experimenter can exert nearly absolute control over the environment and experiences of the organism. Some studies of the aggressiveness of animals are done by making observations of their actions in their natural habitat. Such observations are probably never quite "natural." The classic observations of primates, for example, were done on Monkey Hill in the London Zoo (414). Such a captive colony may resemble, but it will not duplicate, the social life of primates exposed to the natural vagaries of food supply and the constant threat of disease or predators.

As a universal rule, apes, as well as other species, will fight in response to attack by others if they are evenly matched and there is no escape. The primates will also initiate conflict over possessions; in response to the intrusion into their social group of a stranger of their own species; and in defense of "property rights," such as geographical areas of forage and nesting. Analogies can be drawn from these observations to the behavior of small children who frequently come into conflict with one another over 
possessions, treat strange children badly, and react vigorously to violation of their territorial rights in backyards and sand boxes.

For centuries man has used his observations of the animal world as the basis for selecting some species and strains for domestication while capitalizing on the natural aggressiveness of other forms of wild life by channeling their savagery to human ends. Attempts to produce outstandingly vicious strains and breeds of animal are still being conducted for research purposes, and bulls and gamecocks are still being bred for aggressiveness (355). The absence of recognizable breed and strain differences among humans makes experimentation on the development of aggressive strains, through breeding, a meaningless task. The folklore about warlike human groups or nations has always implied the existence of some form of inherited belligerence, but this is without foundation in fact. National pride in the ferocity of its citizens trades heavily on the not-so-secret gratification that accompanies the uninhibited expression of one's impulses.

The most relevant studies of aggression in animals have explored the mechanics of the learning of aggressive responses and how these patterns may be modified by training. As Kuo (225) demonstrated nearly thirty years ago with cats, even the most natural forms of aggressive action may require some collaboration from the environment to reach their characteristic form of expression. A kitten can be taught to kill cnly certain kinds of mice, or it can be conditioned with electric shock to develop an intense avoidance of all mice. Aggressive impulses are quite malleable, and the form of their expression can be altered in a number of fundamental ways $(214,356)$. A mouse can be trained to assault and dominate simply by having it always emerge the victor in its first fighting experiences. If a mouse is allowed to fight only other mice that are trained to run cowering from battle, it gets a false notion of its prowess, and this view of its fighting capacity determines its aggressive reaction to all other mice it encounters. It is logical to expect that a human child able to dominate his age-mates throughout his early years would respond with feelings of invincibility not unlike the trained mouse in these experiments. Among mice, as perhaps among children, an individual severely defeated in its first encounter with combat develops a passivity that is highly resistant to retraining (138). Once burned, twice shy, is an apt description of the response that occurs if the burning takes place at an early age.

Although a fixed passivity and submissiveness can be achieved by exposing an animal to defeat from the onset of its fighting career (357), other methods produce a similar result. Scott (356) raised mice in an environment free from conflict, to evoke what he calls the "habit of not fighting," and he suggests that children too might acquire a passive inhibition of the fighting response if they could live in a setting in which the stimulation to fight were absent. Whether such passivity would be at the cost of initiative is an unanswered question. Yet another means of eliminating aggressive responses, at least temporarily, has been reported $(364,365)$. In this case the mechanism is familiar. It involves raising the intensity of some other need until, by its very insistence, it forces the animal to abandon aggressiveness while the more pressing need is being restored to a comfortable equilibrium. Thus hungry rats accustomed to attacking one another will tend to fight less in a joint feeding situation. Such a life of bread and circuses or constant threat would be difficult to maintain for long.

A primary insight gained from animal studies refers to the difficulty in changing an aggressive or non-aggressive way of life, 
once it is firmly established (255, 256). Among animals and undoubtedly among people, the loss of dominant status is reacted to with considerable violence, and attempts at downward displacement are resisted with great vigor. A dominant cat accustomed to deference on the part of other cats can be converted into a quavering social inferior by placing it in a succession of conflict-laden situations that require solutions but which it cannot solve. Reduced to emotional helplessness, the frightened cat can have its conflict-free status restored by the surreptitious addition of alcohol to its milk. Alcoholic courage makes the cat reckless, and it will take on all comers; this aggressiveness disappears as it sobers up. The analogy between belligerent, drunken cats and similarly inclined human beings is an intriguing one.

Studies of the physiology of rage and anger in animals have sought to discover the existence of characteristics of the nervous and glandular systems which might shed light on the nature or origin of aggressive behavior. Since the emotions we experience are inextricably a part of the internal functioning of the organism, physiological studies hope to discover chemical or neurological means of modifying and controlling aggressiveness. Typical of such research is the artificial alteration of the hormone balance of animals to study the effect of male and female hormones on fighting behavior (33). This can be accomplished through the injection of synthetic hormones or by removing the glands which normally produce these hormones. While physiological experiments have given us a great deal of information about the relationship of emotion and body chemistry in animals, the direct application of these findings to human aggressiveness is quite limited (72). The human animal, with its existence complicated by language and symbols, is much less the victim of its phys- iology and can respond to changes in its internal environment in a variety of ways. A brain tumor or pathological chemical state can be sufficient to override the rational behavior of man, but beyond these diseased conditions there is no evidence that the quantity, quality, or direction of man's aggression is attributable directly or exclusively to his normal chemical or neurological condition.

The study of animals has not yet uncovered evidence that aggression is a product of an instinctive urge in the organism, and it is unlikely that such a conclusion will ever be reached. Although the capacity to be aggressive is characteristic of every form of life, aggressiveness is fashioned from experience. The study of the physiology of anger in animals may one day provide direction for similar explorations of human beings, and it is fair to say that the theoretical gap between human and animal research is rapidly narrowing. At the present time, the information gained from work with animals provides a model of cause and effect which is most fruitfully applied to that brief period in human development when the child has yet to acquire a symbolic means of managing his strong emotions.

\section{The Nature of Man}

Human hostility cannot be comprehended without some consideration of the nature of man, the forces that drive him to action, the needs he must gratify, the conflicts he encounters, and the anxieties that beset him. These aspects of human existence form the basis for the serviceability of an active assault on one's environment and provide the core of man's most brutal and beautiful behavior.

\section{DRIVES AND NEEDS}

In order to account for the fact that human beings do something about the dis- 
comforts they experience, it has been necessary to invent a hypothetical construct called "drive." This is defined as a state of tension within the individual, resulting from deprivation or disequilibrium of a physiological or psychological nature. This definition is equally descriptive of the concept of "need," and the two terms can be used interchangeably. "Drive" usually implies an urge to action that may or may not be characteristic of need. Although for the sake of convenience we tend to describe human behavior as the product of a single powerful drive or need, there is probably no human act that does not represent the resolution of a host of drives of varying urgency. It is the complexity of this interaction of needs that is the inspiration of poets and the despair of social scientists.

The study of motivation-the "why" of man's behavior-draws heavily on a physiological model supplied by Walter Cannon nearly forty years ago (66). Cannon pointed out that life is maintained by a balance, or homeostasis, of systems within the living organism. The human body, for example, has a limited range within which such processes as breathing, temperature, thirst, hunger, and blood pressure can vary without destroying life. As long as these physical factors are within the prescribed limits, the organism is free of the state of tension which would provide the motive or drive to action; when these limits are exceeded, a necessary equilibrium or balance is upset, and the physiological needs of the organism spur it on to behavior which will restore the former tension-free state. This theory suggests that a complete analysis of motivation must consider three distinct aspects of behavior: the nature of the motivating stimulus or need, the quality of the behavior that the need arouses, and the object toward which the behavior is directed.

The study of aggression in the service of need-satisfaction is complicated by the fact that man is capable of acquiring drives which are not purely physiological. The notion of drive seems reasonable for a physiological urge such as hunger, since we can observe that a person has been without food for some time, that he becomes restless and begins to explore his environment until he finds food, and that he eats it and his restlessness subsides. With learned drives or needs, identifying the motivating forces and the objects or goals that will satisfy them are much more speculative matters. When hunger drives clash with the need to diet, the model of homeostasis must be stretched considerably to encompass all the facts. The "need" for a svelte figure to insure acceptance by others or the "need" for bulging muscles as reassurance that one's masculinity has not faded are "needs" that do not have the logical directness of hunger. Since psychological needs seem different in kind from physiological needs, theorists have attempted to maintain a distinction between them with labels such as "biogenic" and "psychogenic," "basic" and "derived," "organic" and "functional," "physiological" and "social," or "primary" and "secondary." The arbitrary nature of such a division can be seen by taking aggression as a case in point. A person might be hungry, thirsty, or cold but is prevented from alleviating this feeling by someone for whom he already has a cordial dislike. As the frustration mounts, he may attack and injure his torturer in a sudden burst of consuming rage. The interaction of physical event and psychological experience is apparent, and the separation of these aspects of motivation is patently artificial.

Over the years, theoretical arguments have raged about the proper division of needs into psychological and physiological categories and over the proper number of each kind (261, 384, 391). Orthodox psy- 
choanalytic theorists, for example, may limit man's basic needs to sex and aggression and describe all other needs as derivatives of these (131). As you can imagine, such a conception requires a highly circuitous explanation of the many needs which each of us seems to possess (398). Theorists of other persuasions succumbed to the temptation of unrestrained list-making, and the catalogue of man's needs became so lengthy that it was useless. Today, the most commonly employed list of needs is that of Murray (288) and his co-workers, whose collection includes needs for acquisition, dominance, affiliation, aggression, abasement, deference, and superiority among those of psychogenic origin.

Maslow (252) offered to compromise this issue of physiological versus psychological needs by putting all of them on the same continuum and ranking them in terms of a hierarchy of urgency or priority. From most to least basic, Maslow lists five categories: (1) physiological needs (hunger, thirst, etc.); (2) safety needs (protection from harm or injury); (3) love needs (affection, belongingness); (4) esteem needs (self-respect, social approval); and (5) selfactualization needs (maximum development of one's potentialities). Until physiological needs have been gratified or reduced to a tolerable level, the individual must respond to them and disregard less basic needs. With satisfaction assured on one level, he is free to achieve on a higher level. This conception of the ordering of human needs helps us to understand why civilized man, when threatened with physiological deprivation, may resort to a savagery that is without regard for safety, love, esteem, or selfactualization.

The intricacy of man's nature is most clearly attested to by the observation that he may be driven to act by powerful needs of which he is unaware. When pressed to do so, the reasons he gives for his actions may be "good" ones rather than "real" ones. The web of rationalization that he may spin to disguise his motives will serve to protect him from the painful necessity of examining them. Thus he may clothe in the trappings of love the hatred that cannot be admitted into consciousness. The overprotective mother who lavishes care and attention on her child may be a model to others, yet be engaged in the process of crushing the initiative and independence of her child. With hostility safely out of consciousness and acceptable attitudes and feelings standing in its place, she can appear to be at peace with the world while exercising the resentment she does not recognize as her own. Killing through kindness is a subtle sadist's delight because it can be prolonged for a lifetime, it is free of the taxation of guilt, and it brings applause from the observing public while wringing resigned acceptance from the victim. It is in the entanglements of conscious and unconscious psychological needs that we are most likely to lose sight of the nature of aggression in man.

\section{CONFLICT AND ANXIETY}

It is not the more the merrier with drives. The simultaneous existence of one or more incompatible drives, urges, wishes, or needs heightens the risk of conflict-incompatible, in the sense that gratification of one would automatically eliminate the possibility of gratifying the other. The familiar conflicts of daily life are usually resolved simply by holding one need in abeyance while gratifying the other. Yet if the antagonistic needs are both intense or both vital to the emotional equilibrium of the individual, such conflict can be highly disruptive to the psychic economy. If conflict were a limited or self-contained process, it would play only a minor part in human adjustment; but, as Miller (273) noted, conflict tends to spread 
to new situations and encompass an ever expanding share of the individual's emotional life.

Conflict may occur between incompatible needs, between incompatible modes of behavior aroused by the needs, or may exist in choosing a means of gratifying the needs. All conflicts are not of equal intensity (253); some involve merely choosing between simple alternatives, such as two television shows scheduled at the same time, which is easily resolved because the deprivation is not very great in either case. Successively more complicated are the conflicting attractions of two vital goals or two paths to the same goal. Although such conflicts can be crippling, the most extreme form of disruption is provided by catastrophic struggles in which no alternative is reasonable and all courses of action are equally threatening.

Another way of describing human conflict is in terms of whether the conflicting alternatives are viewed as positive or negative ones (235). If one has to choose between a Thunderbird and a Cadillac, both alternatives would appear to be positive. For convenience, these can be designated as plus-plus conflicts, to indicate the attractiveness of the alternatives. Conflicts of this sort are usually of minor significance and become severe only when they are rooted in other emotional problems. When needsatisfiers have both positive and negative aspects, such as the thorn that accompanies the rose, then vacillation, indecision, or worry is more likely to result. Minus-minus conflicts are highly threatening and evoke extreme forms of human behavior. "Out of the frying pan into the fire" is a minusminus conflict. The complexity of human behavior allows an infinite variety of combinations of plus and minus characteristics and thus an infinite variety of conflicts.

An important aspect of the concept of conflict is the strength of the opposing forces. If the conflict is between an aggressive impulse and the prohibition of its expression and if both the impulse and the prohibition are intense, the person in whom the conflict rages can be reduced to helplessness by the battle of impulse versus restraint.

Conflict is internal, and it is a symbolic process. This human capacity to deal with the environment in symbolic rather than concrete ways allows us to anticipate the possibility of future events and to make a rough calculation of their probability. While such an ability is necessary for a rational and planned life, it is a mixed blessing. Just as the organism can learn to expect certain happy and gratifying experiences in the future, it also learns to dread painful and frustrating circumstances. The mental distress that accompanies anticipated pain or frustration has been labeled "anxiety," and it has been described as the most intolerable psychic state that a human being has to endure. This state can range from the uneasiness and apprehension familiar to us all to the anguish of full-blown panic; from the tense social situation to the gripping dread of cancer. Anxiety must be learned, and it is the one learned drive which most regularly restrains us from expressing other drives and satisfying our needs.

The acute physiological disturbances that are characteristic of anxiety (trembling, sweating, pounding heart, dry mouth) have their origin in the body's attempt to escape from the painful stimuli that it expects to encounter. A hand on a hot radiator produces pain, removing the hand brings relief; thus pain and radiators become bound together as one experience. Radiators then become cues or signals which evoke apprehension. This is an example of how anxiety gets associated with objects and persons in the environment. When social experiences 
are substituted for physical ones, a child can be taught to avoid contact with aggressive situations as easily as he can learn to avoid hot stoves.

Although a person can feel anxious about imminent physical dangers in the real world, a more fundamental source of anxiety is found in threats to his personal adequacy or the status of his relationships- with others. Since a child depends so completely on others, the possible loss of their acceptance can produce an intense anxiety which drives him to learn forms of behavior that will maintain him in their good graces. This anxiety to preserve one's self-esteem, as well as the esteem of others, is sufficiently powerful to override the demands of physical needs, such as hunger or thirst, and may even push the individual to sacrifice or destroy his own life. While the anticipation of punishment or pain may act to inhibit aggressiveness or to limit its expression, the attempt to escape from anxiety may provoke aggressive outbursts on a monumental scale.

Aggressive actions can also be motivated by the need to resolve situations filled with the anxiety of continuous anticipation; the risk of physical injury resulting from a tempestuous act may be preferred to the dread of waiting for the unknown to happen. Aggressive action, in this instance, relieves anxiety by making the person an active participant in his fate. Soldiers who were able to return the fire of the enemy, for example, were much less likely to be crippled by overwhelming anxiety. Anxiety will spread from the specific stimulus which provoked it until it includes similar, but previously neutral, objects. A child may generalize from his reaction to a gruff policeman in such a way that even as an adult he becomes apprehensive whenever he is stopped by a policeman.

\section{Frustration and Aggression}

The bulk of human aggressiveness can be traced directly to frustration. The civilizing of the child cannot be accomplished without frustration of his needs, for the society insists that he must learn to satisfy his needs at specified times, in specified places, by specified techniques, and in relation only to specified objects. This systematic interference with the needs of its members seems to be a necessary condition of group living, for it makes the behavior of others a dependable and predictable event and allows planning for the common good. Although most well-socialized adults encounter many frustrations in the course of their daily lives, they use established patterns of reaction to overcome them and to prevent their recurrence. The seeming ease with which adults remove, or adjust to, obstacles in their paths is a sharp contrast to the child's fumbling attempt to apply his limited skill and primitive understanding to the management of frustration. Not only do the child's needs seem to him to be overpowering, but the few alternative ways he knows of satisfying them offer little hope of an easy restoration of his emotional equilibrium. The child's methods of meeting his many frustrations tend to be quite simple and direct, and, until he learns a variety of ways to solve his problems, he is bound to feel like the helpless victim of the caprice of his environment. It is in this setting that some of the most fundamental personality characteristics of the individual are established, and his success or failure in mastering frustration has the utmost relevance to the aggressiveness with which he will manage his life.

Frustration involves interference with the gratification of a motive, need, or drive. The source of frustration may be perceived by the individual as internal or external, and it may take any of a number of forms (186). 
Frustration among children, for example, frequently appears as a physical obstruction, since they live in a world built to an adult scale. Frustration can be due to sheer satiation with a task from which there is no escape, or it can be caused by a discrepancy between an individual's desire to solve a problem and his ability to do so. Since so many of our working and social relationships are organized in terms of employers and employees and leaders and followers, frustration can issue directly from unsatisfactory leadership which thwarts gratification of the needs of others. The interpretation of what constitutes frustration is a highly personal and individual matter and depends almost completely on the perception one has that gratification is being, or will be, withheld. To an intensely ambitious person, for example, life may be the continuous pursuit of gratification which, when achieved, is at once replaced by the demands of a new set of goals. As long as gratification is possible, it is a challenge rather than a frustration.

Rosenzweig (341) pointed out that frustration can be delineated further as active or passive. The blocking of an individual's progress toward a goal, when the obstacle simply stands in the way of gratification, is passive frustration. Active frustration occurs when the interference with gratification is coupled with a threat of danger. Thus the passive frustration of a locked door may become an active frustration when the building is burning. The quality of frustration can also be distinguished by describing it in terms of privation, deprivation, or obstruction. The frustrations stemming from privations, for example, have a quite different meaning from those perceived as deprivations or obstructions. The privation of being born into poverty poses a series of frustrations for the individual, but his reaction to them differs considerably from his responses to being deprived of wealth, once he has possessed it. In much the same fashion, being born with a physical defect produces a psychological reaction distinct from that occurring when the defect is imposed by the carelessness of someone else.

The response to frustration is a complex affair, and its determinants include situational factors such as the setting in which it takes place, the intensity of the frustrating experience, its duration, the extent to which the victim sees a way to relieve his dilemma, and the individual's personal history of success or failure in dealing with states of tension. The fact that frustration regularly casts an aggressive shadow makes knowledge of its nature indispensable to an understanding of man's destructive impulses.

Attempts to explore the dimensions of frustration under controlled laboratory conditions have been the primary source of knowledge about its connection with aggression, but what laboratory studies gain in exactness they tend to lose in naturalness. Since experimentally induced frustration is an artifical sample of the normal annoyances of life, the conflict induced in a laboratory may not fit sensibly into the context of the subject's past experiences or affect needs which are important to his adjustment (328). Some of the confusing and contradictory findings that issue from "staged" frustration experiments can be traced to the use of techniques which do not duplicate, or even approximate, real-life situations. Most researchers offer too much safety to the subject or instigate such a low level of frustration that the subject has no reason to respond with socially unacceptable behavior (238). There can be unsuspected forces at work even in a controlled experiment. Some of the classic work on the psychology of frustration and aggression- 
work which became the prime mover of a decade of effort on the part of other researchers-required some reinterpretation when it became apparent that the arbitrariness of the frustration imposed by the experimenters, rather than the frustration itself, might have produced an aggressive response $(74,307,308)$. Logically, the response to frustration resulting from personal inadequacy or from an inescapable fate would involve less overt expression of aggression than that resulting from the egodeflation or deprivation imposed arbitrarily by someone else. A great deal of caution is needed in tracking anger back to its origin, since there are many alluring but false trails. Zander (412) recommended that laboratory frustration should be established by having the subject fail at a task at which he has previously succeeded. In this way the frustrated person will not channel his feelings at a target which has almost invited an attack.

\section{THE RESPONSE TO FRUSTRATION}

In what was probably the most important and stimulating theoretical presentation of frustration and aggression, Dollard and his associates (91) at Yale stated that the existence of frustration inevitably leads to some form of aggression. The critics attacked this statement vigorously. Miller (272) stated, two years later, that this might better be phrased to say that frustration produces instigation to different types of responses, one of which may be aggression. The enthusiasm with which the battle was joined pushed forward our understanding of frustration and aggression at a satisfying rate. The obverse of this statementthe contention that aggressive behavior always presupposes the existence of frustration-met with little resistance or criticism.

The strength of the aggressive motivation, according to the Dollard group, will vary with at least three factors: (1) the strength of the instigation to the frustrated response, (2) the degree of interference with the frustrated response, and (3) the number of frustrated response sequences that the individual endures. The term aggressive "motivation" rather than aggressive "behavior" is used because a factor such as the anticipation of punishment may influence the overtness of a hostile response. When aggressive behavior does appear, it is not always direct and overt; it may be deflected from its original goal, disguised, displaced, delayed, or otherwise altered. Individual differences in the capacity to tolerate frustration also help determine the point at which an aggressive response will occur. The research evidence bearing on each of these determinants of the strength of aggressive motivation can be considered in turn.

1. The strength of instigation to the frustrated response.-This factor is really twofold. It implies an estimate of the strength of the motive being frustrated, and it requires information about the strength of the individual's attachment to a particular object that will satisfy his need. If the motive is hunger, the stronger the hunger, the greater the likelihood of an aggressive response if he is deprived of food. If only certain kinds of food or only foods prepared in a certain way are acceptable need-satisfiers, then being offered an unacceptable substitute will produce frustration and instigate aggressive motivation. In an attempt to test this hypothesis, a number of researchers $(11,12,135,266,267)$ asked subjects to keep records of the incidents which provoked anger, the motives interfered with, and the nature of the frustration they felt. Although diaries and lists of things that annoy people are not the most reliable form of evidence, it seems clear that the stronger the drive being frustrated. 
the greater will be the instigation to an intense or aggressive response.

It is a familiar observation that, as one gets nearer to reaching a goal, the strength of the drive toward it tends to increase. This general rule is easily demonstrated in animals, in which close control can be maintained over their environment (364); it is somewhat more difficult to demonstrate in human beings, with whom such control is not always possible. A compromise can be effected by using children for experimental subjects, as did Haner and Brown (166). In their study they had children play a game which involved moving marbles toward a goal to win a reward. At various distances from the goal, the experimenters sounded a buzzer which ended the game before the children could succeed. This buzzer continued to sound until the child pushed a plunger which would stop it. Assuming that the vigor with which the child slammed the plunger was an adequate indication of his aggressive feelings, Haner and Brown measured the pressure each child exerted on the plunger and compared it with how close he was to finishing the game. They found that the closer the child was to finishing the marble game when his task was interrupted, the greater the force with which he obliterated the offending buzzer. If we can accept this as an accurate measure of frustration, the evidence suggests a positive correlation between the strength of the drive being frustrated and the degree of aggressiveness of the response.

2. The degree of interference with the frustrated response.-Although introspective accounts are notoriously untrustworthy, people often report that their anger mounts apace with increased interference encountered in seeking a goal. When one interference follows on the heels of another, most people reach the linits of their tolerance. A more reliable measure of interference is the degree of anger or hostility apparent in the behavior of the victim of the interference. When an experimenter criticizes or insults a subject in order to frustrate him, the number of aggressive responses tends to increase as the tempo of insulting remarks is stepped up (260). As a check on this hypothesis, adolescent subjects were asked to indicate the most likely way a person would act when confronted with hostile situations ranging from being mildly disliked by another person to being struck by him (155). If we can accept the premise that a very hostile act directed toward a person will produce greater interference with his motives than a less hostile act, then the findings support the hypothesis that the strength of the aggressive response will vary with the degree of interference. Experiments with groups of subjects interacting with one another have shown that those who were the victims of the greatest number of aggressive acts by others tended to be the ones who initiated the most aggression in return (127). Even a good-natured ribbing will produce irritation if it exceeds the intensity that an individual can tolerate.

3. The number of frustrated response sequences.-This factor refers to a familiar situation in which there is an accumulation of aggressive motivations until the last straw is added to the load and the frustrated person can no longer carry the load. Thus a series of minor frustrations of various sorts may culminate in an explosion that is out of proportion to the event which eventually triggers it. The longer the frustration continues without relief, the less attractive and satisfying are mature, non-aggressive responses and the greater the probability of an overt aggressive act. To demonstrate this phenomenon, Otis and McCandless (301) arranged an eight-trial frustration task with which they could successively continue frustrating a group of nursery-school 
children. From the first four to the last four of these trials, the children showed an increase in aggressive behavior and a decrease in non-aggressive behavior aimed at relieving the frustration. It is for this reason that parents tremble at the approach of the hour before supper. Hunger, when mixed with the day's accumulation of frustrations, can transform the family circle into a whining, shouting battleground. While television may not be very educational, it has certainly reduced family conflict in America between the hours of five and seven in the evening.

Further support for this hypothesis was furnished by an intriguing experiment fashioned by Thibaut and Coules (382). In a group note-writing experiment with college students, the investigators, with the assistance of paid stooges pretending to be subjects in the experiment, angered the students by sending them insulting notes. A part of the group was permitted to reply in kind to the "student" who had angered them, while other members of the group were halted briefly in their note-writing activity. When the note-writing was resumed, a greater volume of aggression flowed from the students whose anger had been bottled up by the delay. As Berkowitz (43) has since pointed out, it is a reasonable presumption that the irritation provided by the experimenters in interrupting the task at hand undoubtedly was added to that created by the faked notes. Nevertheless, this finding is congruent with Newcomb's (295) insightful observation that when people get angry at one another, they tend to sever diplomatic relations, and communication between them ceases. Once this happens, it diminishes the possibility of resolving the hostility they feel toward one another, and few constructive alternatives remain. Expressing resentment directly to one's tormenter will bring relief that cannot be matched by expressing anger toward substitute objects.

These general rules about the relationship of frustration to aggression have been powerful stimulants to the study of aggression, but they have also been the subject of healthy criticism and modification. The basic postulate that frustration leads to aggression has been qualified by some writers to apply only when certain kinds of frustration exist. Maslow (249), for example, maintained that sheer deprivation is likely to produce attempts to relieve the situation constructively, while aggression can be expected to occur only when the frustration is in the form of an attack or when it is threatening to the individual. Rosenzweig's concept of active frustration would be a similar case in which aggressive responses would be a predictable outcome (341). McClelland (259) added that the availability of a solution to the frustration would determine whether or not hostility would occur. Having an ace up one's sleeve, while dangerous in some social circles, would make the fall of the cards less frustrating and less an occasion for anger. In any case, the definition of what constitutes a threat and the perception of the availability of a solution remain highly individual issues and are not factors amenable to easy experimental verification. To an incurably optimistic person there may never be a situation without hope of resolution. Unfortunately, much of the research devoted to testing these hypotheses about the instigation to aggression employs a grossly circular logic. If, for example, the experimenter predicts that an increase in aggressive behavior will result from an increase in frustration, he cannot then use the aggressive behavior as proof that he has increased the frustration.

An additional difficulty is posed by the fact that most experimenters make the broad assumption that all forms of frustration are 
qualitatively the same, that they have the same meaning to each of the experimental subjects, and that the same needs and drives are being frustrated. Such assumptions are almost never tenable. Experimental work has yet to overcome these obstacles to a clear statement of the vital factors in the frustration-aggression hypothesis.

\section{FRUSTRATTON AND CATHARSIS}

A frequent assumption in experimental investigations of hostility is that the instigation to aggression is reduced by the act of expressing the angry feeling. Releasing pentup anger gratifies the need for aggression and acts to restore an emotional equilibrium. It is obvious that the model for "blowing off steam" as a means of relief is a physiological one, and it implies that aggressive needs and drives occupy the same status as being thirsty and seeking water. This is an interesting but deceptive analogy.

Everything else being equal, a violent act should reduce the instigation to aggression. If, however, the expression of aggression produces anxiety because it is a forbidden form of response, a hostile feeling may never find open expression (278). This poses a problem for the study of catharsis, since an angry individual might never commit a hostile act or, on the rare occasion when he did, the resulting anxiety might immediately inhibit any extensive display of rage (408). To an observer, the decrease in overt aggressiveness stemming from fear or anxiety is indistinguishable from the placidity that comes from having gratified one's angry urges. The reason for the reduction in overt action may be equally obscure to the aggressive person, and his report of the source of the inhibition may be quite inaccurate. In addition, catharsis may appear to be ineffective as a reducer of aggression if the frustration persists and continues to instigate further hostility. A way- ward child who continues to misbehave may again and again provoke the parent to anger which is not diminished by aggression directed toward the child, since such aggressive behavior does not eliminate the continuing frustration.

Because aggression seems an inevitable aspect of human existence, social planners have long advocated culturally planned means (202) for its discharge. They assume that regular opportunities for catharsis would release the daily accumulation of minor frustrations and that special occasions could then be designed for the expression of overloads of anger. The experimental evidence regarding the effectiveness of catharsis for hostile emotions does not provide unequivocal support for this proposal. Certainly, from the observations of the trainers and managers of professional boxers it would appear that the best fighters are those who spent their early years in a lower socioeconomic culture which abounded in opportunities for the catharsis of combat. This experience did not relieve the instigation to aggression; instead, it consolidated it as a reliable pattern of response to frustration. The body of the professional fighter is his stock in trade, and he must be satisfied with its ability to be destructive (394).

But are boxers more aggressive than the average person, when money is not at stake? Does fighting or participation in an aggressive contact sport make one more or less aggressive? When Husman (197) gave projective tests to collegiate boxers, wrestlers, cross-country runners, and some non-athletes, he discovered that boxers were much less aggressive than those who avoided body contact or limited it to less destructive forms. In fact, measures on projective tests taken just after boxing matches revealed that the boxer's aggressive performance made him feel guilt, even though the combat was socially sanctioned. In a related study 
(211), a projective test was administered to eight collegiate wrestlers at three different times: before the wrestling season, four to five hours before the first match of the season, and the morning after the match. The experimenters concluded that aggressive feelings increased before the wrestling match and then decreased following it.

Studies such as these, which reveal that sanctioned aggression may lead to a reduction in the display of hostility, must be interpreted with caution. To begin with, aggressive sports undoubtedly attract persons whose aggressiveness is not that of the average person. Aggressive boys have quite different attitudes toward athletics when compared with non-aggressive boys (113), and there is probably a natural selection for those who will become athletes. Decreased overt expression of aggression following participation in a sport cannot be ascribed to the beneficial effect of catharsis alone. Each of the studies reported used middle-class college students as subjectssubjects reared in families subscribing to social norms that prohibit open aggressiveness and make it an anxiety-ridden event for the child. The research findings suggest that anxiety resulted from the expression of aggression in these subjects and that this anxiety, rather than catharsis, may be the source of decreased aggressiveness. These studies lack the kind of experimental control that is needed to eliminate the possibility that an alternative explanation, such as anxiety, might better account for the results of the research. For persons other than middle-class college students, the sanction of aggression might produce no decrease in aggressiveness, it might well prove to be a stimulant to bigger and better fights.

Research findings regarding the value of catharsis of aggression among children are suggestive but complicated. All too frequently, research with children fails to make allowance for the fact that, despite catharsis, an aggressive response will continue to occur if the source of frustration is not removed. In one experiment, for example, there was no evidence of a reduction of hostility after sessions of aggressive play therapy (117). The boys in this experiment were observed over a series of play therapy sessions, and their aggressiveness increased from session to session. As the experimenter noted, the sources of frustration which produced the original aggressive feelings were still in operation and may have produced continuing instigation to aggression despite the relief gained from catharsis. Similarly, playing with dolls may not provide an adequate outlet for the real frustrations of daily life. In Appel's study (16) of children who had been in a nursery school where fighting was not prohibited or punished severely, he discovered that these children displayed less hostility when they went to kindergarten than did children from a nursery school that banned fighting. While one might assume that the catharsis of uninhibited assault in nursery school caused the decrease in the aggressive tension displayed by these children in kindergarten, an equally valid conclusion might be that the more a child fights, the greater the variety of techniques he develops for handling conflict without resorting to overt aggression. There are many studies of the reduction of hostility following its expression in group settings $(311,381$, 382 ), and, while they give general support to the notion of catharsis, they must be interpreted with some reservation.

In light of the tentativeness of the experimental evidence about the effects of catharsis, an over-all evaluation of the concept cannot be conclusive. The principal objection to the catharsis hypothesis is that it suggests that each of us has a reservoir of aggression which must be allowed to spill over at regular intervals if we are to avoid 
having the dam burst. This analogy is a sloppy approximation of the facts of human hostility. If a hostile way of life is learned in early childhood in response to bitter experience, it can be based on such deeply ingrained resentment and deprivation that no attempt to drain it off could cope with the rate at which it is replenished from within. Rage at being rejected by parents during the crucial childhood years cannot be assuaged by superficial kindness administered too little and too late. A particularly cogent criticism of studies of catharsis is that they often fail to reckon with the personal history of frustration that each subject brings with him to the research setting. The amount, kind, and quality of catharsis that an individual will find satisfactory can be judged only in terms of his usual means of managing aggressive feelings.

It would be important to know whether the expression of aggression in one setting will affect the hostile feelings we have toward others in a different setting. There are indications that hostility toward others takes the form of a generalized pattern of response that cannot be altered by reduction in the intensity of only one aspect of it. The feeling that people are "just no good" can be kept intact in the face of overwhelming evidence to the contrary simply by allowing an unlimited number of exceptions to the general rule. If it is true that aggression is inevitable and that each of us must hate something, then utopia-builders ought to devote themselves exclusively to the task of manufacturing preferred targets for aggression.

\section{Defenses, Mechanisms, and Aggression}

No attempt to understand the vicissitudes of human aggressive behavior is adequate without concepts similar to that of the defense mechanisms and the existence of an unconscious part of the self. The efforts, for centuries, to explain the motivation of human actions on a purely conscious and rational basis always produced embarrassing paradoxes or left a host of details unaccounted for. Emphasis on the intellectual rather than the emotional aspects of man's nature suggested that man, when faced with conflict, ought to be able to draw up a balance sheet of pros and cons and then, after examining the facts, make a rational decision. When psychoanalysis shifted the emphasis of psychiatric thinking to man's emotions, it became apparent that any attempt to add up the important facts could never strike a balance because essential facts were always missing. It was from these observations that a dynamic view of human functioning was formed and the notion of defense mechanisms evolved.

The ideal way of meeting frustrations or resolving conflicts would be to approach them as problems to solve and to effect the best compromise available. In many instances in our daily lives, exactly this procedure is followed. If society set no limits on the impulses and feelings that the individual could express, no more than problem-solving skills would be needed to manage one's life. In a complex fashion the members of a culture set up an interlocking system in which acceptance and reward are issued only to those who display certain kinds of behavior and become a specific kind of person. A failure to fit these prescriptions is punished by the deprivation of the very things the growing child most needs. Bad little boys and girls not only lose the love and acceptance of their parents, but, once a year, Santa Claus will not bring the presents that every good child receives. Through this process of systematically rewarding certain kinds of behavior and punishing others, the adults in the society manage to force the child to conform 
to the specifications it has set. If the process ended here, the management of prohibited impulses would be much simpler. There would be conformity as long as the prospect of being caught and punished was immediately apparent. Since a child cannot have all his experiences in life under the watchful supervision of the parent, he must learn to heed a broad set of standards of behavior which will be applicable even in unforeseen circumstances. The standards that the child must learn define the kind of person he ought to become, and the failure to achieve these standards threatens to bring rejection from the parents in particular and other members of society in general. Learned in childhood, these patterns of reaction and standards of behavior get stamped into the child's psychic structure and become so much a part of him that being less than the person he ought to be will produce an intense anxiety which is painful to endure.

Having accomplished this process of internalizing maxims of good and evil and success and failure, the developing child must now sort over his wishes, desires, feelings, and impulses to determine which are acceptable to him and can be lived with without anxiety and which must be eliminated for psychological comfort. The simplest and most pervasive example of this process is clearly demonstrable in the feelings of love and hate that the child has toward his mother. Everyone is aware that children love their mothers because mothers care for them, minister to their needs, and provide gratification. The most casual observation would reveal that when the mother spanks the child, deprives him of things he desires, or interferes with his attempts at gratification of his needs, the child, at least at that moment, hates his mother and has powerful aggressive urges directed toward her. The society insists that such hostile feelings have no place in the mother-child relationship and that the child must be free of such emotions if he is to be accepted and loved by his mother and to feel worthwhile as a person. At this point the child faces a conflict he must resolve, and he comes to learn that a number of avenues are open to him, although each will be less satisfactory than being able to accept his impulses and feelings as a normal consequence of human existence. Thus the child must learn to manipulate his feelings if he is to defend himself against the onslaught of unbearable anxiety.

How can the child avoid being caught, by himself or others, with contraband feelings? There are four elements or dimensions of the forbidden situation that he can alter to bring about a new situation more in keeping with society's dictates and his own anxieties. Momentarily, he feels that he hates his mother and wants to kill her. There is the source (himself) of the feeling, the impulse (hate), the object (mother) toward which it is directed, and the aim (kill) of the impulse. Alteration of any one of these aspects will produce a formula which is no longer threatening to his self-esteem or to the esteem others have for him. He can, for example, change the source in some fashion and not tamper with the other elements; now he doesn't hate his mother and want to kill her. Or he can alter the impulse so that he loves his mother, not hates her. The object can be transformed so that he hates school but not his mother. Another compromise that will solve his dilemma is to admit that he hates his mother but merely wishes to reprimand her rather than kill her. In each instance, a slight change in his perception of the reality of hating his mother cleans up the thought and makes it presentable. In extreme circumstances the whole thought must be changed, leaving no element unaltered; in less threatening situa- 
tions it is necessary only to reduce the intensity of each element of the sequence. This means that the kind, quality, and degree of distortion will always be dependent upon the demands made by the environment and the internal psychic resources he has available to him. In one family a child must see, hear, speak, and think no evil, while in another an aggressive outburst is a natural event which must be managed but is viewed as a reasonable consequence of the frustrations of living with other people.

At first, mechanisms for managing hostile feelings are practiced in a conscious form by the child. He will, for example, retain his feelings but suppress the overt attack on the mother to insure her continued acceptance of him. Such feelings, as well as the act of altering a prohibited situation, must be hidden from both the self and others (after all, the best-adjusted adult could not be comfortable thinking murderous thoughts about others all day). Through a process we can label, but not fully understand, the effort that the child once made wilfully and consciously becomes an event which occurs in so subtle a fashion that no one is the wiser.

This description of perceptual maneuvering to escape experiencing anxiety is particularly relevant to aggressive impulses which, because of their potential destructiveness, must be highly regulated and controlled. The average person in our society is made quite uncomfortable by the sight of naked hostility in himself or in others, since one of the hallmarks of maturity is control over aggression. The description of the need to defend one's self makes it appear that this is a consciously willed, mechanical process-something like a bag of tricks used when appropriate to the emergency. A more apt description would be that normal persons cope with frustrations and forbidden impulses and only defend against them when no other alternative remains. When defensive tactics relieve anxiety, this very relief will reinforce the defensive behavior and tend to solidify it into a habitual and characteristic pattern of reaction when faced with conflict in the future. When this occurs, they no longer act as emergency reactions but become predictable character traits that distinguish the individual for life (250). Since a variety of defense mechanisms is available to the individual, he usually proceeds by trial-and-error to select those that are the most effective in freeing him from guilt and anxiety. A mechanism that proves to be effective in one situation is tried in another and its use continued until it fails to accomplish its purpose. Highly flexible individuals may acquire a set of defenses which are adapted specifically to each situation; rigid or less resourceful persons may become general defenders who find one dramatic mechanism that works (such as thoroughgoing repression) and use it for a variety of situations and with all kinds of impulses (49).

Using hostility as the model of impulses to be dealt with, what are the ways in which it can be managed defensively? At a broad level, the choices of the individual are restricted to changing the situation through the process of conscious problem-solving and working out a new relationship with the person toward whom he is hostile; escaping from the situation by running away or retreating into a fantasy life, where the problems do not exist; or changing his perception of the hostile situation through defense mechanisms which render it innocuous.

\section{REPRESSION}

Since all defense mechanisms are said to operate outside the sphere of conscious awareness of the individual, the removal from consciousness must be accomplished by the act of repression. Repression is a con- 
cept which describes the process by which impulses and thoughts are excluded from consciousness and made to remain inaccessible to it. As Sappenfield (346) has pointed out, since repression is used to eliminate impulses which the conscious self finds repugnant, it might well be described as the process by which the "unthinkable" becomes truly unthinkable. Repression is a flight of the ego from danger by removing the danger and making it inaccessible to observation. Horney (192) has indicated that we repress whatever we perceive as a threat to the success, recognition, and security of the personality and that it is espesially necessary to keep internal destructive forces out of consciousness. Repression moves hostile impulses out of view, but it does not alter their strength or essential characteristics. This means that repression must operate continuously to keep these impulses from reasserting themselves or gaining access to consciousness. The most important aspect of repression is that, to the extent that it occurs, the individual will lose insight into some of his motivation. The loss of knowledge about what he really feels amounts to a surrender of part of the power of rational choice and a restriction on the reasonableness of future behavior. The seeming incomprehensibility of some forms of neurotic behavior can be accounted for in this way. If repression operates extensively, the individual is forced to behave in ways that he cannot explain and is powerless to change or control, since the hostile impulse has been withdrawn from the influence of the conscious part of the self. The repression of aggressive impulses is an often necessary, but always dangerous, method of solving emotional problems, since repression can fail and the impulses are reborn as a violent and destructive attack. Repression can be as successful as it is dangerous, for at a single stroke it can remove the thought, "I hate my mother and want to kill her," and leave no loose ends. Nothing remains but a brief gap in conscicusness and a disquieting feeling of emotional abortion.

\section{DISPLACEMENT}

A quite commonplace method of dealing with hostile feelings which cannot be expressed toward the source of the frustration is through the mechanism of displacement. Since a child is forbidden to express his anger toward his mother, he can easily learn to release his feelings by changing the object toward which they are directed. If the prohibition against the expression of aggression is a stringent one, then he must find a substitute object that is only remotely related to the original one. Perhaps his rage can find an outlet only through kicking an inanimate object or tearing the arms off a favorite doll. If all aggressive actions are forbidden, the child may be limited to a blood-curdling fantasy life in which phantasms (which may resemble the mother in certain ways) meet a series of imaginative, but horrible, fates. The most satisfying form of expression would be overt aggression directed immediately toward the mother; as substitute objects become less and less similar, psychologically, to the original object, the amount of gratification decreases accordingly. Repression helps one to displace, for it allows the individual to "forget" the identity of the original object.

In learning to displace his feelings, the aggressive person selects a new target possessing certain characteristics. As nearly as he safely can, without having it apparent to himself or the original object, he chooses a new victim in terms of the similarity to the first object. This similarity is often more symbolic than real, so that a child may anger his teacher, instead of his mother, and yet gain the gratification of defying someone 
in authority. In general, the substitute target is one that is not capable of retaliation for the aggression meted out to it. A boss can displace his aggression against employees who are dependent on him, and a child can displace his anger against a smaller and weaker sibling or another innocent child (59). Displacement is made easier and more attractive when the new victim has done something to justify the punishment he is about to receive. Lacking any safe object, regardless of how distant it may be symbolically from the original, the angry person may be limited to a verbal abuse of highlevel abstractions such as the state of the world, women drivers, minority groups, or baseball managers. Since the world offers a multitude of irritations and frustrations, the displacement of aggression to substitute objects can easily be accomplished. Displacement allows the person to maintain his relationship with the original object while venting his ire in safer surroundings-surroundings that are anxiety-free.

\section{PROJECTION}

A more complex and sophisticated means of gaining relief from anxiety by getting rid of unacceptable thoughts, feelings, and impulses is through projection. A common meaning of projection is the reference of one's own thoughts and feelings to persons or objects in the outside world. It is a mechanism by which one is able to deny the reality that he cannot tolerate. Projection takes place in a series of steps. First, the intolerable feelings are removed from awareness by repression. The process of defense may stop here if repression is adequite to the task, but if the repressive forces fail to contain the hostility, then a further step must be taken. The dangerous thoughts are attributed to others, and the child may change the formula "I hate her and want to kill her" to read, "She hates me and wants to kill, injure, or deprive me." Such an action not only frees him from responsibility for his own impulses but may even provide the justification for an overt attack on the parent. Once he is convinced that others are against him and that he can expect only evil and mistreatment at their hands, his hostility toward them need not produce guilt or loss of self-esteem.

When someone projects his anger or resentment, he chooses objects for projection that offer some basis in reality for the feelings he ascribes to them. If you cut your finger, you become aware of that part of your hand in a thousand ways overlooked in daily life. The pain focuses attention on the finger, and it seems to be hurt at every turn. A normal person devoting a single day to searching for evidences of hostility in others would find it everywhere. Since no one is without hostility in one form or another, the person who projects can make a convincing case for his interpretation of the motives of others. Righteous indignation at the meanness of others coats the accuser with respectability, and in the act of hating hatred he is able to gratify the very impulse he denies so vehemently in himself. It is obvious that projection is the long way around to gratification, but such a circuitous route is demanded by an environment that makes onerous demands for conformity. A simple change in the environment (walking past a graveyard) can induce fear, which then becomes a fertile ground for seeing others as malicious and threatening (287).

\section{SUBLIMATION}

Sublimation is regarded as one of the most adaptive of the defenses because it represents a form of substitution in which primitive impulses and behavior are replaced by behavior which is harmonious with the native impulse but more acceptable socially. Either the aim of the original im- 
pulse or its object may be the focus of substitution. In this way, the formula "I hate my mother and wish to kill or injure her" can be translated, with full social approval, to "I hate female criminals and will devote my life to seeing that they receive the justice they deserve." The aim is altered slightly, the object is rendered unrecognizable, and the source of the impulse and the impulse itself remain intact. With successful sublimation, an unacceptable impulse can be gratified in a second-best fashion, yet prove sufficient to strike a satisfactory emotional balance for life. Where repression of the impulse crushes it and forbids its expression, sublimation allows a slightly modified version to be expressed in an atmosphere that not only is free of guilt and anxiety but may produce the acclaim of one's fellow men.

Because they are socially rewarded, sublimations are seldom subjected to critical examination by the society. The motivation for deeds of service and self-sacrifice is not considered a polite or proper topic for speculation, since, according to the theory, this mechanism is at the base of the constructive parts of a culture. This concept has been resisted with great vigor by the lay public because it is considered degrading to man to have such magnificent edifices constructed of such elemental and shoddy materials. Theorists dedicated to the concept of sublimation have included, to the public's great dismay, most of man's proudest accomplishments under this rubric. Friendship is described as a sublimation of erotic and sexual attachments, and occupations, hobbies, art, literature, civic service, and religion are similarly described as polite forms of more reprehensible urges curbed in childhood. Since sex and aggression are so thoroughly regulated in this society, most sublimations are seen as stemming from one or the other of these impulses, and some theorists maintain that the anxiety connected with these urges is the factor that prevents the acceptance of the idea of sublimation. Photographic rather than actual "shots" of animals, the fighting spirit of sports, "killing" an audience with humor, and being a brilliant surgeon rather than Jack the Ripper are all ways in which socially positive behavior can issue, in slightly disguised form, from more primitive impulses. The amount of disguise necessary for hostile feelings will vary according to the particular demands of the environment and the resources of the individual and may range from highly competitive and destructive sports, such as boxing, to less obvious forms, such as chess. In some instances-the professional soldier, for example-little alteration of the aim is needed, and the impulse can be almost fully gratified.

It is certainly true that some event similar to sublimation must occur if aggressive urges are to be turned to socially acceptable ends. It is also true that many socially meaningful activities offer gratification for impulses that the society demands be denied expression on any other basis. The greatest public resistance is against assuming that all constructive activities draw their energy from forbidden urges that are remnants of the unsolved problems of childhood. There is undoubtedly more than one way to skin this psychological cat and more than one motivation for a person's way of life. The direct translation of primitive to civilized impulse does occur for some individuals, and, without the capacity to sublimate, more drastic measures might be needed to solve emotional conflicts. The simple alteration of the object of aggression provides a practical solution for aggressiveness, since aggressiveness has so many positive social uses (172).

This description of the way in which defense mechanisms can be used to solve the problem of managing hostility provides an 
accurate picture of the deviousness and complexity which sometimes characterize solutions to conflict over aggression. Defense mechanisms are necessary when all other attempts at solution have failed or are barred from use by the peculiarities of the individual's environment. They do not represent an "average" means of meeting the demands of civilized living. Defenses involve an unhealthy distortion of the world as it really is and exact an enormous toll on the integrity of the personality. Defenses cripple, but they do not destroy in the way that feelings of anxiety and worthlessness might if defenses were not available. If a neurotic personality results from the overuse of defenses in meeting the challenges of life, then it might rightfully be said that neurosis is the price we pay for civilization. The defensive maneuvers described are typical of those called upon to handle angry feelings, but this list of the twists and turns that may occur is far from complete or exhaustive. The human mind is most splendid in the evasions of which it is capable.

As drastic as defensive steps may seem, they may fail to be adequate, and a total destruction of the personality may occur in the form of psychosis. As the hastily erected defenses topple before the force of conflicts, last desperate attempts to stem the tide may appear. In a state of amnesia, the person may simply blot out the circumstances that surround him and become a different person, free to try a new approach to the same problems. In rare cases, nearly complete personalities are formed from the discards of emotional life and are hidden away in a closet of the mind where they lurk as invisible threats to the conscious personality. When defenses fail, as they do for an alarming proportion of our society, the personality may disintegrate and collapse into a psychosis in which the "unthinkable" finds its way to expression in shocking and easily recog- nizable forms. It is in psychosis that the intensity and destructiveness of the impulse life of humans appears in its least disguised form; it is a frightening apparition to behold.

\section{Family Influence and Aggression}

According to some schools of thought, the study of aggression might profitably be confined to an extensive exploration of the first few years of the child's life. The helplessness, dependency, and limited range of experience of the developing child provide a unique setting for learning, and it is this very uniqueness that accounts for the importance of each event in shaping the future personality of the child (104). The security, or lack of it, provided by maternal care of the infant, for example, can be the basis of the child's essential trust or mistrust of the world. An infant for whom the environment is only a sporadic and inconsistent provider may acquire a feeling of insecurity based on his realistic appraisal of the world as an occasionally satisfying, frequently depriving, place. Whatever learning is to follow is reacted to in terms of how secure he feels, and this basic security will color all his future activities. For a fearful child and a self-confident child, the lessons of life take on a quite different appearance.

Since the lessons learned in childhood have such a powerful impact on his later experience, it becomes clear that study of the parent-child relationship is essential if we wish to comprehend all aspects of aggression. When the term "aggression" implies action with the goal of injuring someone, it is probably too specific a meaning to fit the variety of child behavior usually studied. Much of the early expression of aggression is in the form of a general assertiveness, ascendancy over others, or the tendency to dominate other children. These are learned patterns of behavior (360).

If the development of the individual is 
traced from conception to birth, it becomes apparent that the genetic inheritance and the intra-uterine environment of the child work to affect his biological functioning and to prepare him for his first responses to the outside world. The changes in a child's behavior which follow his birth and which can be attributed to training-the learning he will engage in-are all-important to the fate of his potential for aggressive action.

Four fundamental conditions must exist in order for an individual to learn (275). A drive must exist within him, a distinctive stimulus or cue must be present to be associated with a response of child to his need, and there must be some reward or reinforcement for his response. Thus a hungry child detects the odor of food, reaches out and gets it, eats it, and reduces his hunger pangs. When this sequence occurs and is reinforced by the reward that the child obtains, he will engage in his newly learned behavior to restore his need to a state of equilibrium when confronted with a similar need in the future. A child in pain who thrashes about and finds that he dislodges the pin that is sticking him will respond in the same fashion to future discomfort. A child angered by another child who has appropriated a favorite toy may hurt his frustrator in the act of reclaiming his property and learn that inflicting pain on another brings the reward of freedom from frustration. This learned response can, if it is not replaced by more socially accepted learning, become characteristic of the child in years to come. The problem posed by the learning of aggressive responses occurs because we know that learning that takes place at an early age is difficult to eradicate. A child who has found bullying others a rewarding way of life for a number of years presents an especially resistant object for retraining. An additional complication is furnished by the process of generalization in learning. A child burned on a hot stove will tend to avoid all other stoves, hot or cold. A child who learns that aggressive action will remove an inanimate object that blocks his progress toward a goal can generalize this lesson to fit those cases involving human objects. Not only is the lesson of aggression directed toward the environment learned with ease, it seems to be unavoidable for an active organism. In the process of learning, the child not only achieves the means for satisfying his needs but acquires new drives and needs which play a dominant role in the determination of later childhood and adult behavior.

An examination of parental behavior and attitudes toward the child should give us some insight into how these responses come to be rewarded, learned, and generalized to other situations. The study of the rewards and punishments in the home can tell us which of the child's many responses will be expressed and which inhibited (52). Typical of the studies of the effect of frustration and punishment on the expression of aggression is that of Hollenberg and Sperry (189). Using four doll-play sessions as a way to observe the aggressive responses of nursery-school children, these researchers demonstrated that the punishment of aggressive responses will act as a deterrent to their expression. When one group of children were punished by verbal disapproval each time they made an aggressive response during the second play session, while another group received no punishment, the effect was apparent in the third and fourth play sessions. The children who had not been reprimanded for their aggressive responses became more intensely aggressive as time went on, while the verbally punished group leamed the limits that had been set in the situation and inhibited their expression of aggression. If aggressiveness is permitted, the child does not have to antici- 
pate punishment and so feels free to aggress more frequently and more intensely. Punishment for aggression in the home should similarly cause such expression to be inhibited. When punishment is applied consistently and regularly, the child will become fearful and anxious about his hostility and will tend to inhibit its expression in all situations where he anticipates punishment. Playing with dolls can be a situation in which aggressiveness is not punished, and it is a setting sufficiently unlike the home situation that the child may express the anger that his parents would prohibit. A dependable relationship exists between the aggressiveness that a child will display when playing with dolls and the degree to which his parents frustrate him at home and punish his aggressiveness. Highly frustrated or highly punished children will exhibit more aggression than those mildly punished or frustrated by parental restraint. These findings suggest that a very shaky control over aggression exists when punitive methods are coupled with high frustration in the child's life. Obedience and inhibition of expression can be achieved, but the angry feelings are just below the surface and will appear with undiminished intensity when a punishmentfree opportunity presents itself.

If a social situation resembles the home situation, then the lessons learned about aggression may generalize and the behavior becomes predictable. Sears (362) observed three groups of nursery-school children at play with one another in order to test the relationship between parental punishment and aggression in a normal social situation. After interviewing the mothers about their child-rearing methods, Sears rated them as non-punitive, mildly punitive, and severly punitive. When he observed their children, he discovered that the greatest number of aggressive responses was made by the mildly punished children. The children of non- punitive mothers and the highly punished children had few aggressive responses. These findings were in line with Whiting's (362) hypothesis that a mild degree of punishment may strengthen the aggressive drive by providing frustration to the child, while punishment, if severe enough, not only frustrates but inhibits the expression of aggression. Children can play peacefully because they are not frustrated at home and have little aggressiveness which must be displaced to innocent playmates, or they can possess a great deal of aggression which has been punished with such severity that its expression produces so much anxiety that it is inhibited. The result is similar but for quite different reasons.

The findings regarding the expression and inhibition of aggression in doll-play and in real-life settings are typical of the intricacy of predicting aggressiveness from knowledge of the parental patterns of frustration and punishment of the child. Children are sensitive to the nuances of pressure regarding when to, and when not to, loose dangerous impulses. A carefully controlled nursery school, where the teacher cuts aggressive outbursts short, will produce the same diminution of open conflict in children as does a verbal reprimand in the doll-play situation.

Although most studies of parent-child relationships and aggression view the mother as crucial in the child's development, the father plays a particularly important role in the learning of aggressive behavior for boys (361). The father is nearly always the model that the boy emulates, and the male parent is characteristically more aggressive and has a greater tolerance, than the mother, for the expression of aggression on the part of the male child. In order to confirm this hypothesis, observations were made of the doll-play aggression of three-, four-, and five-year-old boys and girls from homes in which both parents were present and from 
homes in which the father was absent. In general, the findings confirmed the hypotheses. The father's absence did not affect the amount of aggressive doll play displayed by girls, but three- and four-year-old boys from homes where the father was absent showed significantly less aggression than did boys of the same age from homes where the father was present. The absence of the father as an aggressive model for boys of this age acted to reduce aggressiveness, but the same effect was not found for five-yearold boys. Apparently the wider social contacts of school and peer group provide a suitable means of learning masculine behavior even without the father $(20,358)$.

The influence of both the mother and the father must be studied to account for the variables which influence the child's aggressive feelings and his expression or inhibition of them. The home atmosphere created by the parents becomes the setting in which the child learns his most fundamental lessons (284). A singular problem in assessing something as tangible but as elusive as "home atmosphere" is the selection of terms that will adequately describe it $(22,26,173,232,324)$. A somewhat confusing collection of terms has been used. Democratic, authoritarian, autocratic, indulgent, nurturant, warm, attentive, possessive, restrictive, and happy make up a partial list of the terms used to characterize the atmosphere of a family setting. Unfortunately, an exact correspondence does not exist between these adjectives, and the means of assessing them may vary in trustworthiness.

The general principles which have issued from these studies have some relevance for the study of aggression. Since such words as "democratic" or "authoritarian" represent a collection of interlocking behaviors and attitudes, generalizations derived from them must be treated with some caution. On a broad basis, democracy in the home is char- acterized by a general permissiveness, explanations of the reasons for family rules and regulations, and the avoidance of arbitrary decisions on the part of the parent. Controlled or authoritarian homes emphasize clear-cut restriction and regulation of the child's behavior without consulting him, absolute obedience, and few explanations of the reasons why rules are necessary. Although a great many positive personality traits develop in the child given the emotional support of a democratic home atmosphere, it must be noted that these children also ranked high in aggressiveness, competitiveness, and cruelty to others. They were more disobedient and non-conforming than other children. A controlled, authoritarian home tended to produce quiet, wellbehaved, socially unaggressive children. The risk that parents must run in choosing one method of child control rather than another is apparent in the effect of these methods on the child's total personality. Achieving conformity in children may be at the expense of the child's curiosity, constructiveness, originality, and eventual social status as a leader. Child-rearing is indeed a "package deal" in which the parents purchase what they can afford and, in a sense, get what they pay for. The techniques used in parent-child relationships must fit comfortably with the personality of the parent, and, therefore, any attempt to turn over a new leaf and use other methods usually proves to be an awkward and difficult process that meets with limited success. Most attempts, in education, teach the words without the music, and the result is disharmony. The intelligent decision to alter the means of child-rearing is not always possible for parents because their own maladjustment may stand as a barrier to change (244). Marital maladjustment, for example, tends to be most consistently correlated with such problem behaviors in children as negativism, 
ungovernable temper, and aggression; yet improvement of the marital condition is not easily accomplished. The child used as a pawn in the battle between parents not only witnesses overt aggression but is torn by the love and hate he feels as he tries to maintain an impossible neutrality.

Home atmosphere is usually established not as a conscious, planned design but as a consequence of a series of forces like the parent's own personality, religion, and social status. The taboos imposed on aggressiveness by members of the middle class are not the same as those adhered to by members of the lower classes (81). Lowerclass children are much less likely to be punished for the overt expression of hostility, since in some neighborhoods it is a requisite of life. As Duvall (96) noted, the definition of a "good" child and a "good" parent varies with the social class of the parent.

To complete this account of the influence of the family on the development of aggressiveness, it is necessary to describe one of the important ways in which the child comes to absorb the influences that the family brings to bear on him (identification) and the mechanism (guilt) by which these influences hold sway throughout later life.

\section{IDENTIFICATION}

The concept of identification is extremely important to the emotional learning of human beings. It could reasonably be said that if it did not exist, it would be necessary for someone to invent it. Such a concept is needed to explain the persistence of behavior from one generation to another and to help us understand what otherwise would seem to be a ridiculous and slavish repetition, by children, of the life-patterns of parents when these patterns actually produce pain and dissatisfaction.
There are a number of meanings of the term "identification" in use currently, the most usual being that of the unconscious modeling of one's self in feeling, thought, or action after another person. This meaning is designated by Kardiner (216) as an "enriching" form of identification because it enlarges or expands the personality by providing it with new attitudes and ways of behaving. Identification is a reasonable means of gaining need-satisfaction, since it is a process in which particular characteristics of successful friends, peers, and adults can be selected to be woven into the fabric of one's own life.

At times the term "identification" is used loosely and in error, to be synonymous with the imitation of the behavior of others. The meaning of identification goes deeper than the conscious and superficial "acting like" of imitation, it is the unconscious "being like" another or, in pathological cases, "being" another person. The process of identifying with others has its greatest impact in shaping the personality early in life, and its influence wanes with increasing age. The identification of the child with an angry parent is much more permanent than the hysterical devotion of the teenager to an athlete or movie idol.

The child's choice of a person with whom to identify is not a matter of whim or accident. However, circumstances may restrict the child's choice of persons to emulate. There are city blocks in which the proportion of adult males with prison records is so high that a child in such a neighborhood may be exposed to an antisocial and violent model wherever he turns. The child's primary identifications are made with the likesexed parent, but the close relationship with the mother means that each child incorporates, selectively, a part of the pattern of response of each parent. One interesting explanation for certain kinds of hostile and 
delinquent behavior (208, 209) proposes that in the process of making an identification, the child incorporates the hostilities, resentments, and angers which the parents show in their behavior while giving lip service to conventional morality. The admonition "Do as I say and not as I do" is useless, because the child unerringly seeks out the reality of everyday behavior.

When the child is presented with negative models for identification, the outcome is predictable. He may similarly fail to meet society's standards of control over his impulses by being deprived of a positive model with which to identify. A cold, rejecting parent who fails to provide emotional gratification for the child or who sets impossibly high standards for him to achieve may make it impossible for the child to acquire adequate internal restraint over his impulses. Having no internalized set of standards to guide him, he may respond to the prevailing morality of whatever group pressure he experiences.

The patterns that the child learns by identifying with his parents are further complicated by the fact that a child can identify with his fantasies as well as with reality. Psychoanalytic theorists indicate that the child forms an image of the parents as more powerful, bigger, and more fearsome or prohibiting than they actually are. If he identifies with this exaggerated fantasy of the parent, he may acquire characteristics which make up a significant part of his adult personality and yet cannot easily be traced to reality factors in his past. According to Anna Freud (129), a child may also identify with the most hostile aspects of those who aggress against him. By "being like" the assertive, aggressive person whom he dreads, the child can manage his fears through being as strong and sure of himself as he perceives his aggressor to be. At one moment cringing in terror before the on- slaught, in the next the child may turn on others and repeat the performance word for word and action for action, now playing the role of the aggressor. Bettelheim (44) reported just such a process among prisoners in concentration camps who began to emulate their guards and became as harsh to their fellow prisoners as the guards were to them. Long-time prisoners were observed patching their clothes to resemble the uniform of the guards and were seen playing aggressive hitting games with one another in the same fashion as their Nazi captors. For many normal persons, aggressive feelings are directed toward persons who have the power and the strength. Life is a succession of events marked by "identification" with the underdog, his weakness, and the possibility that he will eventually prove to be stronger than his foe.

Once a pattern of aggressive response has become a tunctioning part of the child's emotional life, its eradication is no simple matter of education or a change in the environment. The expression of hostile impulses may be suppressed or led into socially profitable directions, but a fundamental change can occur only through a reorganization of personality by therapy which seeks out the original situation in which the learning took place.

\section{GUILT}

As the child grows, he becomes more and more independent of the guidance of his parents. Many of the struggles between parent and child come to revolve around the definition of the proper time for the child to assume the freedom to determine his own fate and to make his own decisions. The age-old anxiety of the parent is that the child, once given his freedom, will use it badly. Implicit in this anxiety is the apprehension that the child's adherence to acceptable social norms represents a con- 
formity based on coercion rather than conviction and that at the first opportunity the child will slough off these unwanted restraints and express the impulses that the parents have-labored so long to suppress. As insurance against such a loss of control, parents systematically attempt to make the child feel guilty about the drives which the culture demands must be held in check.

Guilt is one kind of anxiety that a person can experience-an anxiety based on the anticipation of punishment for unacceptable behavior or thoughts. The child must make the prohibitions of adults a vital part of his own self-concept. Once he has taken these standards as his own, he suffers guilt when his conduct falls short of what the parents once expected of him and he now expects of himself. A conscience changes the child's life because he is now capable of suffering a guilt that is quite independent of events in the outside world. Failure is now defined subjectively in reference to the demands of individual conscience, and what may be an inconsequential event for one person becomes a crisis for another. Thus an aggressor can feel guilty about attacking another person despite the forgiveness of his victim. Where once actual punishment by the parents was feared, now the sense of deserving punishment is the source of discomfort. It is never quite as simple as this; for, while we each wish to live at peace with our own view of ourselves, we need also to feel that we are worthy of the esteem of others. In a very real sense, we can speak of one part of the self aggressing against another part by the punishing experience of anxiety and guilt. When there is internal censure and criticism for the aggression of the ego against the outside world, Deutsch (87) describes it as "aggression against aggression."

It is an interesting commentary on the problem of guilt that when hostility is justi- fied by the circumstances (i.e., self-defense in the event of attack), guilt is not usually an outcome. Although unprovoked hostility directed toward others will produce guilt, probably one of the most pervasive stimulators of guilt feelings tends to be hostile thoughts or impulses which may never reach overt expression. Since society condones forms of aggression like self-defense and since male children are permitted a greater range of guilt-free aggressive activities, it takes a great deal of experience with one's hostile impulses to strike the fine balance of expression and inhibition that civilized living demands. Guilt over aggression is determined by the particular characteristics of the aim of hostility, the object toward which it is directed, and the nature of the act of aggression committed. These standards of behavior are learned at an early, and essentially irrational, age and become so imprinted in an individual's pattern of response that they persist long after the situation in which they were learned has disappeared.

The complexity of the dynamics of hostility is clearly presented in what Symonds (379) calls the "neurotic cycle." In order to assure himself of his parent's love, a child finds it necessary to repress his hostility. This hostility, once repressed, may give rise to guilt, which in turn can be assuaged only by punishment. If punishment is not forthcoming or if the punishment seems to be less than the crime deserves, then the child must step up the tempo and intensity of his aggressiveness in order to gain the punishment which will restore his guilt-free equilibrium. This neurotic cycle might better be designated as an ever expanding neurotic spiral, for, while the act of punishment may relieve guilt, if excessive it will provoke fresh resentment and rebellion and an even more intense reaction by the parent. If this spiral of action and reaction is never interfered with or returned to its starting point, 
the parent faces the prospect of a hostile child maturing into an angry adult.

Although the formation of the child's aggressive attitudes and behavior issues quite directly from the lessons learned through the style and form of punishment meted out by the parent, this topic, the nature of punishment, has been little studied. One of the most recent attempts to explore the dimensions of punishment is a new projective device called a "Punishment Situations Index" (277). This consists of sets of cartoons showing a child and a parent in a situation which would commonly be followed by punishment. By recording the response of the parent and the response of the child to the same situation, a view of the meaning of punishment is obtained for each of them. The child fills in his own response to the situation and also tells what he expects his mother's reactions and response to be. In this way you get the child's self-concept of punishment and the child's concept of the mother's feelings about punishment. In a separate session, the mother can make her own projective response and also try to indicate what the child would think and say. In the preliminary work of classifying these views of the situation and views of the anticipated response of others, some first conclusions can be drawn. It is clear, for example, that the parent and child naturally view the punishment situation quite differently. The child's view of the mother's reaction often does not fit the mother's view of what her reaction would be. Mothers direct more aggression against their children than children direct against their mothers, and children see their mothers as directing more aggression against them than the mothers are aware that they express. In a punishment situation, the children tend to project more aggression against themselves than one might suspect. The approach reflected in tests of the perceptions and attitudes of children and parents toward punishment for wrongdoing gives us some insight into the discrepancies between what parents think goes on in the mind of the child and what actually occurs. Since punishment is such a vital interaction between the parent and the child, it is important to know how this is perceived by each of them.

\section{AGGRESSION AND PREJUDICE}

Hostile attitudes toward members of minority groups constitute a special case of aggression, since it is such a pervasive part of the American social scene and since this form of hostility finds sanction in some quarters. By the time a child is four or five years old, he may have developed at least a verbal predilection to disparage others because of their race, religion, or nationality, but this is usually a parroting of feelings held by adults around him. As the child widens his circle of acquaintances, his prejudices become more crystallized; come to resemble adult patterns of prejudice more closely; and become surrounded by a structure of rationalization, with "good" rather than "real" reasons for the way he feels. The study of prejudice is the study of how aggressive feelings come to be associated with objects with which the individual may have had little or no personal experience.

In a series of related explorations of the development of prejudice $(325,326,327)$, lower-middle-class children from five to eight years of age were asked to tell stories about pictures showing Negro and Jewish boys in simple social situations in school and at play. It was clear that even the youngest child had an awareness of group tensions in society, and, with advancing age, there was an increase in the percentage of children who faithfully reflected the form of adult prejudice. The amount of hostility toward Jews and Negroes also increased with age, as did the intensity of the feelings the chil- 
dren had. Interviews with the mothers of these children presented a picture of parents who were opposed, verbally, to segregation and in favor of democratic values but who had little insight into their underlying feelings toward minority groups. Through actions of which they were hardly aware, the parents conveyed the lessons that the children learned so easily. These studies demonstrate the learning of hostility through association with others who possess these feelings and are important to the learner. It is, as is most early learning, an unreasoning absorption of the cardinal values of persons in the child's immediate society.

Children may acquire the hostile attitudes of those with whom they identify in their social group, but a child can also learn to use prejudice as an outlet for resentment of all kinds. Frustrations which produce aggressive feelings in one part of a child's life and which cannot be expressed directly to the frustrator may be displaced to objects or persons that are "safe" targets for anger. Members of a minority group can become scapegoats who are unable to retaliate effectively when attacked by persons in more favored social or economic positions. Being outnumbered is a great handicap in itself and since the power of a society is vested in members of the majority group, retaliation is liable to be dealt with quickly, unfairly, and severely. In children, displacement of aggression is frequently clearly visible to the observer, since it often is direct and without deception. Typical of the research devised to test the reliability of the scapegoat hypothesis is the work of Miller and Bugelski (274). They measured the attitudes of boys toward minority groups and then, later that day, deprived the boys of a pleasurable activity that they had been anticipating with great eagerness. Repeating the attitude tests, following this frustration, they found that the boys showed more prejudice than they had before. Since the experimenters had clearly been the source of frustration to the boys, Miller and Bugelski concluded that the increase in hostile attitudes toward minority groups was a displacement of aggression that properly should have been directed at the experimenters. The prediction that aggression will be displaced following frustration must be qualified, however, by an examination of the nature of the frustrating circumstances. When Stagner and Congdon (376) repeated the essential features of the Miller and Bugelski study on a different group of boys, they eliminated the arbitrary frustration administered by the experimenter and found that displacement of aggression did not occur. When a subject is placed in a situation where he can attribute frustration to his own ineptness or personal failure, he is liable to turn a portion of his aggressive feelings inward rather than displacing them to others. If the frustration is arbitrary and issues from a clearly defined source, toward which aggression cannot comfortably be expressed, we have almost all the conditions necessary to encourage attack on innocent bystanders.

We have discussed two important conditions in which prejudice toward others may arise-identification with prejudiced adults and displacement of aggression-but a broader and more fundamental basis for group hatred is to be found in an individual's basic personality structure. The most general statement of this position can be found in an investigation (2) which concluded that, compared with tolerant people, prejudiced adults are likely to be social conformists who are highly moralistic and authoritarian in their personal behavior and attitudes. According to some experimenters (153), there is a generalized attitude of intolerance which is associated with certain personality characteristics, such as having 
cynical, distrustful opinions of others, feelings of having been treated unfairly by others, and fears of being exploited or duped by others. The prejudiced child tends to be suspicious of the integrity of others, lacks confidence in himself, and feels insecure and uneasy in the world.

In an extensive study of undemocratic opinions and attitudes in children (128), nearly fifteen hundred boys and girls between the ages of eleven and sixteen reacted to statements about minority groups and then the hundred and twenty most and least prejudiced children were chosen for further study, using interview and personality test methods. Prejudiced children, it was discovered, admired greatly those things in the world that are strong, tough, and powerful. They feared any kind of weakness in themselves, yet felt helpless in a threatening world. Since such an outlook on life is learned from the parent, it presents a serious problem that reaches far beyond prejudice. It is apparent that if such attitudes spring from forced submission to stern, rigid, and harsh authority, they will tend to engulf all the child's relationships with others. Harris, Gough, and Martin (170) reaffirm the contention that personality characteristics associated with intolerance are established in early parent-child relationships, for in their study of prejudice they saw the source as rigid, authoritarian handling of control over children and a lack of tolerance of the "annoyance" of rearing children.

If racial and religious hostility can be either an expression of the basic personality of the individual or a fact learned from associates, then attempts to modify these feelings must be arranged according to the source. Hostility acquired by association could be altered in the direction of greater tolerance if such children were provided with an environment that offered experience with democratic principles of living. But, as Mussen (289) observed, children who depend on the use of scapegoats as an outlet for aggressive feelings would hardly be expected to undergo change by exposure to even the most democratic of settings. Mussen tested these hypotheses in an interracial camp for boys in which for four weeks Negroes and whites lived in intimate contact with one another. Measuring the anti-Negro attitudes of the boys before and after the camp experience, he found that those boys who increased in prejudice were hostile, defiant youngsters who felt that they were frequent victims of aggression themselves and who perceived the world as a cruel and unpleasant place in which to live. These were also the boys reported to be dissatisfied with the camp and the other campers. If it was an unpleasant month for this group of children, it is unlikely that any inroads would be made on their attitude toward the Negroes with whom they lived. The children who showed a decrease in prejudice by the end of the camping season fared much better with their peers and were judged to be better able to relate comfortably to others in the camp. In addition, they manifested fewer aggressive needs, were less hostile toward their parents, and held generally more favorable attitudes toward society. Although prejudice can be reduced by educational measures such as planned living experiences, education can reach only those children who are free of profound psychological disturbances. When prejudice is a needed outlet for hostility, contact with persons toward whom the prejudice is directed serves only to reinforce the original resentment. This occurs because the issue is prejudged by the bigot, and his contacts with minority group members are used as a means of seeking evidence for the beliefs he already holds. Since those who have experienced 
the frustration of being discriminated against tend to be aggressive in return, a vicious circle is established that is difficult to break (152).

\section{The Development of Aggression}

Except in rare instances, the aggressive behavior of adults is much more sophisticated and polished than that of children. It is not only that the adult has acquired an infinite variety of means for communicating his feelings, it is also that he has developed more than one kind of emotional response to frustration. These skills in managing aggression are gained during a lifetime of painful lessons at the hands of his parents, his teachers, and his peers. Only the most incorrigible of romantics would describe childhood as the golden years of carefree, happy play untroubled by the worries of the world. In retrospect it does seem that today's problems and responsibilities are more weighty and troublesome than those of youth, but this view is constructed of a combination of a hazy memory and the safe perspective of elapsed time. When we nostalgically recall a youth spent on a farm, we are likely to remember only the cool well water that slaked our thirst on a blistering summer's day. We selectively omit those memories that are painful or unpleasant in order not to disturb our idyllic image. This kind of recall has been labeled "old-oaken-bucket" thinking and is characteristic of the general conception each of us has of his own childhood. Even a casual observation of the emotional upsand-downs of the daily life of an average child would immediately press home the truth that there is at least as much pain in childhood as there is pleasure. It is not that a child weeps as much as he laughs, it is rather that conflicts cut deeper than comparable joys. A tally of the number of angers, resentments, jealousies, irritations, and rebellions that accumulate in just the child's first ten years is ample evidence of the pain of maturing. During development the child does not want for the opportunity to practice managing aggression.

Theorists are in general agreement that aggression is a fundamental characteristic of existence and begins as a reflection of the action and vitality of living $(8,62$.) Through an aggressive or active relationship with his environment and the people in it, the child becomes an active participant in the development of his own personality. If he accepts the pressures of others passively, he acquires a psychic structure not of his own fashioning. In this sense, there are positive values of aggressiveness that are more than just derivatives or by-products of the more malignant qualities of aggression. Since children grow in a setting in which there are other children, aggression seems to be an inevitable consequence of living with others. Jealousy of other children, competition with them for a place in the family, and disputes over property are inescapable $(122,387)$.

An important aim of the study of the development of aggression is to uncover the determinants of the form that aggressive response will eventually take. It is clear $(92,359)$ that the overtness of expression will depend on many factors, the most important of which will be the success that the child achieves in reducing tension.

\section{EARLY INFLUENCES}

The search for the causes of patterns of aggressive response has taken researchers to the earliest experiences of the childthrough infancy, to birth, and the mysterious time before it.

In one study (362) of the antecedents of aggression and frustration, a group of investigators examined mothers' reports of nursing, weaning, and scheduling their children in early life and compared estimates 
of how frustrating this had been with the rated behavior of the children in nursery school. Although they found a predictable relationship between the severity of frustrations and the child's later dependency on others, no such significant pattern of relationships was found between frustration and measures of aggressiveness in preschool children. It seems likely that the frustrations of nursing and weaning occur when the child is so young that his only workable response is to be passive and dependent on others, since he is not yet capable of launching an effective aggressive attack that will bring him satisfactions. Other researchers $(195,196,244,366)$ have taken the position that for most mothers there is not a strong relationship between child-rearing practices in one aspect of socialization, such as feeding and weaning, and the socialization practices which occur later in life, such as toilet training. It is perfectly possible that hostility engendered by highly frustrating experiences during the feeding period may be overcome or assuaged through the careful handling and encouragement of the mother when the important later tasks must be learned. Since hostility is a consequence of a continuous series of experiences with the mother over a long period of time, it may well be that the final form of aggressiveness is a function of the kind of total balance worked out between mother and child. Premature or very severe attempts to toilet-train the child can produce disruptive responses at an age when he is unable to convert his feelings into an effective attack on his frustraters. Among children referred to a child-guidance clinic because of their maladjustments, it was found that in over half of the cases bowel training had been started "too early" according to the estimate of the clinicians. Such training was also accomplished by coercive methods such as a rigid toilet schedule in which the child had to learn to produce on time and suffered shame and punishment if he failed to do so or was the victim of physical devices to force the response (suppositories). The child's immediate reaction to this treatment was the display of a series of symptoms, among which were anger and defiance directed toward the world. Their resistance to the training was such that 58 per cent of the children were still enuretic (196). These findings are highly suggestive of the disruptive effect of harsh relationships between the parent and the child. Most studies report that this parent-child conflict produces negativism, aggressiveness, and patterns of resistance early in the child's life.

During the course of a child's development, battles over specific issues may develop with the parents and be reflected in a loss of maturity on the part of the child and the retreat to hostile means of meeting conflict. More serious effects are produced in the personality when we consider the unrelieved deprivation that comes from institutional living and the lack of a one-toone relationship with a consistent mothering figure. Occasionally objectionable patterns of mothering differ considerably in their impact, from the totally inadequate mothering experienced by a child who spends his early years in a foundling home or orphanage. In such a setting we can get a clearer picture of what happens when the usual level of frustration is raised without the compensation of maternal help in learning to meet it. Goldfarb $(144,145,146,147)$ compared the development of children who experienced the impersonal care of being raised in an institution for the first three years of their life with the development of others reared in foster homes. Intellectual passivity and impoverishment marked the institutional children, and it remained apparent even after adoption and the stimulation of family life. Greater anxiety and gen- 
eral aggressiveness (antagonism to others, impudence, destructiveness, temper tantrums) were also visible. The longer the child had remained in the institution, the greater the personality damage and the more firmly rooted were the patterns of angry response. It is clear that after the gross deprivation of close relationships, the overall adjustment of the child suffers, and irreversible pathology may be formed.

In the early years the mother is the sole representative of the culture and the one who can correct and alter unacceptable patterns of hostility before they become fixed, rigid, and immutable. A child without attention to his basic emotional needs may drift aimlessly, selecting the first device that brings him satisfaction. Since the supply of adult attention is limited in an institution, a child must assert himself by crying, screaming, and having temper tantrums if he is to compete successfully for what little attention is available. The role of the parent in the very early years seems to be twofold: to prevent excessive frustration and to correct deviations before they are beyond change.

\section{LATER INFLUENCES}

Since a child will learn whatever responses are rewarded by others or bring gratification of his needs, it is easy to see how he can grow in sophistication in the use of aggressive devices. When other individuals are blocking the child's way and frustrating him, he can, by accident, learn that an aggressive attack will remove them and free the path to gratification. This path, trod often enough, can become well worn and evolve into the characteristic "style of life" of the mature individual (282). When the child discovers the benefits of hurting others and as he gains experience and learns more about the motivations of others, he will become more and more skilled in using this knowledge of their motivation as a means of controlling them and getting what he wants. Early in his life he may be stubborn and negativistic toward all adult requests and capable only of digging in his heels in defiance $(18,126)$. As he becomes sensitive to the emotions of others, he begins to understand that he can outwit them or outwait them and that defiance of some adult demands will not bring down their wrath on him. Thus strangers will cow a child and cause him to be more restrained simply because he cannot predict their responses. With parents, the child knows exactly what to expect and how far he can go, and he acts accordingly. With strangers he is not safe until he tests their tolerance and probes for the weak spots in their relationships with children. This, of course, is distressing to the parent, who takes it as a sign of personal failure in achieving control over the child. It is not that familiarity breeds contempt, it is rather that familiarity educates the child in predicting the parent's response. As the child progresses in his education in hostility, he acquires greater finesse and soon perceives that symbolic injury and psychological pain are much more excruciating than simple physical hurts. Once this insight is gained, he stands on the threshold of graduate study in the fine art of cruelty.

Systematic observations of anger in children were made long ago, yet they remain useful today because the essential nature of frustration and the response to it have not changed markedly over the years (150, 339). Studying children ranging from seven months to eight years of age for a period of a month, Goodenough (150) collected nearly two thousand instances of anger outbursts recorded by parents. For very young children, the bulk of such outbursts were displays of undirected energy in response to frustration. Kicking, screaming, holding 
the breath, and similar actions were characteristic of the first two years of life. In almost all categories of the expression of aggression, boys exceeded girls throughout the age range. As the child grows older, resistance in the form of sulking, whining, and pouting becomes more common, and the outbursts are pointed more clearly in the direction of the frustrater rather than against the environment in general. As Goodenough indicated, resistance to the parents made up less than 15 per cent of the aggressive responses under one year of age, while accounting for nearly 60 per cent of such responses in children between the ages of one and two. The fact that outbursts become more symbolic and are intended to destroy the other person on a psychological, rather than a physical, basis does not mean that the child's aggressive feelings are any easier to manipulate by the parent. He has learned the cost of direct expression of his hostility and has made it more devious and hidden, but its intensity remains the same as when he was a smaller child.

The form of the child's aggression changes, and so does his ability to nurture his anger and to keep it alive. Of course, the length of time that hostile outbursts remain overt decreases regularly and predictably. Infants under one year of age could sustain expressions of rage for an average of ten minutes; as such tantrums are found to be ineffective and simply irritate others, they decrease to an average of about three minutes. This is the simple but essential meaning of self-control, for the child manages his actions even if he harbors an urge for revenge and makes a mental note to get even later. Although the total time of the outburst shortens, aftereffects, such as brooding, being sullen or resentful, were much more apparent with increasing age.

The child's perception of the source of his frustration also shifts with time. Under two years of age, much of the child's anger was induced by physical restraint imposed on him by his parents-being sent to bed, toilet training, or being refused permission to undertake some activity he desired. Few of the angers of this age are accounted for by friction with playmates, but this is due to the rather distant play relationships that children of this age have with one another. Of course, the physical discomforts of illness, hunger, or fatigue are more likely to take their toll and to instigate young children to aggressive response. For the very young child there is also a freedom from the frustrations attendant on efforts they make to do things for themselves and to be independent of the parents. The simple inability to tie his shoe or take off his own galoshes can precipitate a child into a fullblown rage. It is not just the frustration of the untied shoe, it is also the awareness of helplessness and personal limitation which contributes to the response. The very young child has, as yet, no emotional investment in this kind of self-help and does not see the possession of these skills as valuable indicators of maturity. Some of the most trying times for the child occur when he develops a need to care for himself and is yet without the skills to do so.

Probably no account of the development and control of aggression is complete without a brief description of the pattern of social relationships that children have with one another $(57,258)$. Whatever shortcomings exist in a child's education about anger are soon remedied by the informal lessons he will experience at the hands of his peers. For most of the first year of life children are barely aware of one another, even when playing in the same area. The first contacts they make are similar to those they have with moving toys or animalsaction with little planning or recognition 
of the essential nature of the other object. By the end of the first year, children begin actively to interfere with one another. This happens particularly when the shortage of toys makes the presence of the other child a positive frustration which evokes a primitive form of pushing and shoving between them. These events do not have the flavor of purposeful hostility with a clear-cut aim. By about one and a half years of age, a transition to social responsiveness takes place as the child becomes capable of perceiving the other child as a potentially responsive object. The first natural responses of the child will be co-operative ones if there is no basis for competition and they both have elbow room. Before long, the other child is an object of more interest than play materials alone, and co-operative play begins. This description of the expanding social life of the child provides the basic setting for aggressive response, but the form of social interaction may be quite different for a particular child, especially a disturbed one.

Throughout the preschool period the child's social responsiveness expands rapidly. Between the ages of two and five, few children engage in solitary play if companions are available, there is less parallel play and much more associative and co-operative play. As he seeks out other children, he will experience an increasing number of rewarding interactions, but he will also be subject to the aggressiveness and bossiness he did not realize were characteristic of childhood $(175,206)$.

As the child's social circle widens, it begins more frequently to be the arena of his frustration and conflict, and it becomes the locus of his continuing education in the management of impulses (120). The lessons he learned at home are reinforced and become a permanent part of the child's repertoire, or they are stamped out by the pain they produce. Other children will regularly provide the teaching that parents have neglected up to this time. A parent who could not bear to limit or restrict the child will find that other children will do so in a much less loving and much more violent fashion.

The nursery school is a regular source of observation of children during the time that they are learning about social aggression. This is not a perfectly natural setting or one in which a child has the security of being in his own back yard, but it offers the advantage of having the same children, in the same setting, over a long period of time, and it allows adults to observe without being out of place $(50,158,159,174,291)$. With age, the child not only widens his circle of friends, but the strength of his attachment to others increases apace, and the ratio of friendly to hostile overtures swings to the side of friendship. With the formation of closer friends, the correlation to quarreling also increases. Mutual friends argued more than the average, and those children who squabbled a great deal with one another were also closer friends. The finding that friendship and anger are more intense in the same relationship is not an unusual one; observations of young children reveal that sympathy for the discomforts of others grows along with increased social interaction $(30,32,286)$. The children who interacted the most with others and were frequently hostile to others were also those who displayed the most sympathetic behavior. Gregarious and sympathetic children were also aggressive and unsympathetic. The more active the child, the more opportunity he will have to come into conflict with others, to be aggressive, and to be sympathetic with the victim of his attack. Such children move comfortably from defending a child under attack by others to joining in a group assault on some hapless 
victim. Although it has never been tested, it would seem reasonable to assume that the lessons of aggressive control learned by a very active child would differ considerably from those experienced by a child who was lethargic or passive.

To an adult observer, it sometimes seems that a great deal of the child's anger is unprovoked and that the situations which produce it do not warrant such a violent response. This may well be a problem of adult perspective. Children's conflicts can be quite complex and symbolic. Most social aggression, whether verbal or physical, is a result of trespass against a child's possessions or his freedom of movement. Interference with freedom of movement, for example, can produce rage when it is no more than the ritual act of stepping across a property line drawn raggedly in the sand, since the contest is actually one of establishing dominance and submissiveness between the antagonists $(84,207)$. The very experience of being exposed to numbers of other children acts to make a child more assertive in his relations with others (64). In nursery schools, children soon establish a "pecking order" of aggressiveness, and this dominance arrangement tends to be maintained, so that a child's proneness to conflict is predictable in kindergarten from knowing his status in nursery school (108). This description makes nursery schools appear to have the characteristics of miniature blackboard jungles, and it is true that conflict is a major activity of preschool children. Jersild and Markey (207) report that, on the average, a conflict occured every five minutes in their study of children from two to four years of age. It must be pointed out, however, that these conflicts were not severe, they did not last long, and there were great individual differences in the total number of conflicts for each child. Conflicts among two-year-old children seldom got past one round before they were settled, but among feur-year-olds 67 per cent of the conflicts were likely to flare up a second time (16).

When quarrels occur among preschool children, characteristic differences between the sexes are quite apparent. Boys argue more than girls, even though girls regularly prefer verbal to physical means of resolving conflict. Boys more often choose other boys to be the recipient of their hostility and, at the same time, prefer other boys or adults when they wish to express affection (389). In general, disputes are more frequent between children of the same sex but of different ages, with the younger child being the less aggressive of the two. Actually, younger children are more likely to initiate a fight but, once it has been started, they tend to engage in a holding action rather than an active, assaultive one. The younger child holds on to a toy for dear life while the older one is seeking actively to separate him from it. In a nursery school there is some wisdom in this strategy because when adults interfere in children's quarrels the issue is usually settled in favor of the child being aggressed against at the moment of interference. Often this action is without regard for the issue at hand or considerations of who initiated it. The principle the adult is trying to communicate is "Thou Shalt Not Aggress under Any Circumstances."

Aggressiveness has its social consequences in terms of the popularity of the child (223). Since children tend to learn the lessons taught by the adults, they reserve popularity for those who respect the property rights of others and who are reasonably compliant to rules. Tendencies to play alone, to attack others, to refuse and ignore others, and, interestingly, to offer no resistance when attacked were characteristics of unpopular children. A child's position in his group 
changes his relationships with others, and his patterns of aggressiveness are altered accordingly (94). Children with high group status do exhibit aggressiveness in their play but also show a greater proportion of positive expressions than do low-status children.

Most of the combativeness that has been described has taken place in settings in which adults were always at hand to maintain law and order. Siegel (369) made some revealing observations of what happens when children of like sex play together in a situation free of adult supervision or intrusion. At first, these pairs of children reacted aggressively toward one another, but this hostility decreased regularly from session to session in play. This observation is quite different from the increase in aggression that usually takes place as time wears on under adult supervision. It suggests that children may abdicate the functions of self-control when an adult is present but are perfectly capable of managing themselves when adults are not there to settle the argument.

\section{RECRESSION}

The drama of aggression has made it a fascinating topic of study, but it is not the only possible response to frustration. For the young child, it is high on the list of reactions that he has avajlable to release tension. As he grows older, aggression is superseded by more mature ways of managing conflict, and as long as these devices bring the child gratification, he need not have recourse to blind assault in his relations with others. Into every life some rain must fall, and there are times when the child or the adult finds himself enmeshed in circumstances from which there is no escape and in which constructive attacks on the problem fail miserably. As rational plans are discarded one by one, the child is driven to seek relief through less mature kinds of be- havior. This erosion of the child's maturity may take the form of a return to patterns of response once useful but abandoned in the climb to more adult forms of expression, or it may be represented only by a primitivization of the personality of the child and a decay in the ingenuity and sophistication of his actions. In a now classic study, Barker, Dembo, and Lewin (24) tested the determinants of regressive behavior among nursery-school children by comparing their reactions in two different situations. First, they allowed the child to play freely with toys arranged systematically in an experimental room. The constructiveness of their play with these toys and the original and creative uses made of them were rated by observers. Since this constructiveness was highly correlated with both chronological and mental age, the constructiveness scores were transformed into mental-age equivalents to serve as a measure of the maturity of the child's play behavior.

After these observations and ratings were made, each child was exposed to a threepart frustration. First, in a prefrustration situation, the child was brought into an experimental room in which the standard toys of the previous free-play. period were combined with a set of very fancy and attractive toys. When the child became thoroughly involved in playing in this setting, the experimenter gathered together all the standard toys and arranged them on one side of the room as they had been in the original free-play period. The child was then led to that side of the room, and a wire screen was lowered between the two parts of the room. This became the frustration experience for the child. He could see the attractive toys he had been playing with but had access only to the simple play materials on his side of the room. After a half-hour, for humane reasons, the screen was lifted, and the child 
was once again allowed to play with the fancy toys.

During the time that the child could see the preferred toys, but not get at them, his behavior was observed and rated in terms of its constructiveness. In this way, measures of the child's maturity while playing with standard toys in a frustrating and nonfrustrating situation were available for comparison. Translated into mental-age equivalents, the average regression induced in these nursery-school children was seventeen months. A four-year-old child playing with a constructiveness appropriate to his age (forty-eight months) would, on the average, display patterns of play more nearly typical of a thirty-one-month-old child, when exposed to these frustrating circumstances. In addition, what the authors called "barrier" or "escape" behavior was a frequent response. The child would attack the wire screen, plead with the experimenter to be allowed out of the room, or launch a verbal or physical attack against the experimenter. Access to the attractive toys soon repaired the child's injured feelings, but such an easy solution to the child's loss of maturity seldom occurs in everyday life. If a child regresses under pressure of frustration in the home and becomes more destructive in his play, the irritated parent is liable to punish him in an effort to force a return to greater maturity. The act of punishment frustrates the child further and drives him deeper into his regression and initiates a cycle of behavioral disintegration that may end with the child being carried screaming to his room to cool off.

In the experiment, as in real life, there were individual differences in the ease with which some children chose regression as a response and the degree to which they regressed in the face of frustration (70). Other experimenters have suggested that regression is a consequence of inadequate ego control in the child. Ego control is taken to mean, for example, the child's capacity to delay gratifying his needs or to withstand the effects of being bored by doing simple tasks over and over (48). Children rated high in ego control tended to respond to frustration constructively and were less frequently aggressive than children low in ego control (240). The concept of ego control is quite similar to that of frustration tolerance (341), which implies the existence of an emotional stability based on success in meeting and mastering conflict situations.

In any frustrating situation the presence of friends has a salutary effect $(409,410)$. In an experimental situation quite similar to that of Barker, Dembo, and Lewin, close friends and casual friends were paired in a free-play setting. The close friends played in a more mature and constructive way than did the children who were casual friends. Both close and casual friends had their maturity deteriorate under the duress of severe frustration, but close friends were less likely to regress as much as the casuai friends. Friends seem to sustain one another and to support one another's hold on maturity. In many ways, close friends were able to become even more co-operative when frustrated. They expressed less hostility toward one another and banded together to launch aggressive action against the experimenter.

What is the motivation of regression? The developing child is forced to abandon successful techniques of conflict resolution almost as soon as he becomes skilled in their use because the parents demand that he learn new techniques-ones the society defines as appropriate for each age of the child. At every age in a person's life he has a history of patterns of behavior that he has outgrown in the process of maturing. Under the pressure of unusual frustration which 
will not respond to mature responses, in desperation the outmoded patterns are used once again. Regression is unavoidable for the person with a limited emotional repertoire or an unsure grip on a recently acquired maturity.

\section{The Direction of Aggression}

An analogy might be drawn between human sexuality and human aggressiveness. Ford and Beach (121) reported that when large amounts of a male hormone (androgen) were administered to homosexual male patients it resulted in the intensification of the sex drive with no alteration in direction. The homosexual patients experienced an increased desire which was translated into action in the form of more frequent homosexual contacts. The presence of a hormone acting specifically on the sexual drive encouraged the error of assuming that these chemical agents acted to determine the direction of the sexual drive in humans. Hormones designed to increase the "maleness" of males could do nothing to alter the characteristic behavior through which it found expression. Although we know of no chemical specific to aggression, as hormones are specific to sex, it is true that tranquilizing drugs do act to lessen the intensity of a patient's response to aggressive stimuli. It is typical that highly combative patients become more placid when administered these drugs, but the direction of their hostile urges remains unchanged. If they feel that they are the victims of persecution by others and that their attack on the world is selfprotective, the tranquilizing drugs reduce the degree of emergency they experience at the moment, but the chemicals do not alter the patients' fundamental ideas. The direction that an individual's anger characteristically takes is a lifelong, learned pattern of response and cannot be altered internally except by a process of relearning or through a shift in the balance of psychological forces. Frustrations of any sort, which act to instigate aggressive feelings, will magnify the kind of response typical of the individual. In homicide and suicide we can find examples of aggressiveness in response to extreme frustration and marked by a distinctive direction.

\section{Homicide}

The consideration of homicide as a special category of aggression directed toward others is in keeping with the emotional response that most members of a society have to it. It is not just the finality of the act that makes it a topic of wide social concern, for accidents and disease take a much greater daily toll and result in as deep a personal loss to friends and loved ones. Accidents or fatal diseases have about them qualities of inevitability or unpredictability which must be accepted because they cannot be altered. Murder is disturbing because it seems to be a preventable and unnecessary means of solving human conflict, and we each feel a tiny twinge of guilt about the inability of our social structure to anticipate and ward off such extreme human behavior. Each homicide is a grim reminder of the flaws in our methods of teaching humans to manage their impulses. The moth-and-flame fascination we have for murder cases is on a more personal basis. The specter of rage which knows no limits both attracts and repels us because in it we can recognize our own problems highly magnified. For each of us, the control of hostility is similar to keeping a tiger in a cage. It is a constant threat to which we must be ever vigilant, for there are times when we feel impelled to loose it on others, even though it is forbidden, and there are other times when we consider the possibility of freeing it against the self. Our concern with murder is regularly in terms 
of how it happened and why it happened, so that we may make secret comparisons with the status of our own hostilities. This is not a pretty picture, for it describes anxieties we do not like to admit we have, but it is a necessary explanation of our motives if we are to account for the eagerness with which we read the obituaries and dwell on the details of death at the hands of another. Horror, yes, but fascination also.

Murder has a host of significant correlates, no one of which offers, in itself, an adequate explanation of the act (42). Homicide bears a meaningful relationship to age, sex, race, social status, marital status, income, the business cycle, and innumerable other aspects of human existence. It is from this welter of information that theorists have tried to assemble a coherent explanation of this most extreme expression of hostility.

One of the most abstract relationships that exists is that between hostility and the economic condition of the country. When an economic depression occurs, according to Henry and Short (180), the incidence of homicide and aggravated assault tends to decrease, and, with prosperity, homicide increases. This general conclusion is, of necessity, a somewhat oversimplified one that must be qualified in several ways. The terms "prosperity" and "depression," for example, are vague generalizations used to describe a continuous series of economic events, and such terms ignore the periods of transition between these states. These broad terms fail to account for the lag that may occur between "business prosperity" and the personal prosperity of the average citizen. An additional source of error may be introduced through flaws in the methods of recording assault or murder. It is reasonable to suspect that swings in the business cycle will be reflected in psychological upheaval of various kinds and that economic desperation piled atop other frustrations can light the fuse that produces the fatal explosion. If, as it tends to be in our society, the social status and economic power of an individual are clcsely tied to each other, then the prime result of either a depression or prosperity would be to alter one's social status and to produce commensurate changes in feelings of self-esteem and worthwhileness.

Henry and Short take the position that both homicide and suicide are responses to frustration and that the choice of one or the other as a way of dealing with conflict is closely related to social status. Members of groups of low social status habitually express their aggression toward others with greater frequency than do members of society higher in the sociocconomic scale (318). The reverse of this relationship is suggested for suicide. Higher-status categories will have higher suicide rates, when faced with frustration, than will low-status categories. It is easier to demonstrate that such relationships exist than it is to explain why they exist. Henry and Short's explanation of the genesis of the choice of a target for aggression centers about the strength of external restraint imposed on its members by the society. The behavior of persons of low social power (minority-group members, unskilled persons, poorly educated persons, etc.) is more often required to conform rigidly to the demands and expectations of other persons, and this, it is suggested, lowers the probability of suicide as a response to frustration while raising the probability of homicide. In a socially dependent status, other persons become a legitimate target for aggressive impulses because they are visibly the source of the frustration. When behavior is free of this requirement for conformity to the demands and expectations of others and is more subject to an internal set of restraints, the 
probability of suicide is high and homicide low.

This theoretical explanation is an ingenious one, but a person who characteristically expresses aggression toward others must learn this form of behavior long before he feels the full impact of his relative social position and is capable of reacting to it. The external restraints to which Henry and Short refer must operate early in the life of a child in order to make the outward-turning of anger an automatic response to frustration. We do not yet have a reliable experimental demonstration of differential childrearing practices for persons of higher and lower social classes-practices that we can prove lead to learning to aggress toward others or toward the self. It is a fair estimate of the theoretical climate of opinion to state that a preferred direction for the expression of aggression certainly is learned; it is learned in the earliest relationship of parent and child; it is reinforced through a series of life-experiences; and, when intense anger is coupled with ineffective control, it can culminate in murder or suicide.

The act of murder is multiply determined and represents a response to pressures issuing from a variety of sources. Race, for example, is significantly related to the act of murder. Sutherland (378) reported not only that Negroes had a higher absolute crime rate than whites but that Negro rates of homicide and assault were disproportionately high when compared with rates for whites. In 1940, for example, 3.1 times as many Negroes as white persons per 100,000 population were arrested for all types of crimes, and there were 7.2 times as many arrests of Negroes for homicide. It must be noted here that, in general, persons who murder tend to find victims among members of their own race.

The interpretation of crime rates by race is complicated by the existence of significant variations in homicide by geographical area $(25,319,330)$. The rates for crimes of violence against persons are uniformly higher in the South, for both whites and Negroes, and lower in the North. Crimes against property do not follow this trend. Living in the South and living in a rural area combine to produce an even higher risk of murderous assault. Offenses against the person, ranging from serious assault to homicide, tend to be higher in rural than in urban areas. When homicide rates are examined within a city, there are reliable distributions according to sections of the city (167, 241, 350). In Schmid's classic study of homicides in Seattle, he found 25 per cent of them concentrated in a district less than ten blocks long and four blocks wide $(350)$. Even though homicides do not happen at a greater rate in cities than in the country, they are densely concentrated in particular trouble spots within a city, as the police well know. These parts of the city are characterized as socially disorganized and tend to include areas of "homeless men" living in rooming-house, Negro, and immigrant districts.

Being male or female affects the probability that you will commit murder. In 1950 , for example, eight times more males than females were arrested for assault, and seven times more males were arrested for murder. Males, of course, commit more of all kinds of crimes than women and aggress against others and society in a variety of ways. It is interesting that women exceed men only in inflicting fatal injuries on children under one year of age. The crisis of birth and the responsibility of motherhood are uniquely female problems. In most other situations the female of the species is not nearly so deadly as the male.

Age makes an important difference in an individual's readiness to kill others. The most dangerous ages according to Frankel 
(124) are between twenty and thirty-nine, and the decrease in homicide rates is quite sharp after that time. Nearly five times more murders are committed by persons from twenty-five to twenty-nine years old than by persons between the ages of fifty and fifty-four and the rate is nearly twenty times greater than that for persons over sixty-five. Among Negroes and persons born in a foreign country, the decline in homicide comes at a later age. Not only do they tend to aggress violently against others with greater frequency, but they continue this behavior, without a sharp decline, until they are over forty-four years of age.

The many attempts to unravel the motivation for murder have uncovered a complicated jigsaw pattern of the determinants of fatal aggressive acts. Any act, whether it is murder or abstaining from murder, is multiply determined and can be understood only as a resolution of forces both without and within the individual-a resolution of forces that produces a single act which, in the case of murder, is so dramatic that it obscures the very forces that led to it. In the year 1950, for example, the interplay of these forces and pressures reached a critical point such that the lives of eight thousand persons were forfeit because the exhausted resources of some individuals made murder the only alternative. Somewhere, at this moment, problems are being resolved in this violent fashion.

Some of the richest insights about the complexity of the dynamics of murder are contained in the detailed case studies that have been done of murderers $(23,157,160$, $220,296,340)$. Accounts of murder have always been a popular form of public entertainment, but the more sensational and lurid reports regularly fail to do more than rehash the most superficial views of the reasons why man kills. The primary problem in describing the motivation for murder is that its basis can be traced to successively deeper layers of the personality, since the final act is actually the culmination of a long and complicated chain of events. Most persons are made anxious by such a violent act if it is not comprehensible on a rational basis because they can feel the stirring of similar impulses in their own breasts. The notion that hidden feelings moving in mysterious ways can overwhelm a lifetime of controlled behavior makes each of us apprehensive about the times we barely choked back a consuming rage. Murder is less frightening if it comes nicely packaged in terms of motivations that make it an extreme but rational act.

Since popular accounts rely on a firstlevel analysis of the most obvious causeand-effect relationships, they do not provide much insight into the circumstances that render emotional controls ineffective at a time when they are most needed. Controlled laboratory experimentation with antisocial acts and the determinants of violent attack on another is not an easy task. It requires a means of inducing the expression of some of man's most forbidden impulses and the "murder" must be more than pretend for a subject who is humoring an odd experimenter.

\section{HYPNOSIS AND THE EXPRESSION OF HOSTILITY}

Hypnosis provides a unique means of exploring the strength of human control over aggressive impulses. The induction of the hypnotic trance produces an altered state of consciousness, during which, as folklore would have it, the usual taboos against "criminal" or "antisocial" behavior can be shunted aside and rendered ineffective by the evil machinations of the hypnotist. As Young (411) observed, in his review of experimental hypnosis, the ease with which lifelong moral sanctions are violated in such 
experiments may be more apparent than real. The data accumulated over a number of years have presented a confusing picture, with partisan support for each side of the issue.

In investigations using a variety of hostile, criminal, self-injurious, or antisocial acts as a test, Watkins (390), Wells (400), Rowland (342), Brenman (54), Schneck (353), and Estabrooks $(106,107)$ concluded that hypnotized subjects can be induced to commit acts which they would resist forcefully in a normal state. The opposite point of view is held by Erickson (102), Hollander (188), Bramwell (53), and Full (193), each of whom conducted studies pertinent to this problem. As is so frequently the case, no two experiments were exact replicas of each other, and a great deal of heated theoretical discussion was generated by these differences in experimental procedure.

Some order was brought out of this chaos through the recent interpretations of Weitzenhoffer $(396,397)$. Summing up the observations of a number of investigators and adding his own conclusions, Weitzenhoffer noted that apparently hostile actions can be explained if the experimental subjects (1) believe that protective measures have somehow been provided by the experimenter, (2) have implicit trust in the hypnotist, (3) believe that there are legitimate reasons for the hypnotist's requests, and (4) possess hostile impulses or needs which are ready to be triggered into action if given the opportunity. A fifth alternative, and the most important one to Weitzenhoffer, is that the primary method for eliciting antisocial acts is to instruct the subject in such a way that he no longer perceives the situation as one in which his actions violate his personal standards. Thus, for example, in one experiment in which an enlisted man was made to assault an army officer, the forbidden act was made possible by telling the subject that the officer was really a Japanese soldier who was about to kill him. Presumably, the hypnotized subject's perception of this situation was such that launching a violent attack was not only permissible in these circumstances but logically necessary for self-preservation. Experiments of this kind, as Lyon (243) has indicated, provide the subject with a justification for his actions and allow the hypnotized person to free himself, temporarily, from the usual inhibitions which hold him in check. It would seem logical to suppose that a high correlation exists between the degree to which the hypnotist must distort the truth of a given situation and the sanctity of the moral stricture the subject is pressed to violate. Thus Erickson (103) was able to elicit expressions of moderate resentment, jealousy, and negativism from his hypnotized subjects without offering them a reasonable excuse for their behavior.

The way in which hypnosis can influence the expression of hostile impulses and reduce inhibitions to action has a counterpart in normal techniques of influence. Whenever war is called upon as a solution to international conflict, each nation involved is faced with the task of undoing the early training of its citizen-soldiers in order to convert them into effective instruments of destruction. The means for accomplishing this transformation include not only training in combat skills but an intensive and extensive redefinition of the personal situation of the citizen. The single, most efficient perceptual change, one regularly relied on as a justification for aggressive behavior, involves describing the world as a hostile and dangerous place in which active self-defense is necessary for survival. War for religious purposes, to protect a way of life, and to stave off imminent attack are familiar examples. The ease with which such appeals succeed in the ordinary circumstances of daily life 
helps us to understand how a hypnotized person can, with even less persuasion, be led to transgress the boundaries of socially acceptable behavior.

Investigations using hypnotic techniques have uncovered an important set of clues about human behavior, but these clues must be followed with considerable caution. The altered state of consciousness in hypnosis is not identical with the normal waking state, and the process of hypnosis is much theorized about but little understood. The experimental subjects in these studies are not representative of the general population. They are, rather, a select group of volunteers who are distinguished by their susceptibility to hypnotic suggestion. Despite the limitations inherent in hypnotic experiments, the findings reaffirm the vital part that perception plays in the control of aggressive behavior. If an individual conceives of himself as a rational, sensible being, then he cannot commit an infraction of his own, or society's, standards without seeking a means of justifying his actions. Of course, someone staggering under the burden of an unusually weighty collection of powerful hostilities might require much less justification for relieving himself of part of his load. Boyhood fights, for example, occur when any two spirited young males come to perceive one another as a physical or psychological threat. In instances where no concrete event occurs to initiate the release from inhibitions against fighting, a defiantly placed "chip on the shoulder" serves as a preliminary ritual of mutual justification. The qualities of sham in such a justification by arrangement are never fully comprehended by the participants because even this artificial rationality is effective in resolving the conflict between the need to fight and the prohibitions against it.

This analysis suggests that if it were possible to gain complete control over the perceptual processes of an individual, his behavior could be altered in a predictable fashion. It suggests, further, that any meaningful description of an aggressive situation must include an account of the perceptual distortions that each participant has introduced into it.

\section{CHILDREN WHO RILL}

Murderous assaults by children have always been occasions for deep social concern. Our understanding of the reasons for homicide by children and our treatment of such cases have changed from the time when psychiatry considered such children maniacs who had an innate wickedness and an insufficiency of moral training (234). Death meted out by children has always been a rare event but one that is intensely disturbing because it violates our cherished beliefs about the innocence of the golden years of childhood.

Murder by children before adolescence is unusual, and most of the cases we read about in the newspapers seem to be accidents rather than the outcome of a deliberate plan or a calculated attack. We assume that such accidents lack the intent that would make them homicide; yet the reasoning that applies to accident-proneness, i.e., that self-injury may spring from an unconscious need for punishment, might just as logically fit the case of involuntary manslaughter-accidents which are convenient outlets for the child's impulses. There exist many well-documented cases in which the urge to kill was an accident only in the sense that the child did not choose to have the impulses which drove him to the deed $(34,55,78,88,100,383,403)$. At least for young children, death is little understood, and they do not conceive of it as final and irrevocable but, rather, expect the destroyed object to be restored in some way (399). It is the most thorough form of per- 
sonal retaliation that they have heard of, but its purpose is to remove an unwanted obstacle once and for all, and the "for all" is a vague unit of time for children $(34,37)$.

When children kill, it most often is the natural outcome of sudden violence using whatever weapon is closest at hand. Children may become involved in a homicidal accident in much the same way as an adult. Frustration and anger provoke the child to murderous threats, and when the victim heaps on indignity by making light of these threats, the child is driven to emphasize the intensity of his irritation by brandishing a potentially lethal weapon. If a child in such a disturbed state is provoked further by the taunts of his antagonist, he may commit an act he did not intend at the beginning of the incident. The child may prepare himself, psychologically, to pull the trigger by issuing an ultimatum ("If you don't shut up, I'm going to pull this trigger!") and then, since he has warned his adversary, can feel that he has been invited to commit the act since his victim does not shut up. The logic of rage is tenuous.

When children kill in a premeditated manner, the response of society is uniformly to consider it a symptom of a twisted mind and a dependable indication of psychosis. Undoubtedly, the revulsion each of us feels toward the cold-blooded destruction of another human being is responsible for the eagerness with which we accept this blanket diagnosis when a child is the offender. Psychosis implies an inability to discern between right and wrong and frees the murderer of conscious responsibility for his crimes. It is still difficult for us to conceive of children as fully responsible for so serious an act, although we are much less reluctant to view adults as fully responsible. In some respects this is a hangover from the days when the dynamic structure of children was considered distinct and qualitatively differ- ent from that of adults. The social conception of murder allows few gradations between the extremes of responsibility and non-responsibility.

Children are regularly bewildered by the outcome of their violence when it ends in the death of another. The child can recognize his murderous impulses, but he cannot comprehend the finality and completeness of the consequences of its expression. Since children regularly aggress against others and hostile acts seldom produce death, the problem of diagnosing anger which might trigger fatal action is an almost impossible one to solve. At the present time, the child is confined to an institution and given therapeutic treatment when it becomes apparent to society that he is endowed with "too much" uncontrolled aggression. This is indeed a crude measure and one that regularly fails to detect the equally frequent cases of "model" children who reveal the intensity of their camouflaged hatred in particularly sadistic overflows of deeply buried rage. A quiet, model child who murders is frightening to us all because he acts as a violent demonstration of the deceptiveness of the façade of good adjustment. If surface appearances are so untrustworthy, we are left with the anxiety of being unable to predict the behavior even of those closest to us and unable to assess whether we have succeeded or failed in the task of child-rearing.

\section{Suicide}

There are a number of theoretical explanations of why an individual comes to attack himself rather than others $(115,297)$. A purely profit-and-loss approach to the consequences of turning aggressive impulses against the self would have to entertain a number of possibilities such as the following:

1. If we can accept the premise that it is possible for a person, while learning to manage his aggressive impulses, to introject or 
incorporate some symbolic representation of the punishing parent into his psychic economy, then we can understand that one "gain" from self-punitive action would be to punish not the self but the "other" inside him. In this way a symbolic revenge might be taking place. This is not a theory that is easily judged in terms of its face validity, since it relies heavily on unconscious events -events not available for conscious inspection (132).

2. Self-punishment also serves to ward off the punishment that one might anticipate would come from others (45). An aggressive act which would normally bring retaliation from the injured victim can go without punishment if the offended party feels the aggressor has "suffered enough at his own hand." Being one's own jury and executioner has the additional advantage of increasing the chance that punishment will not be excessive. Retaliation by those aggressed against may, in the heat of rage, exact a greater toll than self-punishment.

3. Self-punishment can be an expression of self-mastery at the same time that it assuages guilt. This is especially apparent in young children who will slap their own wrists for misbehavior but launch a vigorous protest if the parent attempts to inflict punishment. This tends to be a special case of conflict between the need for punishment and the continued effort to exert control over others in the environment. It has all the peculiar characteristics of the man who voluntarily walks the plank when his captors really offer him no alternative. It is an expression of independence even in the face of death.

4. An important element in self-punishment may be a simple matter of the most economical resolution of psychological forces. Overwhelmed by intense feelings of rage, finding that the overt expression of this rage toward objects outside the self is not feasible, and being unable to choke down the hostile feelings, the angry person may have no recourse other than attacking himself or assaulting some neutral object. The violent need for expression, coupled with the elimination of all but one object of attack, may produce self-punishment as the only alternative.

5. Self-punishment may serve the purpose for which it was originally intended. Our society strives to build into its members an internal set of controls and punishments to take the place of parents, police, and other enforcers. Ideally, we wish to have one policeman, jury, and judge inside the psychic structure of each of our citizens so that internal regulation will take the place of external coercion. Self-punishment, then, may merely be an expression of a lesson too well learned.

6. One of the most fascinating theories about the possible meaning of self-punishment has been described by Theodore Reik (335) in his book on Masochism in Modern Man and in the work of Alexander (4). In this theory, punishment can serve as a commodity for barter with the conscience, a means of purchasing the right to indulge in the forbidden act once again (191). A self-imposed penance can even the score, psychologically, and allow the same impulse free rein when opportunity next presents itself. Thus it is possible for an employer, who secretly believes that no one knows how to work hard any more, to criticize his workers and push them to greater effort, yet avoid guilt for his actions through punishing himself by working harder than anyone else. This kind of hostility can be expressed freely day after day because it is bought and paid for in the coinage of selfsuffering.

Each of these possibilities has a natural logic about it, but the motivation for selfpunishment may not be adequate to ac- 
count for an act as extreme as suicide.

The social, religious, and legal reactions to suicide have varied in time from acceptance as a natural event, to condemnation by the church, to definition of it as a criminal act, and, finally, to its description as a product of mental derangement (112). The use of suicide as a legal method of punishment is known to every schoolboy familiar with the execution of Socrates, and for some centuries the suicide of martyrdom was glorified for its dedication to a high order of principle. Legal sanctions for suicide were eventually abandoned, but custom was more resistant to change, and social approval of suicide as a means of restoring personal honor still exists. The evolution of the conception that taking one's own life was a criminal act provided, at one time, for legal suicide if it was for good and sufficient reason, such as sickness, grief, or extreme weariness of life. In time, suicide became a crime-a puzzling crime in which the aggressor and the object of aggression were united in one person. It was a crime of murder in some systems of law and only a felony for others. In those instances where suicide and murder were equated, a variety of punishments was executed against the self-murderer; his property might be confiscated, he might be denied an honorable burial, or he might be hanged for his crime. Through the ages, actual or symbolic attempts have been made to separate the murderer from his victim by dismembering the body of the suicide and by burying the offending hand in one place and the body in another. The complexity of this problem furnished the wherewithal for a great philosophical debate lasting for centuries. Today, only a few vestiges remain of the primitive attempts to achieve social punishment for the murderer of the self. Today's sanctions against suicide are primarily moral, and an attempt to kill one's self can be dealt with by the authorities only if there is a fair presumption of mental illness.

The modern dynamic view of suicide leans heavily on the assumption that behavior is fully determined and that man acts as he must act. The potential suicide must be cured and better fitted to deal with his frustrations; punishment not only would be inhumane but would be logically absurd. To be sure, a rational society must protect its members against becoming the innocent victims of the potential suicide's rush to leave this life, and in this respect the law ought to be preventive rather than punitive. We are not yet able to fit the act of suicide into logic-tight legal and moral compartments. What ought to be society's attitude toward persons who aid and abet or even instigate suicide in another? Are they legally guilty of murder if they allow another to take his own life?

Before considering the determinants and correlates of the act of suicide, mention must be made of what Menninger (268) has described as two partial forms of selfdestruction-chronic suicide and focal suicide. In contrast to our usual conception of suicide as a sudden and acute manifestation of aggression directed toward the self, in chronic suicide Menninger sees a variety of forms of self-destruction in which the individual kills himself little by little over a long period of time. Asceticism as a way of life would fit this description. The ascetic lives a slow death in which he prolongs the suicidal act by a series of ingenious deprivations through which he teeters on the brink but never quite goes over. The martyr does not prolong the act; rather, he arranges for his demise to happen suddenly, at the hands of others, and for a noble end. As Nietzsche pointed out, Christianity permits only these two forms of suicide-asceticism and martyrdom-and ascribes to both of them man's highest aspirations. Chronic suicide can take 
a number of other forms. The hypochondriac and the neurotic invalid achieve the equivalent of a living suicide by capitalizing on fantasied or real, but insignificant, illnesses to remain anxiously alive while suffering a kind of personal and prolonged martyrdom. In much the same fashion, the self-poisoning of the chronic alcoholic and the consequent disruption of his life constitute a slow-motion suicide which, unfortunately, involves all those in intimate contact with him. It combines self-destruction with a subtle aggression against those who accept his self-recriminations at face value and extend a helping hand. At the height of the emotional involvement of others in reforming him, he is driven, inevitably, to turn them against him by repeating the selfattack of prolonged intoxication. Subtler still is Menninger's account of a number of kinds of antisocial behavior which cloak the selfdestructive impulse in the guise of hostility directed toward the rules of society. That some humans commit crimes and then, through some unconscious immoderate act of misjudgment, manage always to get caught and to suffer the misery of imprisonment and deprivation can be understood only as a form of complex but chronic suicide.

A further form is that described as focal suicide in which the dynamics of self-destruction operate as in chronic suicide but are concentrated on a limited part of the body. Focal suicide would appear in such forms as self-mutilation $(73,77,105,118$, 171), the compulsive demand for and submission to surgical operations to receive mutilations at the hands of others, and accident-proneness, in which the suffering is secured at the same time that the intent to injure the self is denied.

Chronic and focal suicides serve as an excellent introduction to the act of pure suicide because, except for the literal loss of life, they meet all the criteria of selfdestruction. Even less obvious forms of attack on the self might be listed as forms of limited suicide; some theorists take the position that nail-biting is an early form of selfdamage $(46,76,248,393)$. The inclusion of acts that produce so little destruction serves primarily to demonstrate the fine gradations of self-attack that exist.

The methods that suicidal persons use to dispose of themselves are a catalogue of the horrors of human invention. Cases are reported in which the victims exploded dynamite in their mouths, threw themselves against revolving saws, thrust red-hot pokers down their throats, hugged red-hot stoves, threw themselves into volcanoes, swallowed poisonous spiders, forced teams of horses to destroy them, and crucified themselves. The dogged determination with which some persons calmly pursue death is equally difficult to describe without suppressing a shudder of revulsion. Failing to achieve the desired end by one means, the zealous suicide may in rapid succession try a series of more violent methods until the cumulative effect finally kills him. The drama of suicide -it occurs nearly sixty times each day in the United States-is a signal indication of the extremes to which human beings can turn in their quest for solutions to unbearable conflict and frustration.

The method chosen for suicide bears a meaningful relation to the victim's perception of the kinds of frustration he is trying to rectify by his death. In those cases in which self-destruction is an impulsive act in response to a towering rage, an individual may seize whatever means are close at hand, and his method may have no important meaning for him. For persons who kill themselves in response to hallucinations or delusions, the content of the delusion may determine the manner in which he exits from this life. Self-crucifixion, for example, would 
be congruent with messianic delusions in which the mentally disturbed person has lost contact with reality and is living out a fantasy of his identification with Christ. $\mathrm{He}$ may be, in his own view, Christ on the cross and not a disturbed persun killing himself in an unusual manner. E. Y. Williams (404) points out that in suicides which are not impulsive or in response to delusional and hallucinatory experiences there is a relationship between the method employed and whether the individual feels that he has been wronged by a cruel and hostile world or by his own personal inadequacies or evil impulses. If the unassuageable psychic pain issues from guilt and notions of failure to achieve one's own goals or to live up to one's own ideals, then the suicidal act tends to take place quietly and unobtrusively. If suicide is a last violent protest against the deprivation and mistreatment he feels he has suffered at the hands of others, then his self-destruction is liable to be a public dramatizing of his outrage. If he leaves a parting message for the world, it is likely to contain a specification of the grievances he has endured and may point the finger of responsibility at thase who forced him to his death. In analyzing cases according to whether the suicide was prompted by frustrations imposed by the self or imposed by others, Willians indicated that the methods used correspond to the person's last feelings. Among his cases, those who jumped, poisoned themselves, or asphyxiated themselves by hanging or drowning saw others as the source of their difficulties; taking gas or slashing the wrists or throat occurred among persons who felt that their problems came from within themselves. Reik (335) has made the interesting observation that women prefer poisoning or drowning as a means of suicide but that men regularly choose the gun or the rope. Even the means of self-inflicted death retain the character- istic difference between the sexes, with more men responding to external dangers in life while women perceive their problems as internal.

By far more suicides are attempted than succeed, and the consideration of attempts which fail makes up a topic in itself. Since suicide can amount to a flirtation with death with no plan for its consummation and may be designed for the sole purpose of evoking sympathy, some researchers (352) have found it expedient to construct an efficiency index to assess the intention of those who attempt, but fail, to kill themselves. In terms of efficiency, hanging and guns seem to be the best, while cutting or poisoning are the most likely to fail. The efficiency of selfextermination increases with age, males are more able than females in this respect, and Negroes more often succeed, when they try, than do whites. Married persons tend to be much less efficient at killing themselves than are persons who are single, widowed, or divorced. An index of efficiency is actually a measure of the seriousness with which the task of suicide is approached. If a suicidal attempt is just a gesture of hopelessness and designed for public consumption, it tends to be done in a halfhearted manner after being sure that others will interfere with the attempt (119). I can recall a case in which a woman attempted suicide only after calling her husband at work and making her intentions known to him. Her attempt was thwarted because she delayed it long enough for her husband to race home to her-she even allowed a little extra time because of the hazardous condition of the roads that day. When an attempt at suicide goes beyond histrionics and threats, the suicidally inclined person is usually hospitalized for treatment and observation (111). In a follow-up of 200 consecutive cases of attempted suicide one year after the attempt, Batchelor and Napier (29) re- 
vealed that 106 such cases were retained one week or less in the hospital at the time of the attempt. Another 69 were kept for one or two weeks before being released. Considering the seriousness of making an attempt on one's life, this brief stay in protective custody would seem insufficient as a therapeutic measure. Yet, of the $200 \mathrm{pa}$ tients, only 3 or 4 had committed suicide a year later, and 7 others had made a second attempt but failed again to destroy themselves. On the basis of this evidence, discharging patients in such a short time seems justified. As an interesting sidelight, the social reverberations which follow the attempt at suicide are much less extensive than one would normally expect. Far from being shunned by those close to him, an attempted suicide may increase the concern that others have about his needs and his problems, and their relationships with him become more considerate and helpful. It may be that the altered perception of others toward him is the therapeutic force which binds him more firmly to life.

Suicide is correlated with a great many characteristics which indicate the status that the individual maintains in the society (395). In general, suicide is more common among privileged groups in America and, while it occurs in substantial numbers at all levels of the socioeconomic scale, self-destruction is an affliction of the well-to-do $(9,93)$. Since humans tend to live up to and a little beyond their incomes, a similar correlation exists between suicide rates and various residential areas of cities $(68,351)$. In skid rows and rooming-house sections of citiesareas characterized by extensive social disorganization and a breakdown of normal ties to home and family-the suicide rates are high in absolute numbers. The distinction between relative and absolute numbers must be kept in mind because the apex of a pyramid of economic well-being does not contain as many persons as its lower socioeconomic base. Since such an area tends to be a low-rent district and a bohemia of drifters and homeless men, it will become a haven for many who have been cut adrift from a close relation with others, and the movement into these areas will bring about an abnormal concentration of potential murders as well as potential suicides. The concept of social disorganization is quite descriptive of what exists within these tracts of cities, but it is more descriptive than explanatory because exceptions do exist and there remain a number of puzzling paradoxes which the concept of social disorganization cannot resolve.

The hypothesis that suicide is a response of persons who are deprived of intimate and meaningful relationships with their fellow men is supported by a statistical analysis of suicide rates in rural and urban areas. Residents of cities have higher suicide rates than do rural residents, and this pattern is highly regular, showing a steady increase in frequency of suicide as the density of population increases. The usual attempt to account for this phenomenon is by contrasting the stability and continuity of family life found in small towns with the lonely crowds and anonymity of the big city. Another test of the strength of the relations one has with others is marital status. The suicide rate of married persons is lower than that for single, widowed, or divorced persons. Of all these categories, the rate is highest among divorced persons. The implication is that, for better or for worse, the married person has at least one more personal relationship than does the single person. A widowed person has lost a relationship to a spouse but often has the compensation of satisfactory memories and the stimulation of sons and daughters to fll the gap. For the divorced person, a once meaningful relationship must have been disrupted by dissension and strife, leav- 
ing the ashes of a mistaken emotional investment. Suicide will be increasingly likely when the bonds of relations with others are not present.

Age, sex, and racial origin are personal characteristics that the individual does not choose as he might a wife or a neighborhood in a rural or urban setting. The suicide rate by age (292), for example, rises sharply from a low of 4.5 per 100,000 for the age group from fifteen to twenty-four, to a high of 27.0 per 100,000 for those aged fifty-five to sixty-four. Suicide rates for all persons aged sixty-five and over are approximately three times as high as the rates for all persons under forty-five years of age. For divorced persons, the frequency of suicide does not level off with age as it does for persons who are single, married, or widowed. The rate climbs from early in life and continues to mount through and beyond seventy-five years of age. Divorce, coupled with the years of separation, increases the likelihood of self-destruction. For those who attempt suicide in old age $(28,300)$ it is usually a no-nonsense attempt. They persist in this effort, frequently using the same method as that tried earlier, and nearly 12 per cent of them will succeed within two years after the original attempt.

Sex and race bear significant correlations to suicide rates. Males are more likely than females to take their own lives, and they are considerably more dedicated to the task when they undertake it. Women attempt suicide more often than men, and they fail at it much more frequently. Suicide among white persons is distinctly more regular than for non-white persons. In 1940, for example, the rate for whites, per 100,000 , was 15.5 , while it was 4.6 per 100,000 for members of all other races $(227,313)$. This relationship has been a predictable one for a number of decades.

Finally, if each of these characteristics is looked upon as an indicator of status position in the society, it is clear that the higher the status, the more likely an individual is to turn his aggression against himself. This would be particularly true in times of economic distress, for the decline in income would provide a sharp frustration and would severely affect the status of persons high on the socioeconomic scale, since they would suffer the greatest relative loss of income (180). This relationship holds for incomethe most obvious indicator of status-and if we rank the characteristics of age, sex, and race in terms of the position the society accords to them, we find that suicide is an event that correlates closely with status. Persons of high status in our society would be well-to-do, young or middle-aged, white, and male; lower status is the lot of poor persons, Negroes, women, and older persons. The facts of rates of suicide are in accord with the theory that higher-status persons suffer the greatest loss in times of economic frustration and are more prone to take their own lives as a means of meeting a crisis.

It should be clear that suicide, murder, or any other human behavior will have correlates with at least a few of the characteristics that make up the complexity of human beings. Viewing any human act as the outcome of a series of internal and external forces that affect the individual, it becomes easier to understand the difficulty of predicting the particular act of a unique human being at any one point in time. Each of these factors is not equal to the next in importance, and prediction gets increasingly more complicated because the relevance of each factor may fluctuate in time. When social scientists are able to measure all the essential forces and weigh their combined effect on behavior, they will be able to predict suicidal hehavior in advance and 
will gain a clearer comprehension of the means of regulating its causes.

Attempts to predict suicide before the act occurs or to understand it in retrospect are difficult theoretical problems. In either instance all the forces in the individual's life are directed at obscuring the motivation of the act being investigated. In addition, the objective and projective tests which exist at the present time are unable to assess the multiplicity of forces which are reflected symbolically in the suicidal act (182-84, $323,344,372)$. There are complicated methodological issues which have yet to be resolved by experimentation, and they are problems that are not easily solved. At one time, some years ago, a theorist was under the impression that he had solved the riddle of suicide. He believed that persons who committed suicide were "quitter personalities" and used the fact of suicide as evidence for the validity of his theory. In theories less circular than this, the accuracy of prediction is far from satisfactory, and the complexity of conception is much greater.

\section{THEORIES OF SUICIDE}

A casual examination of the literature on suicide would suggest that we are more confused about the topic now than were the writers of fifty years ago. Theorists were convinced then that suicide was easily explained in terms of worry over one's health, or else it was an act of mental confusion and derangement. The reasons for suicide were accepted at their face value and seemed apparent to all who studied it. Probably the important change that has occurred in cur perception of this most extreme form of aggression against the self has been a consequence of a closer and more sophisticated look at the act of suicide and the use of a much more complicated model of the dynamics of human behavior. One of the most puzzling aspects of suicide is to under- stand the ease with which some take their own lives, while others endure the most desperate and miserable circumstances in order to cling to it. If the ego of the individual has survival as its main purpose and if, as Silverberg (371) believes, this drive is a powerful force rooted deeply in the lives of all of us, self-destruction poses a paradox for the theorist.

Theories of the origin of the motivation for suicide have been quite varied over the years. The earliest systematic explanations tended to emphasize the pressures issuing from the kind of society in which individuals lived. The sociologic theories proposed at the turn of the century described social forces but neglected the individual in whom these forces had their effect. Freud's elaboration of personal dynamics shifted the emphasis away from a study of society and placed it squarely on a consideration of the internal psychic life of the individual. In the years to follow, it became apparent that sociologic and psychoanalytic theories were not mutually exclusive but rather complementary conceptions of the stimuli to which man responds, and important aspects of both theories have come to be merged into a more comprehensive system. Even the combination of these points of view leaves a number of factual loose ends, and the original sociologic and psychoanalytic observations have undergone considerable modification at the hands of theorists in the last fifty years. Today few, if any, viewpoints about suicide are presented without taking into account the contributions of both sociology and psychoanalysis, for a theory which ignores these elements usually restricts itself to explaining a limited part of the phenomenon of suicide.

Durkheim (95) described three types of suicide: egoistic, altruistic, and anomic. Egoistic suicide is a response to the lack of integration of an individual with other mem- 
bers of his society and to the fact that he does not have a place in the group and its activities. Altruistic suicide is a response stemming from a quite different social condition than that seen in egoistic suicide. An individual can be so closely integrated into society that he does not have the freedom for sufficient individuation and sacrifices himself in the service of the society for the common good. Anomic suicide may occur when the individual's integration in the culture is disturbed by sudden social changes, such as a depression, which detach him from the security of his status. It is clear that Durkheim has suggested that suicide will vary according to how closely related an individual is to others in the society. Those who are isolated from others should be high risks, and those securely integrated should be low risks. Close relationships with others will act as an external restraint against suicide as a response to frustration. It is evident that this theory would lead its advocates to search out the nature of social and cultural changes such as wars, depressions, or mass migrations. If the theoretical concern is with the individual and in predicting his response to frustration, then the precise meaning of such terms as "integration," "social disorganization," and "relational system" must be furnished.

Freud's (132) hypotheses about the dynamics of depression and melancholy provided for the turning of aggression against the self as a response to the relationship with the parents, and this notion became the basic framework for the psychoanalytic theory of suicide. In broad outline, the aggressive impulse or death instinct (Thanatos) assumes a delicate balance with the constructive impulse or life-instinct (Eros) in every relationship that one human has with another or with some object in the outside world. This conception of the human psychic life defines all human relationships as ambivalent, as a final resolution of feelings of love and hate. Even the perception of the self bears this characteristic of mixed feelings and ambivalence, for at times we dislike or are critical of certain aspects of our own personality or behavior. A number of theorists $(179,203,268,298,303,317$, 329) have started with these Freudian premises and elaborated and modified them. Menninger (268) has taken the notions of life and death instincts and made them the basis of a classic and quite detailed account of suicide and murder as the outcome of the battle between these instincts or drives. Menninger sees suicide as composed of a series of elements of the aggressive drive. First, suicide contains the wish to kill-the destructive impulse which is a part of every human being. He points out that the man who kills himself kills something, and to that extent must have been dominated by the wish to kill. Any account of suicide must first come to grips with the primitive wish to kill signified by the act. Second, the suicide has a wish to be killed-not just a wish to die or to be free of his frustrations and problems but a wish to be killed. Being killed is an extreme form of aggression. Many persons with suicidal intentions seek out ways of being killed in which they can remain passive. Catching a destructive disease and standing in front of traffic or a train are ways in which others will kill him, with his participation being kept at a minimum. To understand this element of suicide, an explanation is necessary of how a person learns to orient his life to pain, defeat, and even death at the hands of others. Theorists must explain how masochism comes about and how the wish to suffer can become an integral part of living. Finally, the wish to die must be reckoned with. A person's pleas to the doctor to save his life (when a few minutes before he had tried 
to kill himself) indicate that the wish to kill and the wish to die do not always go hand in hand. Many persons convinced of the desirability of dying cannot bring themselves to kill themselves or to be killed by others. To Menninger, life and death represent a fusion of these constructive and destructive impulses.

Less comprehensive comments about suicide frequently come from observations of a limited number of cases and amount to a description of the dynamics of particular suicidal events. Suicide has been ascribed, in part, to fluctuations in the weather (276) and to reactions to the rate of business activity (194). Some theorists point out the frequency with which there is a dead or absent parent in the fantasies of suicidal persons and suggest that the suicide may see death as a restitution for the failures of his life and the chance to be joined with the dead loved one. Death, in this instance, constitutes a kind of rebirth and the promise of a more peaceful existence. In twenty-five consecutive cases studied by Palmer (303), he found that 84 per cent suffered from the death or absence of a parent or sibling and that 68 per cent had lost a parent before fourteen years of age. A congruent set of findings was reported by other investigators (203, 380, 388). Moss and Hamilton (281) reported that the most outstanding and consistent feature in the background of the cases they studied was what they called the "death trend," which appeared in 95 per cent of the attempted suicides.

In 75 per cent of these cases, the deaths of close relatives had taken place before the patient had completed adolescence. Suicide is rarely found in the families of control groups in which no suicide has occurred. The fantasy of rejoining a lost loved one is certainly more possible for persons who have experienced the death of a close relative. For some patients, loss of a loved one, such as a wife, amounts to losing a relationship that provided a much needed outlet for aggressive impulses. If the patient fails in his search for a new relationship that will offer him a similar target, he may take his own life as the only remaining object for his aggressive impulses. Some people can feel comfortable only when beating a hardy wife (178). Goitein (143) similarly describes suicidal acts as a compensation for homicidal impulses directed against members of the immediate family.

\section{CHILDREN WHO KILL THEMSELVES}

As shocking as it is to learn of children who murder others, it is even more disturbing to read of cases where a child resorts to self-destruction as a solution to his problems. To an adult, a child's problems never seem to warrant so drastic an action. In young children there can never be a suicide which does not indict the adults closest to him; a disturbance of the parent-child relationship is always implicit (237). The parent's task is both to prepare the child to manage and overcome frustrations and to protect him from being overwhelmed by troubles during crucial times in his life. When conflicts and frustrations seem insurmountable, most children are secure in the knowledge that their parents will provide a refuge from trouble. A child who feels he has been abandoned by his parents or that they have turned against him may decide, when he assesses the enormity of the fix he is in, that he has no choice but to die. For many years the child is actually a unit composed of part child and part parent; an organism with the parental part removed may be ill-equipped to deal with the sea of troubles which engulfs it.

Many suicides are childish miscalculations or accidents that got out of hand. Intending consciously or unconsciously to punish himself, the child may become the victim 
of his own ignorance or poor judgment. It has long been apparent that some children have an incredible history of seriously painful, near-fatal accidents. These occurrences can reach such proportions that the child regularly endangers his life and seems to be engaged in a kind of long-term, slow-motion suicide attempt. Children who are "accident-prone" in this way differ in important respects from children who are accidentfree. In Krall's (224) study of children and accidents, he attempted to test the hypothesis that, as a result of being frustrated by parents using harsh or authoritarian childrearing methods, accident-prone children have a distinguishably greater aggressive drive than accident-free children. He felt that, to produce self-injury, the child must also possess a considerable anxiety about expressing his aggressive urges in hostile actions directed toward others around him. A high level of frustration coupled with strong prohibitions against its expression, according to Krall, ought to produce an increase in aggressive acts directed toward the self in the form of accidents in which the child suffers. Examining the structured doll play of children between the ages of five and eight, he concluded that accident-repeating children displayed more aggression, displayed it more quickly, and with less inhibition than accident-free children. This was aggression released in play with dolls and not in real life, but the findings seemed to confirm the hypothesis that accidentprone children had greater quantities of aggression to manage in their daily existence.

It is not always possible to make a sure distinction between suicide and fatal accidents in children. Undoubtedly, some suicides are reported as accidents. Mason (254), for example, reported on a number of diabetic children who used their illness and its physical reaction to retaliate against their environment when it did not grant their wishes. Such children would frequently be found in a coma which would frighten the adults into bending to the children's desires. This coma would incidentally threaten the child's own life. This use of injury to the self as a means of manipulating the environment demonstrates the thin line that exists between suicide and accident.

Where records are available, they indicate that suicide in children is quite rare (68). In Despert's (86) analysis of data compiled by the National Office of Vital Statistics, she found no death by suicide for children under five during the year 1940 . Between the ages of five and fourteen there were 49 suicides recorded, and this figure rose to 1,462 for the fifteen to twenty-four age group. The rate of suicide varies from year to year and differs from country to country, but the variations are quite small, and the pattern of a regular increase in rate with the age of the child has no important exception. As Zilboorg (413) pointed out, psychiatric studies of suicide in children are far from abundant in the literature, and most reports are clinical observations made on a small sample of children who are selfassaultive or preoccupied with thoughts of suicide. In general, suicide in children is two to three times as common in boys as it is in girls and is more prevalent for white than for Negro children.

Theoretical explanations of the reasons for suicide among children range from detailed attempts to account for all the pressures and painful experiences that a particular child has endured, to broader generalizations referring to the nature of the parent-child relationship. The usual case presentation is full to overflowing with so many traumatic incidents, long-standing unresolved problems, and badly managed interpersonal relations that the reader is tempted only to wonder that the suicide attempt did not occur earlier in the child's 
life. Most case histories are gathered after the child is being given therapy, and the importance of a stable relationship with an adult-any reasonable adult-is reflected in the fact that children never commit suicide while in therapy. The thoroughly deprived and rejecting background of such children gives credence to the observation made by Reichart and Tillman (334) that suicide can be a last desperate defense against an impending psychotic break with reality.

On the basis of individual studies of suicidal children $(38,123,215)$, researchers have arrived at a series of dynamic formulations. Most children attempt to kill themselves as an escape from an unbearable situation-one that they have continuously failed to resolve in a healthy manner. Deprivation of love, or at least a child's perception that not enough love is forthcoming to fill his needs, makes every part of his daily life unbearable. The crushing conflict for the child is occasioned in part by his lack of social skill and the limited ability he has to manipulate others. He needs love desperately, he is denied it for reasons he is unable to comprehend, he hates the person who denies love to him, but he cannot risk launching the attack that he feels they deserve because the only result of a display of anger is to incur an even greater wrath and further deprivation from the object of his affections. The suicidal act combines a bid for sympathy with self-injury to assuage the guilt that the child experiences for the hostile feelings he has harbored toward the parent. It is a conflict from which there is no escape but a costly one. For some children, there is submission and a borderline existence, living from hand-to-mouth emotionally; in some instances only a protective withdrawal to an institution salvages at least the child's physical life. For others, a revolt takes place, and aggression is directed against the environment in antisocial and delinquent behavior. In either circumstance the time is past for the one completely effective therapeutic measure-prevention (35).

\section{$\mathrm{X}$. The Measurement of Aggression}

One of the most fundamental problems in the study of aggression is that of describing its dimensions in terms of quantity as well as quality. Without measures of quantity, the attack on aggression will be limited to descriptive accounts and theoretical discussions and will defy any coherent systematization. The difficulties of such measurement are legion, and they can be listed to point up the complexity of the problem. A detailed account of the relationship of overt and fantasy aggression will serve to indicate the theoretical complications and ways of approaching the task.

There are several elements which make it difficult to measure aggressiveness in an individual $(218,219)$. If aggressiveness is assessed from the point of view of the victim, it has quite a different appearance than when its measurement is taken from the report given by the aggressor. While the aggressor minimizes the act, the victim exaggerates it in terms of the combination of physical hurt or deprivation and the injury to his feelings. Since aggression can be expressed in quite devious ways and has a multitude of disguises, efforts to measure it frequently face the task of trying to separate the hostility from its camouflage. Aggressiveness can differ along a continuum of intensity, and it is almost impossible to attain equal distances between points on the scale from most to least aggressiveness. The existence of a conscious and unconscious part of human mental apparatus further complicates the issue of measurement. Does the measurer ignore one while assessing the other, does he study the relation of conscious to unconscious hostility, or must he consider that trustworthy measures of both 
must be made to represent the totality of aggression in the individual? No two sets of environmental pressures are identical at any instant for any individual, and, since aggression is in response to the setting which stimulates it, measures must be made in a number of settings. The experimenter must control the important parts of the environment or at least be prepared to account for its effect in instigating aggressive responses. Aggression, too, is a function of the particular life-history of the individual and his past experiences with meeting and managing his impulses. In this sense, no two human beings are ever equated with each other except on a very approximate scale. The assumed similarity of Freshman college students is undoubtedly a conventional myth with respect to aggression. Man's fantasy life allows him the luxury of a quite complex means of experiencing and expressing aggression and adds another dimension to the accounting for aggression. A tremendous anger welling up in an individual might never reach the stage of overt expression and would thus exist but never be apparent to the observer. In addition, even when the form, type, and level of aggression to be measured are decided upon, allowance must be made for human error in observation and for the fact that the tests that have been developed to quantify hostility do not always measure the same thing $(151,154)$. In many ways, the methods that have been developed resemble the actions of the blind men, each describing a different part of the elephant's anatomy. Each is correct in the conclusions he reaches based on the evidence available to him, but all lack the perspective to make the final correct assessment.

The complexity of the problem of measuring aggression is both alarming and depressing to the social scientist because it makes clear how primitive is the state of the study of aggression. The search continues for a simple, reliable, and valid measure of hostility or aggressiveness, but, as with any simple measure of a complex thing, researchers will probably never attain their goal. When attempts are made to assess the status of an individual's hostilities in terms of the prediction of a single aggressive event, such as suicide, the researcher frequently has to depend on all the information he can gain from a variety of sources before he can make an educated guess about the probability that an individual will inflict injury on himself (401). A number of paper-and-pencil tests have been developed $(60,61,370)$ in which the subject agrees or disagrees with descriptions of aggressive behavior as they apply to him. Projective tests $(79,199,239,262,309$, 377) are also used as a method of tapping and quantifying indexes of aggression. All measures of this sort run into the problem of differentiating between the attitudinal and the motor aspects of aggression. Measures of aggressive attitudes can be made quite separately from observations of motor expression of aggression, but the details of the relationship between attitudes and action are still quite obscure.

Verbal aggressiveness may or may not lead to physical combat, and, for some groups of people, chronic verbal aggression is institutionalized and regulated by informal rules of procedure designed to limit the aggressiveness to a verbal form. Such an institution exists in some groups of $\mathrm{Ne}$ gro and working-class whites and is called "playing the dozens" $(41,148)$. The procedure is fairly standard. A group may be gathered in a poolroom or on a street corner, and as an aggressive way of passing the time they begin a humorous needling of one of the members. This usually focuses on his personal characteristics or the characteristics of the members of his immediate 
family ("Your mother wears Army shoes"). The victim can retaliate in kind ("Your mother rides shotgun on a garbage truck"), and in the course of the exchange the insults become more colorful, personal, and provoking. If the target loses control and erupts in anger, he may be trounced by the others as his penalty for losing the game. Frequently, the insulting exchange continues until boredom sets in and it is discontinued by a silent, but mutual, consent. A similar, but less personal, verbal aggression appears in a game called "Turn Green" which occurs at mealtimes among delinquent and antisocial boys. In turn, each participant graphically describes some revolting event in an effort to nauseate the others at the table. This game continues until one of the group can no longer contain himself, and the over-all effect is usually a decreased appetite even for the most hardened participant.

\section{OVERT AND FANTASY AGGRESSION}

The ideal form of control over aggressive impulses is one in which each individual regulates his own behavior on the basis of a reasoned decision regarding socially acceptable forms of aggressive expression. Thinking, imaginative, and fantasy processes are essential to such a state of affairs, and the relationship between fantasy and overt expression of aggression has been studied intensively in the last few years. Since, for humans, fantasy occupies an intermediate position in time between an aggressive impulse and its expression, it presents the possibility of introducing a delay between the urge and its expression. The ancient admonition to "count to ten" is a crude attempt to achieve such a delay, but delay in itself accomplishes nothing unless it allows the consequences of the aggressive act to become more apparent and to deter the translation of the impulse into action.
Fantasy exists as a link in a chain of events which begins with muscle tension and excitation of the nerves and culminates in behavior. Fantasy can be described as a kind of psychological dispatcher which interprets, categorizes, and responds to stimulation arising simultaneously from inside the body and from the outside world. The existence of such a psychological "middle man" gives the human organism a unique discretion over the form, kind, quality, and timing of his reaction to the stimuli which constantly impinge on his consciousness. Where simpler forms of life are "stimulusbound" and compelled to respond in an almost automatic fashion to certain classes of stimuli, man has the advantage of delay, in which he can assess the situation and then choose the response that is most appropriate to it. As a buffer mechanism between an impulse and its expression, fantasy makes human emotions unusually malleable and allows an almost unlimited transformation and control of their ultimate expression.

In the form of play, children can engage in "reality testing" in which they act out fantasies in order to master the fearful elements they may contain. Thus, playing doctor or dentist is a safe way for the child to relive upsetting experiences and learn to control his reactions to them. In this sense, play has been called the work of childhood, and it is in this medium that some of the most insightful explorations of children have been done. Using dolls and toys as a miniature world to which the child can react as his emotions dictate, experimental studies of doll play have become an important source of information about the reactions of children to the frustrations and conflicts they must cope with in the process of learning to meet life's demands $(10,27,200,315)$. The principal drawback to the use of structured doll play as a means of measuring the 
aggressiveness of children is that the hostility expressed in play with dolls may be an artifact of the experimental situations (314). When a child discovers that mangling a doll evokes no response from the smilingly neutral observer, he may interpret the lack of response as a sanction and an encouragement to him to display more of this behavior. Children regularly become more aggressive in successive doll-play sessions, and this phenomenon may have been produced by the setting and cannot be disentangled from the child's normal response.

One familiar and vital function of fantasy is that of a substitute form of behavior when other lines of action are forbidden or unavailable. The overt expression of aggression is so restricted by society that the privacy of fantasy is frequently the only safe haven for violent feelings. For adults, imaginative productions in dramatics, art, or literature may provide the cardinal outlet for the daily accumulation of frustrations and annoyances. The eternal popularity of blood-and-guts fiction is a monument to the fascination of violent fantasy.

The expression of aggression occasions anxiety for most persons, and if the experimenter wishes to measure the expression of these impulses, he must disguise what he is after on the test or else permit and encourage the subject to express the forbidden impulses. In either case the subject is sensitive to the social desirability of his responses, and he will censor them if it is to his advantage. Thus, when subjects were informed that the test they were taking was used for detecting and studying serious emotional disturbances, it had the effect of making them avoid overt aggressive responses (181). Even the standard instructions to most projective tests are not free of signs that would induce avoidance of threatening material on the part of the subject (322). In most clinical settings the subject is quite aware that the tester is looking for signs of the internal workings of the individual, and the general tendency is to withhold responses that are less than acceptable socially. Some tests are more apparent in this respect than others and have a built-in invitation to avoidance. As the subject more closely approaches a situation in which he is stimulated to express aggression or tell a hostile story in the testing session, he is bound to experience fear of doing so and to express conflict in his response. In any projective study of the aggressive responses, an account of this conflict over expression must be calculated as a function of the testing situation and not a normal caution over expression. Studies which try to separate hostility into its components, such as tendencies to avoid expression, the direction of hostility, and anxiety associated with hostility, produce purer and more reliable measures $(139,140,290,321)$.

A chronic problem in studies attempting to relate fantasy aggression to the probability of the overt expression of aggression is that all forms of hostile fantasy are lumped together without discrimination. The subject's imaginative productions are given a total score indicating how much hostility they portray and whether this "hostility" is social or personal, direct or indirect, or abstract or concrete. Then the experimenter attempts to predict the appearance of aggressive behavior without regard for the fact that an aggressive act is a function of the provoking agent and the context of the situation in which it occurs. It is for this reason that the relationship between fantasy and actual forms of aggressiveness has remained obscure and has been difficult to predict. Ideally, such predictions should be made in terms of an exact statement of the degree of hostility, how it will be expressed, toward whom it will be directed, and under 
what circumstances it will make its appearance.

Kagan (213) has done an experiment that attempts to surmount these obstacles to prediction. He constructed pictures that he felt would evoke fantasy focused specifically on the physical aggression of fighting rather than a variety of other forms of aggressiveness, such as suicide, property destruction, stealing, or verbal exchanges. When he compared the frequency of stories about fighting, told in response to these pictures, with actual fighting in social situations, he discovered that they were significantly and positively related to each other.

Another attempt to account for the combinations of variables that usually influence the relation between a person's fantasy and his overt behavior is that of Hokanson and Gordon (187). These experimenters grouped male college students according to whether they were high or low in the amount of hostility they expressed on a test of manifest hostility. Half of each group was then placed in a situation designed to arouse strong hostility, and the other half of each group was placed in a situation defined as low in arousal of hostility. Both overt hostility and fantasy hostility were provided as outlets for the instigation to aggression, and the degree to which each of these was encouraged as a response was varied for each group. The findings from this research effort are less relevant to the problem of the measurement of aggression than the design itself. The tricky task of juggling a number of the important determinants of aggressiveness is clearly called for if anything more than a superficial statement of the relation of fantasy to behavior is to be achieved.

An important determinant of how much of one's fantasy will appear in behavior is the anticipated response that other persons will have to overt hostility. This involves assessing the relationship between the aggressive needs and the dependency needs of the person intent on communicating his anger to others. Thus the form of maternal discipline and the degree to which a child is identified with an aggressive, like-sexed parent appear to be related to the fate of the child's aggressive drives (230, 362). Lesser $(228,229)$ indicated that when there was maternal encouragement of aggression (as reflected in maternal attitudes and practices regarding aggression), a greater degree of correspondence existed between fantasy and overt aggression of children than under conditions of maternal discouragement of aggression.

Although mothers may have individual preferences and tolerances for the aggressiveness of their children, there are also predictable standards which accompany social status in this society. Middle-class and working-class parents feel differently about the dangers inherent in the expression of aggression, and these feelings play a central part in determining whether the child learns to express or inhibit his aggressiveness. In the American middle class, for example, relatively early in the child's life there are strong pressures exerted by the parents for the inhibition of aggressive behavior $(82,402)$. Since so many of the reports in the literature on aggression have used middle-class nursery-school children or middle-class college students as subjects for study, it has been difficult to find a significant relationship between an individual's behavior and fantasy $(316,345)$. In contrast to this general state of affairs, Mussen and Naylor (290) did find a significant positive relationship between ratings of overt aggression and the number of aggressive themes in stories produced by a group of lower-class, delinquent boys. They hypothesized that, since overt aggression is 
subject to less punishment in lower-class than in middle-class families, lower-class subjects should be less anxious over being aggressive. If they are less apt to inhibit aggressive behavior, it is to be expected that there would be a more reliable relationship with the aggression found in their fantasy life. A middle-class child and a lower-class child with equally aggressive fantasy lives might differ considerably in behavior, with the lower-class child's actions matching his fantasy while the middle-class child inhibits expression of his. Only with an accurate assessment of the degree of drive, the nature of the stimulus evoking aggression, and the kinds of anxieties or prohibitions that inhibit its expression, can prediction be fruitful.

The division by social classes as a means of accounting for the differences in expression of aggression is accurate for groups but not for individuals. Members of each class may, as individuals, differ in the personal history of their aggressive drives. Where a middle-class child will be made anxious about the expression of aggression and thus inhibit it, a lower-class child will inhibit expression because of a fear of punishment from others. The result is the same, but the basis of the inhibition is quite different. Social class is a group variable and predicts significantly only for groups of people and then only on a probability basis. It cannot predict for individuals.

The prediction of aggressiveness from fantasy has other dimensions which have been studied. Watson, Pritzker, and Madison (392) tested the hypothesis that, under conditions which would favor the expression of impulses, neurotics would show more aggression than normals. Matching groups of patients who came to the hospital for psychiatric treatment with an equal number of persons who were not in treatment, they tested this hypothesis in a unique way. Each subject was given 60 sets of scrambled words which could be assembled to have either a hostile or a non-hostile meaning. Thus, the set "Shoot, I'll, You, Ask" could be assembled to read "I'll ask you" or "I'll shoot you" depending on which three of the four words were chosen to make up the sentence. The neurotic group did display more hostility than the non-neurotic group, but this measure is subject to considerable conscious awareness of the aggressiveness of one's responses, and it is difficult to estimate how much validity it has as a means of assessing hostility.

A different approach to the problem of measurement was taken by Holzberg, Bursten, and Santiccioli (190). They assumed that the frequency with which persons told aggressive stories in response to pictures was an indication of the amount of aggressive tension they possessed. Those who overreport (tell a great many hostile stories) and those who underreport (tell very few hostile stories) were judged to possess greater tension in the area of aggression than those who responded with an average number of hostile stories. It has been pointed out (264) that there is some logical circularity in the practice of attributing aggressiveness to the lack of response. Such an act is similar to calling the roll by asking all those who are not present to raise their hands. The lack of an aggressive response can be accounted for in a number of ways other than ascribing it to the inhibition of severe aggressive tension. It is possible that such subjects were not emotionally involved in the experiment and were unmoved by the instigation to aggression.

There is little question that a powerful instigation to aggression will have an effect on the amount of hostility that will appear in the fantasy of the frustrated person (116). If you insult one set of subjects in a laboratory setting and do not insult another group, the insulted subjects will reg- 
ularly express more aggression in their fantasies than will the non-insulted subjects. In general, if the opportunity and the excuse are provided for the person to release his aggressive feelings in action, a decrease in the amount of fantasy aggression will follow. The difficult relationship to tease out is that which determines the flow of such aggression into the outside world. Until we can understand how this mechanism operates, we shall not be able to come to grips with the problem of controlling angry outbursts.

\section{Aggression and Pathology}

Aggressive impulses are the source of man's greatest accomplishments as well as his most notable catastrophes. The disintegrative effect of chronic, unrelieved hostility is nowhere more apparent than in the emotional states we know as neurosis and psychosis. Emotional disorders reflect in clear, sharp detail the feelings and reactions that normally are obscured by convention and self-control; in pathology we can take an unhurried view of emotions that rarely erupt in the normal conduct of human affairs. Just as aggression, in its broadest sense, is a vital aspect of our everyday actions, so, too, is it a basic component of disordered forms of behavior. It is not so much that pathology adds new forces to an individual's psychological balance, it is rather that it produces a redistribution of the existing forces, allowing hostility to outweigh all other feelings. In clinical practice the psychologist confronted with a diagnostic problem looks to an assessment of the status of the patient's hostilities as a fundamental step in understanding the whole person. Hatred and rage stripped bare of restraints are such an insistent accompaniment of a wide range of patterns of mental ilness that Thorne (385) has suggested that acute or chronic frustration-tension-ag- gression reactions may be the primary causes of many forms of pathology. Chronic anger reactions for which the person has found no acceptable outlet may radiate and infuse even neutral situations with a hostile meaning and prompt a lashing-out against imagined threats. Such an aggressive way of life would inevitably provoke retaliation from its startled victims, and yet each victim's act of revenge would only serve to confirm our patient's original impression that he lived in a threatening and dangerous world. Grant (156) presented a series of clinical case histories of patients illustrating just such a lifelong predominance of emotional problems rooted firmly in chronic states of rage and resentment.

Whether unmanageable aggressive feelings are at the core of pathological conditions or merely the effects of maladjustment in other spheres of behavior, the intimate connection between emotional disorder and hostility is easily documented (75). Although aggression may take a more extreme form when it is an expression of mental illness, it is still identifiable in terms of the object toward which it is directed. Phillips and Rabinovitch (312), for example, examined over six hundred patients in order to analyze the tendency of the symptoms of abnormality to appear together or to be mutually exclusive. Of thirty-nine symptoms, taken from many different diagnostic categories, they concluded that three major groupings occurred. One cluster of symptoms that regularly appeared together could be labeled "avoidance of others" and included characteristics such as suspiciousness and hallucinations. A second group of symptoms was described as "self-indulgence and turning against others," while a third included a collection of symptoms which fit a category called "self-deprivation and turning against the self." In general, a person whose emotional illness was revealed by 
symptoms such as refusal to eat, headaches, and attempts at suicide would not be likely to launch violent attacks against others. There is aggressive order even in the apparent disorder of derangement.

The first systematic concepts about the role of hostility and aggressiveness in mental illness were suggested by Freud. It was Freud who first indicated that the melancholic or depressed person has fallen ill as a consequence of hostility which he cannot show openly or direct toward the frustrating person. Unable to express his feelings, his depression deepens apace with his mounting hostility, since the only outlet remaining to him is himself. As Oltman and Friedman (299) have noted, the depressive illness is the culmination of a lifelong personality pattern marked by a highly conscientous, meticulous, perfectionistic, and self-deprecatory way of life.

It is possible to rank emotional disturbances according to the openness and directness of aggressiveness which characterize them $(3,405)$. The hebephrenic schizophrenic would top such a list of assaultiveness, the catatonic schizophrenic would come next, followed by the paranoid schizophrenic, then the patient suffering from manic excitement, and, finally, the ubiquitous neurotic. Normal persons, of course, would display less in the way of violently aggressive outbursts than the average of any kind of schizophrenic. The dedication to assaultiveness or self-injury on the part of certain patients was made clear in Albee's (3) study of one year's accident and injury reports in a psychiatric hospital. He found that 78 patients were responsible for 215 injuries to others, while 74 patients accounted for a total of 119 self-injuries.

It is evident that mental patients can be distinguished both by the degree of their aggressiveness and by the typical direction of its expression, but the influence of hos- tility extends even further. Albee discovered that schizophrenics, as a group, were much more prone than non-schizophrenics to direct their rage against others rather than themselves, and this proved to be an almost impenetrable barrier to therapeutic improvement. Patients whose aggressive urges were directed toward themselves were significantly more able to profit from psychotherapeutic attempts to help them. Studying matched groups of patients who improved or failed to improve following hospitalization, Feldman, Pascal, and Swenson (114) reported that those who tended to direct blame or hostility exclusively onto the environment had a poorer prognosis for their status one year after discharge from a mental hospital than did those who directed part of their hostility toward themselves. Aggression turned toward the world and the people in it acts to keep others at so great a distance that they can neither approach to render therapeutic guidance nor offer support in the crises that come with a return to the outside world. In this sense, man's rage can indeed be his worst enemy.

\section{CULTURE, HOSTILITY, AND PATHOLOGY}

The predictive power we gain from knowledge of patterns of aggression is not limited to individual cases or diagnostic groups. Some fascinating explorations have been made of cultural patterns of hostility and their effect on the incidence of mental illnesses related to them. The patterns of child-rearing that a culture uses to fashion personality traits in its future adults tend also to determine the characteristics that will mark mental illness among its members. The total incidence of psychosis, the frequency of particular kinds of psychosis, and the unique symptoms that a psychotic person will display may reflect the distinctive social and cultural demands that a society makes on its citizens (263). 
A well-documented instance of the social shaping of illness is reported for the studies of Negro Africa analyzed by Benedict and Jacks (39). In the populations studied, depressive states in any form were relatively rare, and this was particularly evident in the statistics which indicate that there was only 1 suicide for every 100,000 persons in the society. This is an especially low rate when it is compared with rates of 10-16 per 100,000 in the United States or 255 per 100,000 in Denmark. Carothers (67) noted that among Kenya Colony natives there was not a single case of depression observed in 120 consecutive hospital admissions diagnosed as manic-depressive psychosis; the patients' aggressive actions were turned on others rather than on the self. Attempts to explain the rarity of depressive forms of emotional disturbance have mentioned that the cultures studied can be distinguished from most Western societies by their freedom from guilt and self-reproach and by the exclusion of ideas of free will and personal responsibility. If tragedy and accident can comfortably be ascribed to the machinations of a supernatural power, the individual is absolved of the overwhelming guilt so characteristic of the Judeo-Christian world.

Even in cultures similar to that in the United States-New Zealand, for exampleBeaglehole (31) related that manic-depressive reactions occurred about twice as frequently as schizophrenic reactions. This figure-perhaps it is a commentary on the nature of our civilization-is an almost exact reversal of the incidence of these two diseases in the United States. Subcultures located in a larger society but isolated from it by choice or by natural barriers may display patterns of psychosis that differ considerably from the society that surrounds them. Among the Hutterites living in selfsufficient communities in the North Ameri- can Middle West, Eaton and Weil (97) found that the Hutterite philosophy of community life made manic-depression much more common than schizophrenia-the reverse of the situation in all other populations in this country for whom comparable data have been obtained.

As interesting and suggestive as these observations of pathology are, they rest quite squarely on the presumption that psychiatric diagnosis is both accurate and dependable. At best, diagnosis is a rough system of categorizing and labeling collections of symptoms-a system irregularly applied and subject to extensive distortion on the part of the individual diagnostician. King (221) spoke for most experienced research workers when he pointed out that matching neuropsychiatric samples by diagnostic category tends to be a most superficial indicator of similarity between persons-a system which ignores a host of differences between them. Modern methods of treatment complicate the diagnostic process even further (17). A depressed patient may be given electric shock treatments shortly after being admitted to the hospital and have his depression eased before the dynamics of his case are fully understood or catalogued. While this may be an act of therapeutic mercy, it obscures the relationship between hostile impulses and the symptoms of mental illness.

\section{AGGRESSIVENESS AND PATHOLOGY}

IN CHILDREN

In assessing the part that hostility plays in pathological disturbances among children, the task is made more difficult because the child can seldom account for the relevant details of his own past. The mother -to whom all researchers eventually turnpresents a formidable set of barriers for the interviewer to hurdle. In studies of the family background of schizophrenia, Gerard and Siegel (136) learned that parents of dis- 
turbed children tended to be sensitive and defensive individuals, often ridden with deep guilt feelings. Anxious to defend both the patients and themselves, parents may distort the facts or omit vital bits of information. The parents of large families naturally find it difficult to recall any but the most superficial points of difference between siblings, and this lapse of memory is abetted by their fear that the slightest hint of difference in the manner in which any of the children were brought up may open the door to criticism of their ability as parents. Even when well-intentioned parents are willing to co-operate, their account of child-rearing procedures may contain more fiction than fact (40). Normal mothers pride themselves on the clarity of their recall, but even they may not be able to sort out the original event from the embellishments added in the retelling.

Although childhood emotional problems are similar in kind to those of the adult, the pathologies of children are much less sophisticated and somewhat more direct translations of impulse into action. Some theorists (168, 169) argue that diseases such as classic manic-depression should be recognized as a psychiatric entity in children and treated accordingly, but most clinical workers feel that childhood diseases resemble, but do not duplicate, adult difficulties. Certainly the use of manic-depression as a diagnostic category for youthful problems is rare. Between the ages of five and sixteen, only six cases were so designated out of one thousand diagnoses reported (163). Disagreement about what ought to be the proper diagnosis in such cases occurs because diagnosis most frequently is made without any long-term observation of the child (348). Ideally, even though an-infant's emctional capacity may be limited by the primitive state of its nervous system
(51), we ought to know the child's emotional development from birth.

The serious emotional illnesses of children regularly revolve around the difficulties they experience in learning to control the expression of hostile impulses. The symptoms of this struggle with aggression are often highly visible because the arena for the battle is the musculature with which the child puts his anger into action. For some children, activity and an aggressive orientation to life can be associated almost from the time of birth. One theorist (343) has suggested that excessive nervous and emotional activity can be inherited, as can phlegmatic and depressed types of behavior. If so, the extreme differences in gross activity level at birth may predict that the future task of restraint of activity may become a serious challenge to some children and a simple achievement for others. Despite the innate differences in motility of children, the society will decree that they must all fit within the same narrow limits of control over natural impulses.

There is no more dramatic example of the struggle for muscular inhibition than that revealed in cases of children who developed involuntary "tics" as a primary symptom of their emotional problem. In the second year of an infant's life, especially in the short period after independent movement is established and before verbal expression is achieved, a variety of emotions find their outlet only in the language of bodily movement. Rage, anger, impatience, and frustration are expressed through muscular activity, and, as Burlingame (58) observed, under the impact of conflicting emotions such activity may become diffuse, spread over the whole body, be undirected and chaotic, and culminate in a temper tantrum. Since children must often be restrained for their own safety as well as for the safety of the environment, such bodily 
restraint blocks their main avenue of expression, leaving a great deal of tension undischarged. Where restraint is in a sudden or unexpected manner, the child is liable to respond with a paroxysm of aggression. When such restraint is a consistent feature of the child's life, his attempts at self-control may become the central theme of his existence.

As the child develops, purposeful, intentional motility should gradually come to displace the diffuse and impulsive motility he displayed as a child. Society's emphasis on achieving motor control and the central role that the skeletal musculature plays in emotional expression for children make this a particularly susceptible area for behavior disorder. Blinking, jerking, twitching, or sniffing are transient expressions of tension which $(233,245)$ almost every normal child experiences while growing up. It is when these expressive movements represent the acting out of impulses which the parents disapprove that the child is driven to suppress and hide his gestures, leaving the "tic" as the last remnant of a continuing conflict. Of the thirty-nine tiqueurs studied by Mahler (245), thirty-seven were males, and only two were females. The greater aggressiveness of boys and the degree to which they rely on their neuromuscular apparatus for attack and self-defense make them ready victims of the symbolic aggressive indecision represented by pants-hitching, lip-pursing, eye-blinking, collar-loosening, and arm-twitching tics. Gerard (137) adds that in all her cases the mothers, and sometimes both parents, were ambitious for intellectual achievement by the child while demanding non-aggressive, restrained, conforming behavior from him. The involuntary muscle spasms of a tic may be likened to a repeated-but never completed-hostile gesture.

When a child has shifted from bodily to verbal techniques of expressing himself, he may still use inhibition, restraint, or withdrawal as a way of resolving his conflicts. Among Despert's (85) patients, she felt that a capital symptom of childhood schizophrenia was mutism. This flat refusal to speak or to communicate with the world was, for the child, a paralyzing attempt to cope with his environment by avoiding the use of an organ that was capable of expressing his hostile and destructive feelings. When either elective mutism or tics prove to be unrewarding ways of managing angry emotions, and as the child's emotional disturbance deepens into schizophrenia, his unconfined aggressiveness becomes a prominent characteristic of his illness. Studying boys seen at a clinic, Frazee (125) compared the symptoms of one group, who later became psychotic, with those of another group who did not. Topping the list of symptoms of prepsychotic children was display of temper, which appeared in 74 per cent of the cases, while apparent in only 39 per cent of those cases which did not develop schizophrenia.

Under adverse circumstances, some children never acquire the capacity to deal with their hostile impulses, and in the battle to gain control over their inner urges they deviate from normal patterns of behavior in ways which reveal their helplessness and dependence on the adults around them. With growth and maturity come a sophistication and variety in emotional expression; for children the means at hand are few, and they are simple and direct. For the middle-class child, neurosis may be the only available resolution of his problems (157).

\section{AGGRESSION AND PHYSIOLOGY}

Pathological emotional states in which the individual is no longer the conscious master of his hostility constitute a perfectly 
reasonable and proper topic for study by psychologists, psychiatrists, and psychoanalysts. Over the years, psychological interest has veered toward symptoms which are produced by disturbances in the autonomic nervous system, and many psychoanalysts are busy studying the origin of spastic bowel, eczema, peptic ulcer, bronchial asthma, migraine, diabetes mellitus, and a host of conditions which in the past were excluded from psychiatric interest because of their supposedly organic causes. From these studies has come the concept of "organ neurosis," which suggests that powerful emotions, barred from outlet in the muscle system of the body, provoke an abnormal use or stimulation of an internal organ system, thus disturbing its normal function.

The action of the autonomic nervous system in states of anger or fear demonstrates quite clearly how extensive are the bodily changes which accompany emotion. In classic terms, the body is prepared for fight or flight when it becomes aware of noxious or dangerous stimuli in the environment. The autonomic nervous apparatus changes the blood pressure by increasing the rate and amplitude of the heart beat, it increases the ability of the blood to coagulate, it pours a greater amount of glycogen and adrenalin into the blood stream to furnish additional energy to the muscles, it dilates the blood vessels to carry these products to the muscles, and it reduces the blood supply to digestive and other organs that do not need to be mobilized for action. Each of us has felt these violent physiological changes when we were very angry or frightened, and we know from personal experience that they can produce exhaustion if continued over a long period. The study of aggression and human physiology focuses on the effects of psychological pressures which act to stimulate a continual state of excitation of the nervous system and the attendant havoc upon the body. Psychosomatic illness is one way of turning aggression on the self so that the self becomes the victim of emotions which are denied access to any other form of expression.

Before describing some representative theoretical approaches to the physical consequences of hostile feelings, we must take note of the core theoretical problem of all such studies-the mind-body problem. The term "psychosomatic" does a considerable disservice to what we think of as a reasonable and logical conception of the functioning of the human organism. The division into psyche and soma or mental and physical implies the existence of two distinct entities interacting with each other-a palpable, "real" body being influenced by a vaporous, nebulous mind. When the Journal of Psychosomatic Medicine was founded in 1939, the editorial staff made a clear statement about this confusing philosophical issue in their first edition. They explained that psychic and somatic phenomena take place in the same biological system and are probably two aspects of the same process; thus, any division of the two must be understood as a convenient, and somewhat dangerous, convention to simplify our thinking about the problem. This laudable caution has been less than successful as a guide for theorists. It is almost as if the "mind" refused to accept the fact that it does not exist as a separate entity. For our purposes, this issue can be side-stepped by taking the position that feelings and emotions always are accompanied by physical changes in body chemistry and nervous activity. Our concern is with what happens and not how it got there. Thus rage consists of physiological processes which take place somewhere in the central nervous system, and the physiological effect of rage is a chain of events in which every link can be described, at least theoretically, in physiological terms. Ideas, 
fantasies, or impulses which are a part of this process are unique only in that they can be studied by introspection and verbal report.

Schur (354) has pointed out that a great many theorists use an oversimplified model of tension which gets dammed up and then courses through the body, laying waste organ systems. Such a conception is presented by Harris (171), who interviewed women and claimed that a direct relationship existed between the subjective feeling of poor health and the holding-in of angry feelings. A wide variety of behavior has been attributed to physiological changes of all kinds. Aggressive acts committed against society by first offenders who are forty or fifty years old may be, according to Abrahamsen (1), a consequence of the physiological imbalances which come with increasing age. The additional impetus of an altered chemical state may contribute decisively to an antisocial act on the part of a person who previously was under adequate self-control. Emotions certainly can give rise, immediately and dramatically, to physical symptoms. Catalepsy is used by Levin (231) as a compelling example of such an event. In a cataleptic attack the patient collapses completely and is helpless, although conscious, for a brief period. And then he recovers completely. Levin feels that these attacks are likely to occur in the presence of aggression that must be kept in check. He notes that when aggression is justified and therefore does not provoke feelings of guilt, catalepsy is not likely to occur. The conflict between an aggressive impulse and physiological attempts to inhibit it sets up a high level of excitation in the cortex, and it is possible that this excitation spreads to the part of the brain that controls bodily movement and produces a sleeplike state. It is obvious that a number of other conditions must exist before a per- son will fall victim to as dramatic a demonstration of the internal war against hostile urges, but, for sheer directness of response, catalepsy is an outstanding physiological display.

Among physical symptoms that have been studied extensively are the various allergies, peptic ulcers, headaches, gastrointestinal disorders, and the elevation of blood pressure without an organic basis (essential hypertension). Each of these symptoms, of course, has an "organic basis," but the search that goes on is for the trigger of the physiological chain of events. Let us look at the example of headache for which no organic pathology exists. The hypothesis that such headaches occur as a result of repressed hostility was examined by Lustman (242), using hypnosis as an experimental technique. Eleven neurotic subjects were hypnotized and returned, in fantasy, to a time early in their childhood and asked to describe an unpleasant or hostility-provoking experience from that period. The three patients who regularly suffered from socalled inorganic headaches all developed such headaches as they relived the rage they had experienced at that time in the past. Of the eight patients who did not usually have symptomatic headaches, none developed them during the experiment. Having tension-produced headaches is not a simple function of unexpressed rage. It depends, in great part, on the intensity of the rage, the amount of guilt the individual has about his hostile feelings, and the degree to which he can express them with safety. In the experiment described, the patients who developed headaches while re-experiencing childhood resentments were free of such symptoms when they were hypnotized and asked to describe the same incidents from an adult perspective. It would seem that when the adult capacity to repress resentment is available to the neurotic person, it 
acts to protect him from being aware of his problems of hostility.

Extensive studies have been made of the relation of hostility and allergic reactions in children (21). In Miller and Baruch's (270) exploration of allergy, they examined the forms of expression of hostility that the children showed in their daily behavior. Rating 90 allergic and 53 non-allergic children according to whether they tended to express their anger directly to others, indirectly, or to displace it toward persons or objects that did not deserve it, they discovered an interesting set of relationships. Children who had allergies displayed less outgoing hostility of all kinds when compared to allergy-free children. When the researchers assessed the percentages of children who turned aggression on themselves, the proportions were reversed, with 55 per cent of the allergic children and only 28 per cent of the non-allergic children who were the recipients of their own hostile feelings. To fit findings such as these into a proper perspective, two considerations must be kept in mind. First, the untangling of cause and effect is not an easy task. Does the allergy act as a limiting condition on the form that aggressive expression will take, or does the allergy represent a symptomatic outlet for the anger? A second consideration is that something akin to somatic predisposition or constitutional weakness must be taken into account. A child having a chemical or physical hypersensitivity to certain allergens in nature may experience a severe reaction which then complicates all his later relationships with the world and the people in it. The subtle interaction of body chemistry and emotion has yet to be unraveled in a satisfactory manner.

Similar clinical speculations exist in some detail in the work on essential hypertension $(257,347)$. The cases studied had, as a prominent dynamic feature, a surface sub- missiveness which masked chronic, hostile, unsuccessful, nearly conscious rebellion against this submission to others. The chronic elevation of blood pressure is launched physiologically by this intense anger which is not adequately expressed or repressed. Miller's (271) investigations related fluctuations in blood pressure and inhibited aggressions among psychotic patients. Studying depressed patients who attacked themselves and paranoid patients who defended themselves against their hostilities by accusing others of having aggressive tendencies toward them, Miller assessed the emotional state of each patient in an interview and then tried to predict the blood-pressure reading they would show. He indicated that his results showed a reliable correlation between inhibited aggression and elevated blood pressure.

The gastrointestinal tract is another part of the human anatomy that can respond actively to aggression. In this case, Alexander and Menninger (7) studied paranoid patients whose psychological symptoms were fear of being attacked, persecuted, or treated unjustly by others. Their perception of others as potentially assaultive and the world as a jungle of raw emotion came to be associated with the rather mundane symptom of chronic constipation.

Taking a less specific approach to emotion and illness, investigators $(162,212)$ have made measurements of a series of physical indicators of emotion such as galvanic skin resistance, respiration, and pulse rate. By making these measurements before and after a period of induced frustration, they hoped to examine hypotheses about the rate at which normal and neurotic persons would demonstrate a recovery to a normal physiological state following frustration. In general, Jost (212) reported that the neurotic group of children he worked with showed more extensive changes and 
took longer to return to their prefrustration level. Even normals respond to frustration with an increase in activity at the physiological level, and Jost suggests that these measures of bodily reaction might serve as good measures of the strength of the frustrating experience.

Using electrical recordings of bodily changes of the sort used by Jost, Ax (19) studied the physiological correlates of fear and anger in normal subjects. As a stimulus for fear he administered electric shocks to the little finger of his subjects, explaining that the shocks were a result of a dangerous high-voltage short circuit. To anger his subjects, he had the tests administered by a highly insulting worker who was described as having been fired previously for arrogance and incompetence. To be sure, such experimental methods are not perfect, and probably no laboratory situation, however cleverly contrived, can duplicate the emotions that one normally experiences. Yet on the basis of this work, Ax maintained that fear and anger can be differentiated on a physiological level. This represents a dramatic experimental advance and paves the way for studies that may bring us closer to an understanding of the contribution of man's unique nervous system to the expression of aggression.

\section{Culture and Aggression}

Every culture must provide a solution to the hostility among its members which threatens constantly to disrupt the smooth flow of interpersonal relations so necessary to a well-functioning society. An examination of anthropological accounts of how aggression is managed in primitive or preliterate societies reveals a number of interesting variations but probably no single pattern that contains a universally acceptable answer.

Among the Pueblo Indians, the Hopi (98) are a society based on a notable maladjustment of its people-maladjustment in the sense of a state in which continued friction predominates in personal relations and in which the worst is regularly and anxiously anticipated. Gossip, witchcraft, fear, discord, and mutual distrust pervade the daily interactions of the tribal members. In part, the antagonistic attitudes of the adults can be traced to the sharp and consistent restriction of the overt expression of aggression by the child after an earlier period in which his aggressiveness was a successful and rewarding way of behaving. At the same time, control over the child was gained by systematically grinding extensive fears into him from his first days. Among the Hopi, physical aggression is suppressed, and competition with others is held to be in particularly bad taste, so that it does not offer a culturally approved outlet for the dammed-up feelings. It is pointed out that only the verbal aggression, in which he excels, remains to the Hopi.

The Saulteaux are an offshoot of the Ojibwa-speaking peoples living near Lake Superior. To a casual observer, the Saulteaux would appear to have interpersonal relations marked by co-operation, patience, and self-control, a tribe in which there were no official records of murder, suicide, war with whites or other Indian tribes. While there seemed to be no manifest expression of aggression, Saulteaux patterns of social behavior created a fundamental distrust in interpersonal relations, and the outwardly placid character traits were an effective façade for deep hostility and dislike of others. The chief culturally sanctioned means for disposing of this unexpressed aggression seem to have been malicious gossip, slanderous accusations behind the victim's back, and the use of sorcery and magic as a means of retaliation. These 
forms of covert aggression were widely used (165).

The ways of regulating aggression could be multiplied with the examination of each new culture. Hostility and aggressive behavior are the most powerful obstacles to the formation of a culture which can devote its energies to constructive efforts. Institutions to deal with such feelings are a cornerstone of the ultimate pattern that a society will follow (305). Consideration of various cultures establishes a fundamental lesson about the management of anger. Starting with the premise that an average quantity of aggression is the inheritance of each individual, it becomes clear that a dependable relationship exists between the freedom for its overt expression and the degree to which covert forms of it will make their appearance. The quantity of aggression given in the beginning seems fixed and unalterable, and if it finds no overt channel for expression, it becomes covert; the proportion of open or hidden expression tolerated in public and private life comes to characterize the individual as well as the society in which he lives. Further, it would appear that there are few adequate substitutes for the direct expression of aggression. The variety of substitutes needed seems to be a function of the number of frustrations the society imposes and, in general, how early they are forced on the child. In some social groups the rivalry and hatred expressed openly would seem to be beyond the bounds that group life could absorb, yet the social unit survives even if at some cost to its creativity. In other cultures the suppression of all forms of overt hostility and the guilt associated with angry thoughts are so extensive that substitute forms of outlet must carry an unreasonable burden. It may be that a self-destructive cycle exists, one that comes to an equilibrium over a period of time. A culture that permits and encourages hostility and protects itself by directing the accumulated rage against enemies outside the society may, through destructive warfare and the inevitable reduction of tribal vigor or through the circumstances of encroachment by even stronger tribes, come to follow peaceful ways by necessity rather than choice. Through a similar process of attrition, tribes which the environment once treated kindly may find that a more aggressive and warlike spirit is needed to wrest basic gratifications from nature, and they may gradually convert their institutions and child-rearing practices to the production and encouragement of a culturally useful aggression. Although evidence does not yet exist for this hypothesis, it seems reasonable to assume that a continual waxing and waning of cultural sanction of the proportion of overt and covert aggression is taking place in various cultures at all times. It may be reasonable, further, to assume that cultures at the extremes of both overt and covert permission of aggressive expression have within them the seeds of their own destruction. Just as the unsatisfactory results of corporal punishment drive parents to reason with their children and then dissatisfaction with this method leads to a return to spanking, it may be that at the extremes the cost of the methods of handling aggression may be so great as to force a reaction toward equilibrium and a median position. The relativism of cultural solutions to the problem of aggression are important to us because it sets a limit on human invention.

The cultural process channels aggression in directions that suit its purpose for the good of society. Once a pattern of expression is set for a society, it may continue long past the time of its usefulness because it continues to be passed on to the next generation by parents who learned the lesson so well. Even within a society the relations 
between groups of different race, language, or religion may establish fixed patterns for the regulation of aggressive impulses (320). In the history of Negroes in our own society, for example, the roles they were required to take in their relations with the dominant white group allowed little variation in the expression of aggression. Before the Civil War, Negroes, as faithful slaves, were allowed to aggress only against members of their own group and were subject to an extreme penalty if open hostility toward the ruling whites were to become apparent. Since slaves depended on their masters for food, shelter, and protection, their situation was quite similar to that of the parent and child. Indeed, slaves were treated as though they were simple children in adult bodies. In this case the slave, like the child, obeyed a needed and feared master-parent toward whom aggressive feelings had to be suppressed and prevented from overt expression. Following emancipation, the Negro continued to live by the whim of the white master and was still required to suppress his hostility for fear of retaliation from his ex-masters. The overt behavior of the $\mathrm{Ne}$ gro became meek, humble, and unaggressive, concealing his true attitude from the whites and sometimes even from himself. In this way he assured his acceptance and continued reward from those who possessed the power to dispense the essential gratifications. Aggression became limited to fantasy life, and even these feelings toward his oppressors took their toll in guilt. The masklike quality of the role of the deferential, obsequious Negro was most apparent when it was sloughed off in the company of his companions, who made no demands for suppression of angry feelings and toward whom less hostility existed. Today, as the compensations available to the self-effacing, humble Negro become less than those attainable by direct, aggressive action sanc- tioned by law and social sentiment, the pattern of inhibition of the expression of hostility is undergoing a steady alteration in the direction of freedom from restraint.

The sensitivity of the developing child to the limts he must maintain over his hostility and the approved forms for its expression help him to establish a workable pattern of behavior in relations with others. Negroes, as a minority group in this culture, must learn one pattern to fit the demands of those close to them in their own group and must interchange this pattern with another when relating to members of the majority group.

\section{THE SOCIAL REGULATION OF AGGRESSION}

A society can give informal sanction to the most extreme forms of aggressive expression (90). In Kardiner's (217) evaluation of early Comanche Indian culture, for example, he described a society which developed strong and uninhibited individuals devoted almost exclusively to "criminal" ends. The society established an ideal of bravery and aggressive accomplishment and allowed no escape or form of passivity for its members. Status among the Comanche was determined by prowess, daring, strength, and skill, and a warrior's position among his fellow tribesmen diminished as these powers waned with advancing age. The culture avoided its own destruction by the simple device of directing all its warlike actions against outsiders in the neighboring tribes. When the Comanche were surrounded by white men, herded into a restricted territory, and kept from further marauding, it caused the decay of the culture, for the mainstay of its vigor had been swept away.

In line with Kardiner's analysis of the structure of this Indian culture, Alexander (5) stated that, for any group, wars help to externalize aggression and to reduce ani- 
mosity among its members. He suggested that hostility toward an outgroup may be the prime condition for internal peace. An excellent example of this hypothesis was furnished by Goldfrank's (149) report on the Teton Dakota Indians. Prior to 1850 , murder of one tribesman by another was frequent, and the cause could usually be traced to the frustrations issuing from an unequal distribution of the tribal wealth. For thirty years following the arrival of the white man, there was a decrease of ingroup homicide while the tribe presented a united front to this enemy from without. When peace with the white man was finally achieved, in-group murder made its reappearance.

Science-fiction writers are fond of imagining the earth beset by invaders from outer space and like to toy with the idea that the world would then respond to this threat by a peaceful unification for the common good. At best, such a solution would be a temporary one, and it would be a detour around the problem rather than a successful conquest of it. If society is not prepared to organize itself in terms of this solution to the problem of aggression, Wellisch (399) offers an alternative scheme. He suggested that individuals who have failed to control their aggressive impulses might be placed in a subculture in the larger society, where they could be managed with greater ease. A self-sufficient colony for maladjusted children, furnished with real and foster parents and heavily staffed with workers devoted exclusively to the task of improving the mental health of the residents, would allow a society to protect itself from the internal disruption of uncontrolled hostility. As Bromberg and Rogers (56) have indicated, the anger of delinquents needs the strength of adult authority if it is to be controlled and directed along less destructive paths. A controlled miniature society could cer- tainly provide an authority more antiseptic than the prisons in which delinquents are currently housed. The problem is not solved so easily, of course. It is not just that there is disagreement about the curative powers of firm authority with delinquents (210), it is also that any institution must cope with problems that would not usually arise in a society where hostilities are less concentrated in a single area (99).

The best of all possible arguments against such colonies is furnished by the observation that utopian plans are always painted with broad strokes (6). In many respects we are not yet prepared to manage a theoretical model society, for we know too little about human beings and effective methods of gaining a workable self-control over violent impulses. We are not yet at the point where we can staff such a society with models of integrated humans in whom impulses seldom gain the upper hand when faced with raw emotion and assault (265). Since our current institutions exact a form of social revenge on those who falter in their learning of self-control, it would take a great deal of education to convert this hostility toward deviants into a sympathetic concern for their well-being.

Farber $(109,110)$ suggested a less disturbing alternative to selective isolation of aggressive members of a culture. Since the politically effective implementation of warlike attitudes usually rests in the hands of the few leaders of nations, it is reasonable that the control of aggressiveness in these leaders might remove the primary source of war. In much the same fashion, the invention of a new form of mass therapy might leave the leaders with no one to follow them into hostile action. Controlled subsocieties and compulsory therapy for the leaders of all nations are as workable as belling the cat. Who will do it and how it 
will be done are the vital questions which no one seems to be able to answer.

\section{The Modification of Aggressive Behavior}

\section{AGGRESSION AND EDUCATION}

At least thirteen of the child's formative years are spent in school. To the child, the business of life is transacted in an educational framework that is the cardinal feature of his daily existence. Schools establish what amounts to a single standard of behavior and achievement, and it is in comparison with these ideals that the child measures his success or failure and, in turn, his worth as a person. The school system is compulsory for the child, and the tasks he must learn to perform, his teachers, and his companions for these years are not of his own choosing. It is in such a setting that the child will spend the bulk of his waking hours, with the time remaining in each day being absorbed by television, supper, and a brief period of play. School weans children from a close relationship to parents not only by providing stimulation to widen his experience but by becoming the focus of his attention during the daylight hours. The school life of the child is of interest in the study of aggression because it plays an integral part in determining the final outcome of the control of aggression, and it offers one of the most vital means of shaping humanity to desirable ends. By the time some children come under the influence of the educational system, a succession of painful frustrations and unresolved conflicts have sapped their energy to a remarkable degree. The resulting destructive fantasies and hostile patterns of reaction not only render the child incapable of managing the academic curriculum but pose painful problems of coexistence for the teacher and the other children (374).

Each setting populated by people has about it a characteristic atmosphere to which each member of the group must be sensitive and which will pattern the relationships he has with others. The interplay of personalities within a group and the goals, aims, and traditions of a group all merge to produce the unique flavor which marks an assemblage of persons. The classic study of group atmosphere was done over twenty years ago by Lewin, Lippitt, and White (236). Their study concerned the relations of members of a boys' club to their adult leaders rather than that of a pupil to the teacher, but the situations are similar in many important respects. In order to isolate the effect of types of adult leadership on the behavior of children, the researchers systematically varied the actions of the leaders to produce democratic, authoritarian, and laissez faire group atmospheres. In establishing a democratic setting, the leader called for group discussion and decision-making in the choice of goals, the selection of working partners, and the assignment of individual responsibilities. The democratic leader gave advice as a resource person, encouraged and assisted efforts of the group members, and, in many respects, acted more like a senior member of the group than a guiding authority. In contrast, the authoritarian role required the adult to determine all policies, procedures, and activities and arbitrarily to assign tasks to individuals while remaining aloof from close personal contact with the members of the group. Laissez faire leadership was leadership dispensed only on request. The leader remained passive and left the group to its own devices in making decisions about what to do and how to do it. In a detailed analysis of the fate of each group as it experienced, in turn, the three kinds of leadership, the data indicated that the group atmosphere created by the leader was an important determiner of the way the children 
behaved. Hostility and aggressive exchanges between the boys appeared most frequently in the laissez faire and authoritarian climates, and a disorganization of working habits also appeared.

In a series of studies $(13,14,15)$ of the responses of pupils to the group atmosphere created by teachers, the dimensions of integrative (democratic) and dominative (authoritarian) teacher behavior was studied. Integrative behavior included sympathetic, approving, and encouraging relationships with children, while dominative actions were evidenced when teachers used commands, threats, or other coercive means of getting the child to conform. It was observed that the pupils of a dominative teacher became rebellious and displayed less constructive behavior than did the children whose teacher relied on integrative methods of relating to her pupils. A dominative teacher evoked dominative behavior in her pupils, while a teacher using integrative methods evoked integrative responses from her students. A follow-up of the teachers and their pupils a year later disclosed that the teachers were behaving in their accustomed integrative or dominative manner but that the students were able to alter their responses and adapt to the orientation of their new teachers in the next grade.

One might conclude from these studies of group atmosphere that teachers have, with increasing age, become set in their ways, while children, with the resiliency of youth, can adapt to the forms of leadership they fall heir to. Each of us can recall at least one teacher who was bitter and harsh with us, and yet we managed to survive the experience. We can also recollect the retaliatory actions we took toward such a teacher, but we are probably unable to assess the lasting effect that this hostile relationship had on us. The misfortune of being subjected to a succession of such unproductive encounters can reasonably be expected to leave its stamp on the developing personality and to prepare the individual to react negatively to authority figures that he will meet in the future. Teachers, then, need preparation and guidance in managing the aggressive responses of children and require insight into the contribution that they themselves make to the hostile exchange. Some excellent books are available for just such a purpose, but something more than self-help is needed to alter lifelong patterns of adult behavior (89).

The teacher does not stand alone in the task of shaping our youth to the desirable end of control over their hostile impulses. The demands of the teacher are usually reinforced by the parent, and even the textbooks that the children use play their part in this process. The central values of the society regarding the management of aggressive feelings and actions are communicated to the child by his parents, his teachers, and the books from which he learns to read. In a fascinating investigation of the contents of children's textbooks, Child, Levine, and Potter (69) analyzed the types of story, the kinds of characters, and the sorts of behavior displayed by the heroes and heroines in third-grade readers. Almost without exception, swift and unerring punishment or disapproval followed temper displays, flagrant disobedience, and verbal or physical aggression on the part of the central characters in the stories. Aggression, even in the form of initiative and enterprise by children who were story heroes, was liable to end disastrously. The active execution of plans was most rewarded when those plans were adult-suggested or -inspired. The most flagrant hostile or disobedient impulses were not intrusted to child characters with whom the reader might identify; they most often appeared in animals, elves, or other per- 
sonages psychologically distant from the child. The impact of such propaganda for conformity is hard to evaluate, since it occurs in a context which adds additional pressure in the same direction. This rain of influence on the behavior of the child must have a consequence, but its exact nature cannot be predicted. It is possible that too much flag-waving for obedience may produce a rejection of the intended lesson.

\section{THE PLANNED MODIFICATION OF AGGRESSION}

The educational system is a miniature society for the child and a most important one, but it is not oriented exclusively to the task of forming the child's emotional life to conform to a socially acceptable pattern. Although the average child soon learns to regulate his impulses, the teacher will inevitably encounter a number of children who deviate from the norm in the direction of ascendance over others or an illogical submission to physical or psychological bullying. Although the swashbuckling domination of others provokes the most extensive counterattack by adults, children who can never muster the courage to assert themselves are an equally great source of concern. Chil-

- dren who fail to achieve a balance of selfassertion and compliance require retraining directed exclusively at this facet of their adjustment (293).

Since a child regularly practices his skills in human relations in fantasy and through play, Halliburton (164) has suggested that the aggressiveness which accompanies selfassertion can be modified by games designed to provide controlled creative and destructive experiences. Providing a hostile delinquent with the thrill and excitement of adventure, while eliminating the antisocial aspects of it, would be a proper example. Trying to get as close to the aggressive impulses as possible, Tolsma (386) used a punch ball or a rebounding dummy on which his patients could vent their feelings and at the same time learn the senselessness of aggressive action. The simple catharsis of emotion in a play situation can offer temporary respite from pressing frustrations, but there is some question about the permanence of such changes. The fire that melts the butter hardens the egg, and Stagner (375) reported that individuals who take part in sublimation-like activities, such as football, tend to be more aggressive than those who do not. Unless a child can accept and live with the rules of the game, play will be as great a source of stimulation to hostility as any other activity. Games, as a concrete way of learning self-control, are not being exploited fully because their therapeutic value is still poorly understood. At the present time, games and play serve primarily as ways of handling the overflow of feelings that lack any other outlet. Games do offer the advantage of aggressiveness without destructiveness, and hostility can be converted to good humor under the proper circumstances. Although laughter and humor do not have the characteristics of formal and organized play, they offer relief of tension by redefining anger-provoking situations to emphasize their more ludicrous elements. The study of humor as an outlet for aggression has received a great deal of attention in the last few years $(63,101$, 161).

When given training calculated to teach them new ways to react to others, Davitz (83) maintained that children taught aggressive responses will behave more aggressively after they have been frustrated, while children trained to handle situations constructively will respond to frustration with mature and constructive approaches. Using games as training sessions, he was able to demonstrate that planned experience with situations similar to that in which frustra- 
tion is likely to be encountered can determine the constructive or destructive reaction that the child will have. It is of interest that such training works well, but not perfectly. Some children trained in one way reacted in the opposite fashion. It is clear that planned change falls into a context of the child's previous experiences and must be fitted to the needs of the child if it is to bring about a change. Training is not an injection that automatically controls the disease.

Once a child has been taught the skills which will allow him to be more self-assertive, he tends to retain this ascendancy over others when he finds himself in new situations resembling those for which he was trained $(201,302)$. One of the complications of instilling more self-confidence in a child is that his newly acquired assertiveness tends to take both desirable and undesirable forms. Personal power over others can easily be corrupted into selfishness, cruelty, and hostility (283). It is not sufficient to exert pressure on a child to inhibit his usual aggressive approach to others; to be effective, the training must substitute new skills which will bring as much reward and success in interpersonal relations as did his previous aggressiveness. Chittenden (71), for example, concentrated on educating dominant children about the value of cooperative behavior. In individual sessions of doll play, the experimenter told the nurseryschool child about two dolls who came in conflict with each other. The experimenter and the child then discussed how each doll would feel and react, and together they considered a variety of desirable ways to solve the problem. After such child seminars on co-operative rather than destructive social behavior, the aggressiveness of the children diminished considerably in play situations and was marked by an attendant increase in co-operative exchanges between playmates.

\section{THE THERAPY OF AGGRESSION}

Modification of the intensity and direction with which hostility will be expressed is no doubt an easier task when the subjects are very young children. Once a pattern of reaction takes root in the life of a child, it tends to become a part of his conception of the kind of person he is, and, according to Pearson (310), he is likely to part with this familiar form of adjustment with some reluctance. With some logic, an aggressive and assertive child can reflect on his illgotten but extensive gains and insist that some forms of crime do, indeed, pay. Such a child might not respond to an educational appraisal of the rightness or wrongness of his way of life and would modify his behavior only to the degree that he judged to be necessary to insure minimal acceptance by adults and the least interference with his aggressive activities. Typically, attempts to educate him produce only a firm resolution to be more stealthy in his future enterprises. Children for whom ordinary measures are ineffective need more than moral lessons and skill training. They require assistance in understanding the motivation for their angry feelings in order to be free of an emotional slavery to them. When hostility is a neurotic master, then remedial treatment must go deeper and encompass the very roots of the self.

The most common mistake in providing re-education for children who are aggressively beyond the reach of normal corrective experience stems from the notion that the usual educational procedures will be effective if they are repeated often enough. The child is frequently treated in the same fashion as an automobile stuck in the mud. The wheels are spun with increasing intensity, no forward movement results, and, with both automobiles and children, the end result is to deepen the mire. Clinicians experienced with such chronically aggressive 
children know full well the need for carefully designed settings and specially developed techniques in the task of emotional re-education $(279,280,363)$.

In the view of some theorists, all antisocial activity is, in some degree, neurotic behavior which requires treatment tailored to fit it. To say that all aggressive activity is neurotic if it violates social standards of conduct is to define the term so broadly that it becomes meaningless. Nacht (292), for example, pointed out that the success of therapy frequently depends on the amount of aggressiveness that the patient has available to use in working his way back to mental health. It is through the power of aggressive resources that some of the most essential features of therapy are achieved. Defense mechanisms must be destroyed, new adjustments must be tried in the face of resistance from persons important in the patient's environment, and self-examination must be pursued despite the anxiety and anguish it occasions. When the therapeutic problem is to convert a passive personality structure into one more normally assertive, Cameron (65) stated that practice with aggressiveness is needed to break through the anxious avoidance of others that is the mark of passivity. Starting with the assumption that extreme passivity is a carefully constructed mask for powerful but inhibited hostility, Cameron helped the patient to recognize the hostility hidden within him and to identify the key figure toward whom these feelings were directed in the patient's life. After preparing the patient to assert himself against this key figure, at first by fantasy or acting out potential situations, the patient was ready for the assertion phase of therapy. Since an unaccustomed assertion of individuality increases the anxiety of the passive person, the final phase of this direct and active therapy was devoted to the management and consolidation of the gains of this first standing fast against the world.

Aggression comes in many forms and requires therapeutic methods designed to fit the psychological needs of the individual. There is a misconception that all aggression springs from frustration and that "warmth and love" are the only antidotes needed to cure it. As Sobel (373) pointed out, this may work for reactive hatred to a particular threat but will not alter conditions that have existed so long that the person has developed a readiness to hate regardless of the stimulus. When an adult or a child responds to the world as he perceives it and his perceptions do not match up with the way the world really is, then the task of therapy is to correct the discrepancy between the real world and the patient's perception of it. When the patient's problems are complicated by hostility and aggressiveness, Fried (133) recommended a combination of group and individual psychotherapy alternating with each other. He felt that hostility is so complex a phenomenon that some vital parts of its operation might be overlooked if the therapist studied only the aggressiveness that the patient directed toward him in the one-to-one relationship of the therapy hour. The members of a group can provide a kind of stimulus to anger to which the patient may be uniquely vulnerable, and this facet of his hostility might make its appearance only in such a setting. Certainly the treatment for a person who has limited tolerance for frustration and no respect for authority must be quite different from that devised for the dependent and submissive person who responds with an outburst of rage when he does not get what he wants and frequently fights because of fear of others rather than anger toward them (198, 407).

\section{Delinquency}

If an individual's control over his hostility is personally satisfying and socially accepta- 
ble, it presents no problem to him or to the other members of society. If his manner of managing aggression does not satisfy the individual's needs but is socially acceptable, it will result in some form of inner disturbance. If the kind, quality, and quantity of aggressiveness is satisfying to the individual but socially unacceptable, one result may be crime among adults and delinquency among young adults. If the control of angry feelings is neither satisfying to the individual nor socially acceptable, the outcome may be a form of neurotic or psychotic antisocial activity.

Delinquency is a legal rather than a psychological concept, and as such it has been, and is, defined in different ways in different places. Whatever it may be, it has been pursued with great vigor by social scientists, and references to this topic now number in the thousands. As a social phenomenon, it has a history at least as ancient as that of aggression, it has been viewed with alarm by every generation of parents, and it is a concept which is about as elastic as any invented by man. The "delinquency" to which most persons refer is the official delinquency reflected in court records and police files, but it can also be the unofficial delinquency which is ascribed to any youthful misbehavior for which society has a distaste.

The primary complication in the study of the aggression that delinquency represents is that our society is composed almost exclusively of law-abiding lawbreakers. The legal code which outlines proper behavior has reached such a saturation point of specification of kinds of misbehavior that lawbreaking through ignorance or with deliberation seems unavoidable. Thus the incidence of hidden delinquency-acts which are invisible, are not recorded, or go unpunished-by far exceeds the incidence of aggression against persons or property that comes to our official attention (285). If every youthful antisocial act which is detected were to be duly noted and tallied, it would produce a statistical crime wave unlike anything in man's history. This is not to say that something called "juvenile delinquency" does not exist in a very real and troublesome form, it is rather to underline the importance of being aware of the relativity and slipperiness of the term. As a semanticist might point out, the word is not the thing itself but only a representation of the real object. This seems to be the case with the word "delinquency."

One further caution ought to be noted regarding consideration of this form of social aggression. With few, and very recent, exceptions, institutionalized or convicted offenders have been used as research subjects in the study of delinquency. Institutionalized adolescents are far from representative of American youth in general. It is not only their incarceration that makes them different, it is that their numbers are regularly drawn from the lower socioeconomic levels of society. Study after study has demonstrated that arrest, conviction, and institutionalization are events that occur more frequently for lower-class than for middle-class persons. This fact tells us in advance that studies of institutionalized delinquents will report a host of correlates that reaffirm what we already know, namely, that the characteristics of members of the lower socioeconomic classes are also characteristic of delinquents. These characteristics may also function as the causes of delinquency, but we are not yet able experimentally to verify such an assumption. Finally, delinquents make very unco-operative research subjects. They are suspicious, defensive, evasive, and easily provoked to anger and resistance by attempts to probe for their core conflicts. It can be added that among members of the delinquent population, it has been my priv- 
ilege to make the acquaintance of some of the most accomplished, straightfaced, artful liars imaginable.

\section{THE CORRELATES OF DELINQUENCY}

The actual number of delinquents cannot be estimated, even when a single criterion, such as arrests, is used as a measure. Estimates that have been made range from two out of every hundred children and adolescents to a guess of six out of every thousand. It is evident that the number of boys designated as delinquent always exceeds the number of girls. This proportion ranges between 70 and 90 per cent in favor of boys and reflects the difference in the sexes that applies to almost any sort of overt expression of aggression. Female delinquency most frequently takes the form of sexual promiscuity or stealing and rarely appears in the form of destruction of property or crimes of violence against a person. The occasional female delinquent who aggresses in the same way that the male delinquents do is usually more seriously disturbed emotionally than the average delinquent of either sex.

The home and family life of the delinquent have been studied intensively in the search for correlates of his behavior (141, $142,367,368)$. The home of the delinquent is usually dilapidated, crowded, and poorly furnished, and it is most frequently located in a section of the city that can be described as deteriorated and marked by social deprivation of every sort. As one might imagine, community centers or youth groups dedicated to combating the effects of the neighborhood setting have an uphill fight when they attempt to match the pallid pleasures of clean living with the excitement and adventure of delinquency. When a boys' club is founded for this purpose, it undergoes a predictable social fate. At first, its membership is made up of boys who are socially well adjusted as well as those who are maladjusted or social isolates. After a short time, the isolates and the aggressively antisocial children drift away and do not return (80). Unless such a center is under the leadership of someone who makes a sustained effort to hold such children in the program (and this requires compromises which are usually distasteful to those who back the program financially), it soon becomes a center for the correction of those who need no correction. This separation of the white sheep from the black sheep is inevitable because even the sheep of different psychological colors find one another mutually offensive.

More crucial than the depressed physical conditions of their life are the relationships that delinquents have with their family and friends. In particular, the emotional relations they have with their parents are far from healthy ones. In one study (226) of 116 delinquent boys, 55 (47 per cent) had been rejected by their mothers, and 40 ( 34 per cent) had been rejected by their fathers. In 20 cases the rejection by the mother began before birth, before the age of two in 6 more cases, and during early childhood in the remaining 29 cases. The instability of the parents was also reflected in their marital adjustment. In these cases there were 11 divorces, 22 separations, and 50 cases of severe quarreling marked by intermittent desertion. The emotional disturbance of these parents was clearly apparent for 31 mothers and 36 fathers. Not every child lived in an environment which contained all these destructive factors, but 85 per cent of them suffered from at least one of these family circumstances, and 53 per cent of them had to live with more than one. Exposure to maternal rejection, paternal rejection, parental incompatibility, or emotionally disturbed parents must leave its mark on the child, and it makes a convinc- 
ing case for the inevitability of aggression directed toward others in the form of delinquency $(338,406)$.

One of the outstanding and classic studies of delinquency and the personality of delinquents is that of Healy and Bronner (176). These investigators gathered extensive case-history data on 105 juvenile offenders, each of whom had a non-delinquent brother or sister near his own age. These non-delinquent siblings served as a control group that had been exposed to approximately the same environmental conditions, and they were studied in the same way as their delinquent brothers. Despite the similarity of environments of the two groups of children, 91 per cent of the delinquents were unhappy and discontented in their life-circumstances or extremely disturbed by emotion-provoking experiences or situations. Only 13 per cent of the control cases displayed similar inner stresses. Although many of the delinquent subjects showed more than one type of maladjustment, the list of emotional difficulties they experienced was a disturbing one. The delinquent children, in contrast to their non-delinquent counterparts, felt rejected, deprived, insecure, and not understood by others. They had intense feelings of being thwarted in their need for self-expression and experienced a strong sense of inadequacy or inferiority. Confusion, unhappiness, and guilt also characterized these children. For those non-delinquent children who gave evidence of possessing a similar degree of emotional discomfort, there seemed always to have been a set of counterbalancing satisfactions which blunted the edge of their distress. A study such as this is highly descriptive of the personality correlates of delinquency but does not speak to the issue of causation. The enigma of non-delinquency is at least as great as that of delinquency.

The delinquent child, deprived of appro- priate models in his neighborhood or reward and emotional support from his parents, gains even less gratification from his daily contact with school and the process of education. Although the average intelligence of delinquents is slightly lower than that of the non-delinquent, it is not significantly lower to account for their delinquency or their negative reaction to schooling (269). The typical delinquent is non-verbal, nonintellectual, and rejects traditional school subjects of any sort. This rejection of academic endeavor soon causes him to be held back in grade until, before long, he finds himself the biggest, oldest, most hostile, and least interested member of the class. His response to failure to achieve in a situation from which there is no prolonged escape is uniformly an aggressive one, and it takes the teacher as its target. This hostile action tends to be returned in kind by the teacher, and her rejection is congruent with all the other experiences of his life. As his hostility mounts, the punishment for it increases accordingly, and he is driven to find an escape from the intolerable situation through the defiance of truancy. Running away usually occurs after a long history of aggressive misconduct and always plunges the child deeper into his battle with rules and regulations. A truant child argues, with considerable logic, that his aggressive actions are provoked by the hopeless situation that society forces on him, but this reasoning falls on deaf ears. There is a world of adults and a world of children, with no provision for those who do not fit comfortably into either. When the delinquent child leaves school at the earliest legal age, he seldom finds that he has improved his lot. It is more likely that a feeling of helplessness will be added to his existing anger when he discovers that he is not accepted as an equal in the world of workingmen and he can no longer retreat to the world of his age mates 
that he left behind. To solve this dilemma, he will buy (or sometimes steal) a car, which is the badge of manhood and independence, and then hang around the fringes of the educational system while immune from its influence. It is clear that he has a personal problem made worse by society.

\section{THEORETICAL VIEWS OF DELINQUENCY}

The history of theories about the causes of delinquency has undergone some interesting variations. In very early times, disordered behavior of any sort was ascribed to possession by demons and evil spirits, and treatment amounted to exorcising the devil within. Then the notion appeared that antisocial activity was a consequence of inheritance and that such persons could be described as physical types distinguishable from the average citizen's characteristics. The hypothesis that criminals were subhuman types was abandoned when measurement of the physical characteristics of prisoners failed to demonstrate reliable and valid differences from the normal population. Similarly, the development of dependable intelligence tests dissolved the hope that hostile actions against society could be attributed to defective mentality. Next, extensive exploration of the environment of the delinquent uncovered the fact that he was likely to be immersed in surroundings which were unhealthy from the point of view of conformity to society's dictates. The miserable homes, neighborhoods, and living conditions of the delinquents were, for several decades, held to be the cause of antisocial behavior. The cry to clear out the slums which breed delinquency is still heard, but its call is less strident. The embarrassing fact became apparent that, from this same barren and wretched soil, grew honest persons who managed their aggressive impulses easily and, occasionally, a model leader of men who exceeded the per- sonal growth of those growing in more lush and fertile areas. Somehow, for such persons, an internalization of non-delinquent values must occur, which values, if established early enough, serve as an insulator against delinquency (331). The current emphasis in the theory of delinquency is placed on considerations of personality development issuing from the treatment that the child receives from his family and in the setting of school, home, and neighborhood. The modern approach to the puzzle of delinquency allows researchers to consider the multiple influences on a child's life and to bind these influences into a coherent pattern that makes up the individual personality (36).

In one sense, delinquency needs no explanation. If it is a particular way of integrating interpersonal relations to avoid anxiety and if the delinquent lives in a loveless world where relationships bring pain and disappointment, then he may have no choice but to define his world as one in which motivation is based only on reward and punishment and not on deep relations with others (47). Delinquency can be a satisfying pattern of life, since it may provide the delinquent with gratification for his needs and impulses with the least possible delay and simultaneously allow him to express his anger and contempt for those who have rejected and neglected him. For many delinquents, this way of life is pursued enthusiastically, not furtively, and the sense of accomplishment and achievement that they experience is indistinguishable from that issuing from a socially acceptable way of life.

Any discussion of social aggression must discriminate between adaptive and maladaptive forms of the phenomenon (204, 205). Delinquency, when adaptive, is goaloriented, requires careful planning and skilled, determined action. Some varieties 
of delinquent activity-confidence games, for example-require a high order of perceptual skill to detect the greed and larceny in the heart of potential suckers in order to lure them into a shady deal and bilk them in the process. If delinquency is sanctioned by the group code or the model with whom the delinquent is identified, it is adaptive and demands as much effort as a nondelinquent way of life.

Maladaptive delinquency differs from the adaptive version by being not the seeking of a goal but a renunciation of any goal and disorganization punctuated by violence. This kind of disorganization occurs, according to N. R. F. Maier $(246,247)$, when an original goal is abandoned and frustrated behavior-behavior without a goal-takes its place. Maier gives the example of a man standing in line to purchase a railroad ticket who gets in a fight with someone who pushes in ahead of him. As a result, both men get arrested, and neither makes his train. The original need remains unsatisfied, and the fighting was not ticket-getting behavior. The person who is frustrated still has his original goal, but his behavior is no longer contributing to his achievement of that goal. For some of the most severe delinquents, life is a continuous response to frustration and is, essentially, not goal-directed but driven by anxiety and frustration from one hostile act to another (185, 222, 336). Maladaptive delinquency represents a failure of personal and social controls over aggressiveness, and its results are as tragic for the individual as they are for society (337).

There have been a number of attempts to segment the problem of understanding delinquency and to break it down to a manageable size by classifying delinquents according to types. Typical of these attempts is the modified psychoanalytic system of Abrahamsen (1). He lists a series of types of delinquency that merits description here. One group of offenders is that designated as momentary. He pointed out that they might also be called "situational," "accidental," or "associational" offenders. They may be pressed to the delinquent act by the urging of companions, or they may capitalize on a particularly seductive opportunity that presents itself. Keys left in the ignition of an automobile may be the only inducement needed to provoke the antisocial behavior, and, when apprehended, the violator may feel intensely guilty over his act. This type of delinquency does not arise from the depths of rage and antagonism; it is frequently an expression of resentfulness and spite that is more temporary and superficial.

Another type, according to Abrahamsen, is the neurotic offender whose compulsive stealing or fire-setting is an expression of personal conflict in the individual's life. Almost any form of neurosis may evolve in such a way that antisocial or destructive acts come to be the principal form in which the symptoms manifest themselves. It is as if the aggressive behavior is almost a dynamic accident in the individual's psychic economy.

A complex category is that of persons whose unconscious guilt feelings impel them to aggress against others in order to be punished for crimes which they feel they have committed in their childhood. These unconscious "crimes" may be no more serious than the resentment they felt toward their mother at an early age. Since these feelings are unconscious, they furnish motivation of which the person is unaware and cannot control. Abrahamsen (1) feels that these delinquent or criminal types may betray themselves in the act of committing crimes by leaving a clue that will insure their detection. The punishment they then receive reduces the devouring guilt they have experienced for a lifetime. When reading ac- 
counts of just such events in the newspapers, we usually attribute such acts to accident or stupidity on the part of the offender, but it goes much deeper than that psychologically.

A further class of delinquency can originate in character disorder. Such persons are free of the usual neurotic symptoms because aggressive actions and antisocial behavior are a part of their very way of life. The list of their crimes may be extensive, and they suffer little guilt over them-remorse, perhaps, and fear of punishment but not guilt as it is usually defined. In the course of the formation of the individual's character, the lack of a close and meaningful relationship with the parents produces, in essence, a defect of conscience such that his impulses may dominate his life and his character may become defiant, egotistic, and lacking in responsibility. With little regard for the feelings or wishes of others, coupled with a calculated capacity to ingratiate himself for his own ends, he reacts like a cunning and undisciplined child limited only by the possibility that he might get caught breaking the law.

Two other types of delinquent have been described. The true psychopath (true, to differentiate him from other disorders that at times are labeled as psychopaths) and the psychotic aggressor. In both instances the behavior is marked by primitive, impulsive, and violent evidences of civilization's failure. The psychopath fails to develop beyond this subhuman emotional level, and the psychotic reacts to a logic that no longer matches that of others in the population. The psychopath seeks no justification for his actions and feels the need for none. The psychotic may interpret his aggressions to make them more meaningful to himself, but his rationalizations are the product of a sick mind. In some respects, these types are the most dangerous to organized social living.
Descriptions of personality types are convenient methods of differentiating human behavior in order better to understand it, but any system of types must violate the individuality that we know humans to possess. There is probably no case that can be classified into a type category with absolute accuracy and certainly no case about which all authorities would ever agree.

Some research has been directed to the early detection of potential delinquents, in an attempt to predict their behavior before it becomes a fixed response to frustration (141, 142). First offenses of delinquents may occur as early as the age of four, and, by twelve years of age, nearly 90 per cent of the delinquents have taken their first steps on the road to an adult criminal career. The problem of prediction is that at one time or another almost every child engages in delinquent behavior in some form. A great deal of this behaivor goes undetected, and, of course, every child caught stealing from the dime store is not a potential public enemy. No sure way has yet been devised to separate delinquent from non-delinquent children before they have displayed continued and clear delinquent behavior.

The core of hostility in the dynamics of delinquency is best revealed in the detailed accounts of the close observation of such children by Redl and Wineman $(332,333)$.

In Pioneer House in Detroit, delinquent and antisocial children were given therapy by a staff of workers who lived with them and helped them manage their daily conflicts. In the accounts of this classic and heroic effort at rehabilitation, it was evident that rage was the prime mover of delinquent children. The title of one of the books (Children Who Hate) is an apt description of the core of delinquency, while the title of the other (Controls from Within) reflects the necessary goal of any therapeutic effort. 
These books are a storehouse of comment and observation on the inevitable entanglement of aggression and civilized existence. In delinquency we can see the squabbles of the nursery school magnified almost beyond human comprehension.

\section{Epilogue}

An epilogue is defined as a concluding section serving to complete the plan of the work. The most appropriate conclusion might be to repeat the opening sentence of the monograph: "In man's attempt to apply the scientific method to human affairs, the study of aggression has commanded an inordinate amount of the energy of social scientists." Viewing the crucial role that hostility and conflict play in every aspect of human affairs, it is clear that an ordinate, rather than inordinate, amount of the energy of social scientists is being expended in the quest for greater understanding of man's impulsive nature and the control of his aggression.

There is one final observation that must be made to underscore the urgency of the need for a workable means of resolving conflict. The threat to mankind posed by the invention of new and exotic lethal weapons has obscured the much more fundamental and widespread change which is taking place in the early experience of children. The massive studies of middle- and lowerclass family life in Western society have prepared us to deal more intelligently with familiar forms of aggression which spring from the child's relationship to his parents, but what of the aggressions which may result from patterns of early experience which only faintly resemble Western family life? The Kibbutz, the Commune, and other designs for group and community rearing of children are engulfing an ever increasing proportion of the child population of the world and are altering the psychic structure of the child in unpredictable ways. The dimensions of aggression which are being nurtured in these early experiences are unknown quantities which will inevitably force their own day of reckoning. Subtle changes in the emotional organization of children bring about steady and almost imperceptible changes in the course of the future of mankind. They are like psychological time bombs which are set to explode twenty years after the mechanism is primed; yet the sound of the ticking has not alarmed us.

There are many hazards and obstacles in the study of patterns of child-rearing other than that of the traditional family circle in Western society, but the need for such exploratory work was never greater. In terms of the resolution of human conflict, it is later than we think.

\section{REFEREN CES}

1. Agrahamsen, D. Crime and the Human Mind. New York: Columbia University Press, 1944.

2. Adorno, T. W., Frenkel-Brunswik, E., Levinson, D. J., and SANFond, R. N. The Authoritarian Personality. New York: Harper \& Bros., 1950.

3. Albee, G. W. "Patterns of Aggression in Psychopathology," Journal of Consulting Psychology, XIV (1950), 465-68.

4. AlexANDER, F. Psychoanalysis of the Total Personality. ("Nervous and Mental Disease Monograph Series," No. 52.) New York: Nervous and Mental Disease Pub. Co., 1929.

5. - - . "Peace Aims," American Journal of Orthopsychiatry, XIII (1943), 571-81.

6. ---. "A World without Psychic Frustration," American Journal of Sociology, XLIX (1944), 465-69.

7. Alexander, F., and Menninger, W. C. "The Relation of Persecutory Delusions to the Functioning of the Gastro-intestinal Tract," Journal of Nervous and Mental Disease, LXXXIV (1936), 541-54.

8. AlLEN, F. H. "Aggression in Relation to Emotional Development, Normal and Pathological," Mental Hygiene, XXXIV (1950), 353-62. 
9. Alpert, H. "Suicides and Homicides," American Sociological Review, XV (1950), 673.

10. Ammons, Carol H., and Ammons, R. B. "Aggression in Doll-Play: Interviews of Two- to Six-Year-Old White Males," Journal of Genetic Psychology, LXXVIII (1953), 205-13.

11. Anastasi, Anne. "A Methodological Note on the 'Controlled Diary' Technique," Journal of Genetic Psychology, LXXIII (1948), 237-41.

12. Anastasi, Anne, Cohen, Nadia, and Spatz, Dorothy. "A Study of Fear and Anger in College Students through the Controlled Diary Method," Journal of Genetic Psychology, LXXIII (1948), 243-49.

13. Anderson, H. H., and Brewer, J. E. Studies of Teachers' Classroom Personalities. I. Dominative and Socially Integrative Behavior of Kindergarten Teachers. ("Psychological Monographs," No. 6.) 1945.

14. - - Studies of Teachers' Classroom Personalities. II. Effects of Teachers' Dominative and Integrative Contacts on Children's Classroom Behavior. ("Psychological Monographs;" No. 8.) 1946.

15. Anderson, H. H., Brewer, J. E., and Reed, M. F. Studies of Teachers' Classroom Personalities. III. Follow-Up Studies of the Effects of Dominative and Integrative Contacts on Children's Behavior. ("Psychological Monographs, No. 11.) 1946.

16. Appel, M. H. "Aggressive Behavior of Nursery School Children and Adult Procedures in Dealing with Such Behavior," Journal of Experimental Education, XI (1942), 185-99.

17. Ascher, E. "A Criticism of the Concept of Neurotic Depression," American Journal of Psychiatry, CVIII (1952), 901-8.

18. Ausubet, D. P. "Negativism as a Phase of Ego Development," American Journal of Orthopsychiatry, XX (1950), 796-805.

19. Ax, A. F. "The Physiological Differentiation between Fear and Anger in Humans," Psychosomatic Medicine, XV (1953), 43342.

20. BACH, G. R. "Father-Fantasies and Fathertyping in Father-separated Children," Child Development, XVII (1946), 63-80.

21. Bacon, Catherine L. "The Role of Aggression in the Asthmatic Attack," Psychoanalytic Quarterly, XXV (1956), 309-24.
22. Baldwin, A. L., Kalhoun, Joan, and Breese, Fay H. Patterns of Parent Behavior, p. 58 ("Psychological Monographs," No. 3.) 1945.

23. Banay, R. S. "Study of a Murder for Revenge," Journal of Criminal Psychopathology, III (1941), 1-10.

24. Barker, R., Dembo, T., and Lewin, K. Frustration and Regression: An Experiment with Young Children. ("University of Iowa Studies in Child Welfare, XVIII, No. 1.) 1941.

25. Barnes, H. E., and Teeters, N. K. New Horizons in Criminology. New York: Prentice-Hall, Inc., 1951.

26. Baruch, Dorothy W. "A Study of Reported Tension in Interparental Relationships as Co-existent with Behavior Adjustment in Young Children," Journal of Experimental Education, VI (1937), 187-204.

27. - - . "Aggression during Doll Play in a Preschool," American Journal of Orthopsychiatry, XI (194I), 252-60.

28. BAtchelor, I. R. C. "Management and Prognosis of Suicidal Attempts in Old Age," Geriatrics, X (1955), 291-93.

29. Batchelor, I. R. C., and Napier, MargaRET B. "The Sequelae and Short-Term Prognosis of Attempted Suicide," Journal of Neurology, Neurosurgery, and Psychiatry, XVII (1954), 261-66.

30. Bathurst, J. E. "A Study in Sympathy and Resistance (Negativism) among Children," Psychological Bulletin, XXX (1933), 625.

31. Beaglehole, E. "Culture and Psychosis in New Zealand," Journal of Polynesian Sociology, XLVIII (1939), 144-55.

32. Beaver, A. P. The Initiation of Social Contacts by Preschool Children: A Study of Technique in Recording Social Behavior. ("Child Development Monographs," No. 7.) 1932.

33. BeEman, E. A. "The Effect of Male Hormone on Aggressive Behavior in Mice," Physiological Zoölogy, XX (1947), 373405.

34. Bender, Launetta. "Psychiatric Mechanisms in Child Murderers," Journal of Nervous and Mental Disease, LXXX (1934), 32-47.

35. - - . "The Treatment of AggressionRound Table. III. Aggression in Childhood," American Journal of Orthopsychiatry, XIII (1943), 392-99. 
36. ---. Aggression, Hostility, and Anxiety in Children. Springfield, Ill.: Charles C Thomas, 1953.

37. Bender, Lauretta, and Curran, F. J. "Children and Adolescents Who Kill," Journal of Criminal Psychopathology, I (1940), 297-322.

38. Bender, Launetta, and Schilder, P. "Suicidal Preoccupations and Attempts in Children," American Journal of Orthopsychiatry, VII (1937), 225-34.

39. Benedict, P. K., and Jacks, I. "Mental Illness in Primitive Societies," Psychiatry, XVII (1954), 377-89.

40. Benjamin, J. D. "Methodological Considerations in the Validation and Elaboration of Psychoanalytic Personality Theory," American Journal of Orthopsychiatry, XIX (1949), 342-50.

41. Berdie, R. F. "Playing the Dozens," Journal of Abnormal and Social Psychology, XLII (1947), 120-21.

42. Berg, I. A., and Fox, V. "Factors in Homicides Committed by 200 Males," Journal of Social Psychology, XXVI (1947), 109-19.

43. Berkowitz, L. "The Expression and Reduction of Hostility," Psychological Bulletin, LV (1958), 257-83.

44. Bettelheim, B. "Individual and Mass Behavior in Extreme Situations," Journal of Abnormal and Social Psychology, XXXVIII (1943), 417-52.

45. BIEBER, I. "The Meaning of Masochism," American Journal of Psychotherapy, VII (1953), 433-48.

46. BILIIG, A. L. "Finger Nail-biting: Its Incipiency, Incidence, and Amelioration," Genetic Psychological Monographs, XXIV (1941), 123-218.

47. Bцосн, D. A. "The Delinquent Integration," Psychiatry, XVI (1952), 297-303.

48. Block, Jeanne, and Martin, B. "Predicting the Behavior of Children under Frustration," Journal of Abnormal and Social Psychology, LI (1955), 281-85.

49. BLuM, G. S. "Defense Preferences in Four Countries," Journal of Projective Techniques, XX (1956), 33-41.

50. Body, Margaret K. "Patterns of Aggression in the Nursery School," Child Development, XXVI (1955), 5-11.

51. Bonsfield, W. A., and Orbison, W. D. "Ontogenesis of Emotional Behavior," Psychological Review, LIX (1952), 1-7.
52. Bornston, Frieda L., and Coleman, J. C. "The Relationship between Certain Parents" Attitudes toward Child Rearing and the Direction of Aggression of Their Young Adult Offspring," Journal of Clinical Psychology, XII (1956), 41-44.

53. Bramwell, M. J. Hypnotism: Its History, Practice, and Theory. Philadelphia: J. B. Lippincott Co., 1930.

54. Brenman, M. "Experiments in the Hypnotic Production of Anti-social and Selfinjurious Behavior," Psychiatry, V (1942), 49-61.

55. Bridgeman, O. "Four Young Murderers," Journal of Juvenile Research, XIII (1929), 20-27.

56. Bromberg, W., and Rodgers, T. E. "Authority in the Treatment of Delinquents," American Journal of Orthopsychiatry, XV (1946), 672-85.

57. BuHLER, C. "The Social Behavior of Children." In C. Murchrson (ed.), A Handbook of Child Psychology, chap. ix, pp. 374-416. 2d ed. Worcester, Mass.: Clark University Press, 1933.

58. Burlingham, Dorothy. "Notes on Problems of Motor Restraint during Illness." In Rudolph M. Loewenstein (ed.), Drives, Affects, and Behavior, pp. 169-75. New York: International Universities Press, Inc., 1953.

59. Burton, A. "The Aggression of Young Children Following Satiation," American Journal of Orthopsychiatry, XII (1942), 262-67.

60. Buss, A. H., and DurkeE, AnN. "An Inventory for Assessing Different Kinds of Hostility," Journal of Consulting Psychology, XXI ( 1957), 343-49.

61. Buss, A. H., Durkee, AnN, and Baer, M. B. "The Measurement of Hostility in Clinical Situations," Journal of Abnormal and Social Psychology, LII (1956), 84-86.

62. Buxbaum, Edith. "Activity and Aggression in Children," American Journal of Orthopsychiatry, XVII (1947), 161-66.

63. Byrne, D. "The Relationship between Humor and the Expression of Hostility," Journal of Abnormal and Social Psychology, LIII (1956), 84-89.

64. Caille, R. K. "Resistant Behavior of Preschool Children," Child Development Monographs, XI (1933), 1-42.

65. Cameron, D. E. "The Conversion of Passivity into Normal Self-Assertion," Ameri- 
can Journal of Psychiatry, CVIII (1951), 98-102.

66. Cannon, W. B. Bodily Changes in Pain, Hunger, Fear, and Rage. New York: D. Appleton \& Co., 1920.

67. Carothers, J. C. "A Study of Mental Derangement in Africans, and an Attempt To Explain Its Peculiarities, More Especially in Relation to the African Attitude to Life," Journal of Mental Science, III (1947), 548-97.

68. Cavan, Ruth S. Suicide. Chicago: University of Chicago Press, 1928.

69. Child, I. L., Potter, E. H., and Levine, E. M. Children's Textbooks and Personality Development: An Exploration in the Social Psychology of Education. ("Psychological Monographs," No. 3.) 1946.

70. Child, I. L., and Waterhouse, I. K. "Frustration and the Quality of Performance. I. A Critique of the Barker, Dembo, and Lewin Experiment," Psychological Review, LIX (1952), 351-62.

71. Chittenden, G. E. "An Experimental Study in Measuring and Modifying Assertive Behavior in Young Children," Monograph of Society for Research in Child Development, VII (1942), 1-81.

72. Clark, G., and Birch, H. G. "Hormonal Modification of Social Behavior," Psychosomatic Medicine, VII (1945), 321-29.

73. Cleveland, S. E. "Three Cases of SelfCastration," Joumal of Nervous and Mental Disease, CXXIII (1956), 386-91.

74. CoHen, A. R. "Social Norms, Arbitrariness of Frustrations, and Status of the Agent of Frustration in the Frustration-Aggression Hypothesis," Journal of Abnormal and Social Psychology, L (1955), 222-26.

75. Conen, F. "Hostility and Psychotic Symptoms," Psychiatric Quarterly, XXVIII (1954), 264-78.

76. Coleman, J. C., and McCalley, Jean E. "Nail Biting among College Students," Journal of Abnormal and Social Psychology, XLIII (1948), 517-25.

77. Colom, G. A., and Levine, M. H. "Selfinflicted Pre-frontal Lobotomy: Report of a Case," Journal of Nervous and Mental Disease, CXIII (1951), 430-36.

78. Conklin, E. S. Principles of Adolescent Psychology. New York: Henry Holt \& Co., 1935.
79. Counts, R. M., and Mensh, I. N. "Personality Characteristics in Hypnotically-induced Hostility," Journal of Clinical Psychology, VI (1950), 325-30.

80. Croft, I. J., and Grygier, T. G., "Social Relationships of Truants and Juvenile Delinquents," Human Relations, IX (1956), $499-66$.

81. Davis, A. "American Status Systems and the Socialization of the Child," American Sociological Review, VI (1941), 345-54.

82. Davis, A., and Havighurst, R. J. "Social Class and Color Differences in Child Rearing," American Sociological Review, XI (1946), 698-710.

83. Davitz, J. R. "The Effects of Previous Training on Post-Frustration Behavior," Journal of Abnormal and Social Psychology, XLVII (1952), 309-15.

84. Dawe, H. C. "An Analysis of Two Hundred Quarrels of Preschool Children," Child Development, V (1934), 139-57.

85. Despert, J. Louise. "Schizophrenia in Children," Psychiatric Quarterly, XII (1938), 366-71.

86. - - . "Suicide and Depression in Children," Nervous Child, IX (1952), 378-89.

87. Deutsch, A. Our Rejected Children. Boston: Little, Brown \& Co., 1950.

88. Deutsch, Helene. Psychoanalysis of the Neuroses. ("International Psychoanalytical Library," No. 23.) London: Hogarth Press, 1932.

89. D'Evelyn, Katherine. Meeting Children's Emotional Needs. Englewood Cliffs, N.J.: Prentice-Hall, Inc., 1957.

90. Devereaux, G. "Mohave Indian Infanticide," Psychoanalytic Review, XXXV (1948), 126-39.

91. Dollard, J., Doob, L. W., Miller, N. E., Mowrer, O. H., Sears, R. R., Ford, C. S., Hovland, C. I., and Sollengerger, R. T. Frustration and Aggression. New Haven: Yale University Press, 1939.

92. Doob, L. W., and Sears, R. R. "Factors Determining Substitute Behavior and Overt Expression of Aggression," Journal of Abnormal and Social Psychology, XXXIV (1939), 293-313.

93. Dublin, L. I., and Bunzel, B. To Be or Not To Be: A Study in Suicide. New York: Smith \& Haas, 1933.

94. Dunnington, Margaret J. "Behavioral Differences of Sociometric Status Groups 
in a Nursery School," Child Development, XXVIII (1957), 103-11.

95. Dunkheim, E. Suicide. Translated by John A. Spaulding and George Simpson. Glencoe, Ill.: Free Press, 1951.

96. Duvall, E. M. "Conceptions of Parenthood," American Journal of Sociology, LII (1946), 193-203.

97. Eaton, J. W., and Weil, R. J. "The Mental Health of the Hutterites," Scientific American, CLXXXIX (1953), 31-37.

98. EgGan, Donotry. "The General Problem of Hopi Adjustment," American Anthropologist, LV (1943), 357-73.

99. EIssLer, Ruth S. "Riots: Observations in a Home for Delinquent Girls," Psychoanalytic Study of the Child, III/IV (1949), 449-61.

100. Elurs, H. Studies in the Psychology of Sex. New York: Random House, 1936.

101. Epstein, S., and Smith, R. "Repression and Insight as Related to Reaction to Cartoons," Journal of Consulting Psychology, XX (1956), 391-95.

102. Errckson, M. H. "An Experimental Investigation of the Possible Anti-social Use of Hypnosis," Psychiatry, II (1939), 391-414.

103. - - . "Experimental Demonstrations of the Psychopathology of Everyday Life," Psychoanalytic Quarterly, VIII (1939), 338-53.

104. Erixson, E. Childhood and Society. New York: W. W. Norton \& Co., 1950.

105. Esman, A. H. "A Case of Self-Castration," Journal of Nervous and Mental Disease, CXX (1954), 79-82.

106. Estabrooks, G. H. Hypnotism. New York: E. P. Dutton, Inc., 1944.

107. - - . "The Possible Antisocial Use of Hypnotism," Personality, I (1951), 294-99.

108. Ezexiel, L. F. "Changes in Egocentricity of Nursery-School Children," Child Development, II (1931), 74-75.

109. FARBER, L. "Psychoanalytic Hypotheses in the Study of War," Journal of Social Issues, XI (1955), 29-35.

110. - - - "The Anal Character and Political Aggression," Journal of Abnormal and Social Psychology, LI (1955), 486-89.

111. Farberow, N. L. "Personality Patterns of Suicidal Mental Hospital Patients," Genetic Psychological Monographs, XLII (1950), 3-79.

112. Farrar, C. B. "Suicide," Journal of Clini- cal and Experimental Psychopathology, XII (1951), 79-88.

113. Fauqien, W. "The Attitudes of Aggressive and Submissive Boys toward Athletics," Child Development, XI (1940), 115-25.

114. Feldman, Dorothy A., Pascal, G. R., and Swenson, C. H. "Direction of Aggression as a Prognostic Variable in Mental Illness," Journal of Consulting Psychology, XVIII (1954), 167-70.

115. Fenichel, O. "The Clinical Aspect of the Need for Punishment," International Journal of Psychoanalysis, IX (1928), 47-70.

116. Feshbach, S. "The Drive-reducing Function of Fantasy Behavior," Journal of $A b$ normal and Social Psychology, LI (1955), 3-11.

117. - - . "The Catharsis Hypothesis and Some Consequences of Interaction with Aggressive and Neutral Play Objects," Journal of Personality, XXIV (1956), 449-62.

118. FidLer, R. F. “A Psychiatric Review of Fifty Cases of Gunshot Wounds Self-inflicted," Journal of Mental Science, XCIV (1948), 565-74.

119. Fiscr, M. "The Suicidal Gesture: A Study of 114 Military Patients Hospitalized because of Abortive Suicide Attempts," American Journal of Psychiatry, CXI (1954), 33-36.

120. Fite, M. D. "Aggressive Behavior in Young Children and Children's Attitudes toward Aggression," Genetic Psychological Monographs, XXII (1940), 151-319.

121. Fond, C. S., and BeAch, F. H. Patterns of Sexual Behavior. New York: Harper \& Bros., 1951.

122. Foster, S. "A Study of the Personality Make-Up and Social Setting of Fifty Jealous Children," Mental Hygiene, XI (1927), 53-77.

123. Fowler, Claire. "Suicide as a Symptom of Neurotic Conflict in Children," Smith College Studies in Social Work, XIX (1949), 136-37.

124. Frankel, E. "One Thousand Murders," Journal of Criminal Law and Criminology, XXIX (1939), 672-88.

125. Frazee, Helen Elizabeth. "Children Who Later Become Schizophrenic," Smith College Studies in Social Work, XXIII (1953), 125-49.

126. Frederiksen, N. "The Effects of Frustration on Negativistic Behavior of Young 
Children," Journal of Genetic Psychology, LXI ( 1942), 203-26.

127. French, J. R. P. “Organized and Unorganized Groups under Fear and Frustration." In K. Lewin, C. E. Meyers, J. Kalhoun, and M. L. Farber (eds.), Authority and Frustration. ("University of Iowa Studies in Child Welfare.") Iowa: University of Iowa Press, 1944.

128. Frenkel-Brunswix, Elsa. "A Study of Prejudice in Children," Human Relations, I (1948), 295-306.

129. Freud, ANNA. The Ego and the Mechanisms of Defence. ("International Psychoanalytical Library.") London: Hogarth Press, 1937.

130. Freud, S. The Economic Problem in Masochism. In Collected Papers, XXII (1924), 255-68. ("International Psychoanalytical Library," Vol. II, No. 8.) London: Hogarth Press, 1921.

131. - - Civilization and Its Discontents. New York: Jonathan Cape \& Harrison Smith, 1930.

132. Mourning and Melancholia. In Collected Papers, Vol. IV. London: Hogarth Press, 1950.

133. Fried, Edrita. "Benefits of "Combined Therapy' for the Hostile Withdrawn and the Hostile Dependent Personality," American Journal of Orthopsychiatry, XXIV (1954), 529-37.

134. Gardner, G. E. "The Community and the Aggressive Child: The Expression of the Aggressive-destructive Impulses in Juvenile Delinquent Acts," Mental Hygiene, XXXIII (1949), 537-50.

135. Gates, G. S. "An Observational Study of Anger," Journal of Experimental Psychology, IX (1926), 325-36.

136. Gerard, D. L., and Sieger, J. "The Family Background of Schizophrenia," Psychiatric Quarterly, XXIV (1950), 46-73.

137. Gerard, Margaret W. "The Psychogenetic Tic in Ego Development," Psychoanalytic Study of the Child, II (1948), 133-62.

138. Ginsburg, B., and Allee, W. C. "Some Effects of Conditioning on Social Dominance and Subordination in Inbred Strains of Mice," Physiological Zoölogy, XV (1942), 485-506.

139. GLUCK, M. R. "The Relationship between Hostility in the TAT and Behavioral Hos- tility," Journal of Projective Techniques, XIX (1955), 21-26.

140. - - . "Rorschach Content and Hostile Behavior," Journal of Consulting Psychology, XIX (1955), 475-78.

141. Glueck, S., and Glueck, Eleanor. One Thousand Juvenile Delinquents. Cambridge: Harvard University Press, 1934.

142. - - Unraveling Juvenile Delinquency. New York: Commonwealth Fund, 1950.

143. Gortein, P. L. "Mind of a Murderer," Journal of Criminal Psychopathology, III (1942), 625-47.

144. Goldfarb, W. "Infant Rearing and Problem Behavior," American Journal of Orthopsychiatry, XIII (1943), 249-66.

145. - - "The Effects of Early Institutional Care on Adolescent Personality," Journal of Experimental Education, XII (1943), 106-29.

146. - - . "Infant Rearing as a Factor in Foster Home Placement," American Journal of Orthopsychiatry, XIV (1944), 162-67.

147. - - . "Psychological Privation in Infancy and Subsequent Adjustment," ibid., XV (1945), 247-55.

148. Golichily, C. L., and SCheffrer, I. "Playing the Dozens," Journal of Abnormal and Social Psychology, XLIII (1948), 104-5.

149. Goldprank, E. S. "Historic Change and the Social Character: A Study of the Teton Dakota," American Anthropologist, LV (1943), 67-83.

150. Goodenough, Flonence. Anger in Young Children. ("Institute of Child Welfare Monograph Series," Vol. IX.) Minneapolis: University of Minnesota Press, 1931.

151. Goonstein, L. "Interrelationships among Several Measures of Anxiety and Hostility," Journal of Consulting Psychology, XVIII (1954), 35-39.

152. Gordon, A. L. "Frustration and Aggression among Jewish University Students," Jewish Social Studies, V (1943), 27-43.

153. Gough, H. G., Harris, D. B., Martin, W. E., and Edwards, M. "Children's Ethnic Attitudes. I. Relationship to Certain Personality Factors," Child Development, XXI (1950), 83-91.

154. Grace, H. A. "Hostility, Communication, and International Tension. I. The Hostility Inventory," Jonrnal of Social Psychology, XXXIV (1951), 31-40.

155. Graham, Frances K, Charwat, Wanda 
A., Honig, Alice S., and Weltz, P. C. "Aggression as a Function of the Attack and the Attacker," Journal of Abnormal and Social Psychology, XLVI (1951), 512-20.

156. Grant, V. W. "Anger Reactions in Paranoids," Journal of Clinical Psychology, X (1954), 275-79.

157. Green, A. W. "The Middle-Class Male Child and Neurosis," American Sociological Review, XI (1946), 31-41.

158. Green, E. H. "Friendships and Quarrels among Preschool Children," Child Development, IV (1933), 237-52.

159. - - "Croup Play and Quarreling among Preschool Children," ibid., pp. 302-7.

160. Greene, J. E. "Motivations of a Murderer," Journal of Abnormal and Social Psychology, XLIII (1948), 526-31.

161. Grziwor, R., and Scodel, A. "Some Psychological Correlates of Humor Preference," Journal of Consulting Psychology, XX (1956), 42.

162. Haggard, E. A., and Freeman, G. I. "Reactions of Children to Experimentally Induced Frustration," Psychological Bulletin, XXXVIII (1941), 581.

163. Hall, MUriel Barton. "Our Present Knowledge about Manic-depressive States in Childhood," Nervous Child, IX (1952), 319-25.

164. Halliburton, J. K. "A Note on the Resolution of Aggressive Impulses through Creative-destructive Activity," Occupational Therapy, XXIII (1944), 284-95.

165. Hallowell, A. I. "Aggression in Saulteaux Society," Psychiatry, III (1940), 395-407.

166. Haner, C. F., and Brown, Patricia ANn. "Clarification of the Instigation to Action Concept in the Frustration-Aggression $\mathrm{Hy}$ pothesis," Journal of Abnormal and Social Psychology, L (1955), 204-6.

167. Harlan, H. "Five Hundred Homicides," Journal of Criminal Law and Criminology, XL (1950), 736-52.

168. Harms, E. "The Problem of Depressive and Manic Sickness in Childhood," Nervous Child, IX (1952), 310-16.

169. - - . "Differential Pattern of Manic-depressive Disease in Childhood," ibid., pp. 326-56.

170. Harris, D. B., Gough, H. G., and Martin, W. E. "Children's Ethnic Attitudes. II. Relationship to Parental Beliefs concerning
Child Training," Child Development, XXI (1950), 169-81.

171. Harris, I. D. "Mood, Anger, and Somatic Dysfunction," Journal of Nervous and Mental Disease, CXIII (1951), 152-58.

172. HaRT, H. H. "Sublimation and Aggression," Psychiatric Quarterly, XXII (1948), 389412.

173. Hatrwick, B. W. "Interrelations between the Preschool Child's Behavior and Certain Factors in the Home," Child Development, VII (1936), 200-226.

174. Hatrwick, L. A. "Sex Difference in Behavior of Nursery School Children," Child Development, VIII (1937), 343-55.

175. Hattwick, L. A., and Saunders, M. K. "Age Difference in Behavior at the Nursery School Level," Child Development, IX (1938), 27-47.

176. Healy, W., and Bronner, A. F. New Light on Delinquency and Its Treatment. New Haven: Yale University Press, 1936.

177. HeмpнiLl, R. E. "A Case of Genital SelfMutilation," British Journal of Medical Psychology, XXIV (1951), 291-95.

178. Hendin, H. "Psychodynamic Motivational Factors in Suicide," Psychiatric Quarterly, XXV (1951), 672-78.

179. HendRICK, I. "Suicide as Wish-Fulfillment," Psychiatric Quarterly, XIV (1940), $30-42$.

180. Henry, A. F., and Shont, J. F., Jr. Suicide and Homicide. Glencoe, Ill.: Free Press, 1954.

181. Henry, E. M., and Rotter, J. B. "Situational Influences on Rorschach Responses," Journal of Consulting Psychology, XX (1956), 457-62.

182. Hertz, Marguerite R. "Suicidal Configurations in Rorschach Records," Rorschach Research Exchange, XII (1948), 3-58.

183. --_. "Further Study of Suicidal Configurations in Rorschach Records," American Psychologist, III (1948), 283-84.

184. - - . "Further Study of 'Suicidal' Configurations in Rorschach Records," Rorschach Records," Rorschach Research Exchange, XIII (1949), 44-73.

185. Hinl, L. B. "The Use of Hostility as Defense," Psychoanalytic Quarterly, VII (1938), 254-64.

186. Himmelweit, Hilde. "Frustration and Aggression: A Review of Recent Experimental Work." In T. H. PeAr, Psychological Fac- 
tors of Peace and War. New York: Philosophical Library, 1950.

187. Hokanson, J. E., and Gondon, J. E. "The Expression and Inhibition of Hostility in Imaginative and Overt Behavior," Journal of Abnormal and Social Psychology, LVII (1958), 327-33.

188. Hollander, B. Methods and Uses of Hypnosis and Self-Hypnosis. New York: Macmillan Co., 1928.

189. Hollenberg, Eleanor, and Sperry, MarGARET. "Some Antecedents of Aggression and Effects of Frustration in Doll Play," Personality, I (1951), 32-43.

190. Holzberg, J. D., Bursten, B., and Santiccroli, A. "The Reporting of Aggression as an Indication of Agressive Tension," Journal of Abnormal and Social Psychology, $\mathrm{L}$ (1955), 12-18.

191. Hora, T. "Masochistic Use of Anxiety," American Journal of Psychotherapy, VII (1953), 449-53.

192. Horney, Karen. New Ways in Psychoanalysis. New York: W. W. Norton \& Co., Inc., 1939.

193. HuLL, C. L. Hypnosis and Suggestibilityan Experimental Approach. New York: D. Appleton-Century Co., 1933.

194. Hurlburt, W. C. "Prosperity, Depressions, and the Suicide Rate," American Journal of Sociology, XXVII (1932), 714-19.

195. HuschKa, Mabel. "The Child's Response to Coercive Bowel Training." In S. ToMpKINs (ed.), Contemporary Psychopathology. Cambridge: Harvard University Press, 1943.

196. - - . "A Study of Training in Voluntary Control of Urination in a Group of Problem Children," Psychosomatic Medicine, V (1943), 254-65.

197. Husman, B. F. "Aggression in Boxers and Wrestlers as Measured by Projective Techniques," Research Quarterly of the American Association for Health and Physical Education, XXVI (1955), 421-25.

198. Hybl, A. R., and Stagner, R. "Frustration Tolerance in Relation to Diagnosis and Therapy," Journal of Consulting Psychol. ogy, XVI (1952), 163-70.

199. Ingram, Winifred. "Prediction of Aggression from the Rorschach," Journal of Consulting Psychology, XVIII (1954), 23-28.

200. Isaacs, Susan. Social Development in
Young Children. New York: Harcourt, Brace \& Co., 1937.

201. JACK, L. M. "An Experimental Study of Ascendant Behavior in Pre-School Children." In L. M. JaCK, E. M. Manwell, and I. G. Mengrer, Behavior of the Preschool Child, pp. 7-65. ("University of Iowa Studies in Child Welfare," Vol. IX.) Iowa City: University of Iowa Press, 1934.

202. James, W. "The Moral Equivalent of War," In Memoirs and Studies. New York: Longmans, Green \& Co., 1911.

203. Jamieson, G. R. "Suicide and Mental Disease: A Clinical Analysis of One Hundred Cases," Archives of Neurology and Psychiatry, XXXVI (1936), 1-12.

204. JENkins, R. L. "The Sense of Guilt and Its Relations to Treatment Work with Offenders," Mental Hygiene, XXVI (1942), 56882.

205. - - "Adaptive and Maladaptive Delinquency," Nervous Child, XI (1955), 9-11.

206. Jersild, A. T., and Fite, M. D. The Influence of Nursery School Experience on Children's Social Adjustments ("Child Development Monographs," No. 25.) New York: Teachers College, Columbia University, 1939.

207. Jersild, A. T., and Markey, F. V. Conficts between Preschool Children. ("Child Development Monographs," No. 1.) New York: Teachers College, Cólumbia University, 1935.

208. Johnson, Adelame M. "Sanctions for Super-Ego Lacunae of Adolescents." In Ruth S. Eissler (ed.), Searchlights on Delinquency. New York: International Universities Press, 1949.

209. Johnson, Adelaide M., and Szurek, S. A. "The Genesis of Anti-social Acting Out in Children and Adults," Psychoanalytic Quarterly, XXI ( 1952), 323-43.

210. Johnson, O. G., and Stanley, J. C. "Attitudes toward Authority of Delinquent and Nondelinquent Boys," Journal of Abnormal and Social Psychology, LI (1955), 712-17.

211. Johnson, W. R., and Hutron, D. C. "Effects of a Combative Sport upon Personality Dynamics as Measured by a Projective Test," Research Quarterly of the American Association for Health and Physical Education, XXVI (1955), 49-53.

212. Jost, J. "Some Physiological Changes dur- 
ing Frustration," Child Development, XII (1941), 9-15.

213. Kagan, J. "The Measurement of Overt Aggression from Fantasy," Journal of Abnormal and Social Psychology, LII (1956), 390-93.

214. KAHN, M. W. "The Effect of Severe Defeat at Various Age Levels on the Aggressive Behavior of Mice," Journal of Genetic Psychology, LXXIX (1951), 117-30.

215. Kallmann, F. J., DePorte, J., DePonte, Elrzabeth, and Feingold, Lissy. "Suicide in Twins and Only Children," American Journal of Human Genetics, I (1949), $113-26$.

216. Kandinen, A. The Individual and His Society. New York: Columbia University Press, 1939.

217. - - . The Psychological Frontiers of Society. New York: Columbia University Press, 1945.

218. Karpman, B. "Aggression," American Journal of Orthopsychiatry, XX (1950), 694-718.

219. - - (chairman). "The Psychopathic Delinquent Child" (Round Table, 1949), American Journal of Orthopsychiatry, XX (1950), 223-65.

220. ---. "A Psychoanalytic Study of a Case of Murder," Psychoanalytic Review, XXXVIII (1951), 139-57.

221. KING, G. F. "Research with Neuropsychiatric Samples," Journal of Psychology, XXXVIII (1954), 383-87.

222. KNIGHT, R. P. "Intimidation of Others as a Defense against Anxiety," Bulletin of the Menninger Clinic, VI (1942), 4-14.

223. KocH, H. L. "Popularity in Pre-School Children: Some Related Factors and a Technique for Its Measurement," Child Development, V (1933), 164-75.

224. Krall, Vita. "Personality Characteristics of Acident Repeating Children," Journal of Abnormal and Social Psychology, XLVIII (1953), 99-107.

225. Kuo, Z. Y. "The Genesis of the Cat's Response to the Rat," Journal of Comparative Psychology, XI (1930), 1-35.

226. LANDER, J. "Traumatic Factors in the Background of 116 Delinquent Boys," American Journal of Orthopsychiatry, XI (1941), $150-57$.

227. Lendrum, F. C. “A Thousand Cases of At- tempted Suicide," American Journal of Psychiatry, XIII (1933), 479-500.

228. LESSER, G. S. "The Relationship between Overt and Fantasy Aggression as a Function of Maternal Response to Aggression," Journal of Abnormal and Social Psychology, LV (1957), 218-21.

229. - - - "Conflict Analysis of Fantasy Aggression," Journal of Personality, XXVI (1958), 29-41.

230. Levin, H., and Sears, R. R. "Identification with Parents as a Determinant of Doll Play Aggression," Child Development, XXVII (1956), 135-53.

231. Levin, M. “Aggression, Guilt, and Catalepsy," American Medical Association Archives of Neurology and Psychiatry, LXIX (1953), 224-35.

232. LEvy, D. M. "Hostility Patterns: Deviations from the 'Unit Act' of Hostility," American Journal of Orthopsychiatry, XIII (1943), $441-62$.

233. - - . "On the Problem of Movement Restraint: Tics, Stereotyped Movements, Hyperactivity," ibid., XIV (1944), 644-71.

234. Lewin, B. D. "Child Psychiatry in the 1830's-Three Little Homicidal Monomaniacs," Psychoanalytic Study of the Child, III/IV ( 1949), 489-93.

235. Lewin, K. A Dynamic Theory of Personality. New York: McGraw-Hill Book Co., Inc., 1935.

236. LewiN, K., LipprtT, R., and White, R. "Patterns of Aggressive Behavior in Experimentally Created 'Social Climates," Journal of Social Psychology, X (1939), 27199.

237. Liebermann, L. P. "Three Cases of Attempted Suicide in Children," British Journal of Medical Psychology, XXVI (1953), 110-14.

238. Lindzey, G., and RieckeN, H. W. "Inducing Frustration in Adult Subjects," Journal of Consulting Psychology, XV (1951), 1823.

239. Lindzex, G., and Tejessy, Charlotte. "Thematic Apperception Test: Indices of Aggression in Relation to Measures of Overt and Covert Behavior," American Journal of Orthopsychiatry, XXVI (1956), 567-76.

240. Livson, N., and Mussen, P. H. "The Relation of Ego Control to Overt Aggression and Dependency," Journal of Abnormal and Social Psychology, LV (1957), 66-71. 
241. Lotrier, S. "Distribution of Criminal Offenses in Metropolitan Regions," Journal of Criminal Law and Criminology, XXIX (1938), 37-50.

242. Lustman, S. L. "The Headache as an Internalized Rage Reaction: a Preliminary Report," Psychiatry, XIV (1951), 433-38.

243. LyoN, W. "Justification and Command as Techniques for Hypnotically-induced Antisocial Behavior," Journal of Clinical Psychology, X (1954), 288-90.

244. Macfarlane, J. W., Allen, L., and HonzIK, M. P. A Developmental Study of the Behavior Problems of Normal Children between Twenty-one Months and Fourteen Years ("University of California Publications in Child Development.") Berkeley: University of California Press, 1954.

245. Mahler, Margaret S. "A Psychoanalytic Evaluation of Tic in Psychopathology of Children," Psychoanalytic Study of the Child, III/IV (1949), 279-310.

246. MAIER, N. R. F. Frustration: The Study of Behavior without a Goal. New York: McGraw-Hill Book Co., Inc., 1949.

247. - - "Frustration Theory: Restatement and Extension," Psychological Review, LXIII (1956), 370-88.

248. Malone, A. J., and Masslen, M. "Index of Nailbiting in Children," Journal of Abnormal and Social Psychology, XLVII (1952), 193-202.

249. Maslow, A. H. "Deprivation, Threat, and Frustration," Psychological Review, XLVIII (1941), 364-66.

250. - - "The Dynamics of Psychological Security-Insecurity," Character and Personality, X (1942), 331-44.

251. - - . "A Comparative Approach to the Problem of Destructiveness," Psychiatry, V (1942), 517-22.

252. - _... "A Theory of Human Motivation," Psychological Review, L (1943), 370-96.

253. ---. "Conflict, Frustration, and the Theory of Threat," Journal of Abnormal and Social Psychology, XXXVIII (1943), 8186.

254. Mason, P. "Suicide in Adolescents," Psychoanalytic Review, XLI (1954), 48-54.

255. Masserman, J. H. Behavior and Neurosis. Chicago: University of Chicago Press, 1943.

256. - - . "Experimental Neuroses and Group Aggression," American Journal of Orthopsychiatry, XIV (1944), 636-43
257. Matarazzo, J. D. “An Experimental Study of Agression in the Hypertensive Patient," Journal of Personality, XXII (1954), 42347.

258. Maudry, M., and Nexula, M. "Social Relations between Children of the Same Age during the First Two Years of Life," Journal of Genetic Psychology, LIV (1939), 193-215.

259. McClelland, D. C. Personality. New York: Dryden Press, 1951.

260. McCrelland, D. C., and Apicella, F. S. "A Functional Classification of Verbal Reactions to Experimentally Induced Failure," Journal of Abnormal and Social Psychology, XL (1945), 376-90.

261. McDovgalL, W. An Introduction to Social Psychology. New York: John W. Luce \& Co., 1926.

262. MCGeE, S. "Measurement of Hostility: A Pilot Study," Journal of Clinical Psychology, X (1954), 280-82.

263. MCNerL, E. B. "Social Class and the Expression of Emotion," Papers of the Michigan Academy of Science, Arts, and Letters, XLI (1956), 341-48.

264. McNeIl, E. B., and Cohler, J. R. "The Effect of Personal Needs on Counselor's Perception and Behavior," Papers of the Michigan Academy of Science, Arts, and Letters, XLII (1957), 281-88.

265. - - . "Adult Aggression in the Management of Disturbed Children," Child Development, XXIX (1958), 451-61.

266. Meltzer, H. "Students' Adjustments in Anger," Journal of Social Psychology, IV (1933), 285-309.

267. - - . "Anger Adjustments in Relation to Intelligence and Achievement," Journal of Genetic Psychology, L (1937), 63-82.

268. Menninger, K. Man against Himself. New York: Harcourt, Brace \& Co., 1938.

269. Merrill, M. A. Problems of Child Delinquency. Boston: Houghton Mifflin Co., 1947.

270. Miller, H., and Baruch, Dorothy W. "A Study of Hostility in Allergic Children," American Journal of Orthopsychiatry, XX (1950), 506-19.

271. Miller, M. L. "Blood Pressure Findings in Relation to Inhibited Aggressions in Psychotics," Psychosomatic Medicine, I (1939), 162-72.

272. Miller, N. E. "The Frustration-Aggression 
Hypothesis," Psychological Review, XL.VIII (1941), 337-42.

273. - - "Experimental Studies of Conflict." In J. McV. Hunt (ed.), Personality and the Behavior Disorders. (New York: Ronald Press Co., 1944.

274. Miller, N. E., and Bugelskx, R. "Minor Studies of Aggression. II. The Influence of Frustrations Imposed by the In-Group on Attitudes Expressed toward Out-Groups," Journal of Psychology, XXV (1948), 43742.

275. Mrrler, N. E., and Dollard, J. Social Learning and Imitation. New Haven: Yale University Press, 1941.

276. Mirss, C. A. "Suicide and Homicides in Their Relation to Weather Changes," American Journal of Psychiatry, XCI (1934), 669-77.

277. Morgan, Patricil K., and Gaier, E. L. "The Direction of Aggression in the Mother-Child Punishment Situation," Child Development, XXVII (1956), 447-57.

278. Morlan, G. K. "A Note on the FrustrationAggression Theories of Dollard and His Associates," Psychological Review, LVI (1949), 1-8.

279. Morse, W. C., and Wineman, D. "Group Interviewing in a Camp for Disturbed Boys," Journal of Social Issues, XIII (1957), 23-32.

280. - - . "The Therapeutic Use of Social Isolation in a Camp for Ego-disturbed Boys," ibid., pp. 32-40.

281. Moss, L. M., and Hamliton, D. M. "The Psychotherapy of the Suicidal Patient," American Journal of Psychiatry, CXII (1956), 814-20.

282. Moulton, R. W., and McNeIl, E. B. "The Relationship of the Socialization Process to the Handling of Aggression in Psychiatric Patients," Papers of the Michigan Academy of Science, Arts, and Letters, XLII (1957), 289-97.

283. Mummery, Donothy V. "An Analytical Study of Ascendant Behavior of Preschool Children," Child Development, XVIII (1947), 40-81.

284. - - "Family Background of Assertive and Non-assertive Children," ibid., XXV (1954), 63-80.

285. Murphy, F. J., Shirley, M. M., and WitMER, HELEN L. "The Incidence of Hidden
Delinquency," American Journal of Orthopsychiatry, XVI (1946), 686-96.

286. MURPHY, LoIs B. Social Behavior and Child Personality: An Exploratory Study of Some Roots of Sympathy. New York: Columbia University Press, 1937.

287. Murray, H. A. "The Effects of Fear upon Estimates of the Maliciousness of Other Personalities," Journal of Social Psychology, IV (1933), 310-29.

288. Murray, H. A., et. al. Explorations in Personality. New York: Oxford University Press, 1938.

289. Mussen, P. H. "Some Personality and Social Factors Related to Changes in Children's Attitudes toward Negroes," Journal of Abnormal and Social Psychology, XLV (1950), 423-41.

290. Mussen, P. H., and Naylor, H. K. "The Relationships between Overt and Fantasy Aggression," Journal of Abnormal and Social Psychology, LI (1954), 235-40.

291. Muste, Myra J., and Sharpe, Doris F. "Some Influential Factors in the Determination of Aggressive Behavior in Preschool Children," Child Devolopment, XVIII (1947), 11-28.

292. NACHT, S. "Clinical Manifestations of Aggression and Their Role in Psychoanalytic Treatment," International Journal of Psychoanalysis XXIX (1948), 201-23.

293. Nagelberg, L., and Spotnitz, $H$. "Strengthening the Ego through Release of Frustration-Aggression," American Journal of Orthopsychiatry, XXVIII (1958), 794801.

294. National Office of Vital Statistics. Vital Statistics of the United States, I, 20916, Table 8.43. Washington, D.C.: U.S. Public Health Service, 1950.

295. Newcomb, T. M. "Autistic Hostility and Social Reality," Human Relations, I (1947), 69-86.

296. Newstatter, W. L. The Mind of the Murderer. New York: Philosophical Library, Inc., 1957.

297. Nunberg, H. "The Sense of Guilt and the Need for Punishment," International Journal of Psychoanalysis, VIII (1926), 420-33.

298. O'Connor, W. A. "Some Notes on Suicide," British Journal of Medical Psychology, XXI (1947), 222-28.

299. Oltman, J. E., and Friedman, S. "The Role of Hostility in Affective Psychoses," 
Journal of Nervous and Mental Disease, XCVII (1943), 170-96.

300. O'Neal, Patricia, Robins, E., and Schmid, E. H. "A Psychiatric Study of Attempted Suicide in Persons over Sixty Years of Age," American Medical Association Archives of Neurology and Psychiatry, LXXV (1956), 275-84.

301. Otrs, Nancy B., and McCandless, B. "Responses to Repeated Frustrations of Young Children Differentiated According to Need Area," Journal of Abnormal and Social Psychology, L (1955), 349-53.

302. PAGE, M. L. The Modification of Ascendant Behavior in Preschool Children. ("University of Iowa Studies in Child Welfare," Vol. XII, chap. iii.) 1936.

303. Palmer, D. M. "Factors in Suicidal Attempts: A Review of 25 Consecutive Cases," Journal of Nervous and Mental Disease, XCIII (1941), 421-42.

304. Palmen, H. Psychopathic Personalities. New York: Philosophical Library, 1957.

305. Parsons, T. "Certain Primary Sources and Patterns of Aggression in the Social Structure of the Western World," Psychiatry, X (1947), 167-81.

306. Parten, M. B. "Social Participation among Preschool Children," Journal of Abnormal and Social Psychology, XXVII (1932), 243-69.

307. Pastone, N. "A Neglected Factor in the Frustration-Aggression Hypothesis: A Comment," Journal of Psychology, XXIX (1950), 271-79.

308. - - "The Role of Arbitrariness in the Frustration-Aggression Hypothesis," Journal of Abnormal and Social Psychology, XLVII (1952), 728-31.

309. Patrie, F. A. "The Effect of Hypnotically Induced Hostility on Rorschach Responses," Journal of Clinical Psychology, X (1954), 161-64.

310. Pearson, G. H. J. "The Chronically Aggressive Child," Psychoanalytic Review, XXVI (1939), 485-525.

311. Pepitone, A., and Reichling, G. "Group Cohesiveness and the Expression of Hostility," Human Relations, VIII (1955), 327-37.

312. Phillips, L., and Rabinovitch, S. S. "Social Role and Patterns of Symptomatic Behaviors," Journal of Abnormal and Social Psychology, LVII (1958), 181-86.
313. Piker, P. "Eighteen Hundred and Seventeen Cases of Suicidal Attempts: A Preliminary Statistical Study," American Journal of Psychiatry, CV (1938), 97-117.

314. Pintler, Margaret H. "Doll Play as a Function of the Experimenter-Child Interaction and Initial Organization of Materials," Child Development, XVI (1945), 145-66.

315. Pintler, Margaret H., Philltps, Ruth, and SeArs, R. R. "Sex Differences in the Projective Doll Play of Preschool Children," Journal of Psychology, XXI (1946), 73-80.

316. Pitluck, Patricia. "The Relation between Aggressive Phantasy and Overt Behavior." Unpublished doctoral dissertation, Yale University, 1950.

317. Pollack, B. "A Study of the Problem of Suicide," Psychiatric Quarterly, XII (1938), $306-30$.

318. Porte, J. V., and Parkhunst, E. "Homicide in New York State," Human Biology, VII ( 1935), 47-73.

319. Porterfield, A. L. "Suicide and Crime in the Social Structure of an Urban Setting: Fort Worth, 1930-1950," American Sociological Review, XVII (1952), 341-49.

320. Powdermaker, Hortense. "The Channeling of Negro Aggression by the Cultural Process," American Journal of Sociology, XLVIII (1943), 750-58.

321. Purcell, K. "The TAT and Antisocial Behavior," Journal of Consulting Psychology, XX (1956), 449-56.

322. - - . "Some Shortcomings in Projective Test Validation," Journal of Abnormal and Social Psychology, LVII (1958), 115-18.

323. Rabin, A. I. "Homicide and Attempted Suicide: A Rorschach Study," American Journal of Orthopsychiatry, XVI (1946), 516-24.

324. Kadxe, Marian J. The Relation of Parental Authority to Children's Behavior and Attitudes. ("University of Minnesota Institute Child Welfare Monograph Series," Vol. XXII.) 1946.

325. Radke, Marian J., and Troger, H. G. "Children's Perception of the Social Roles of Negroes and Whites," Journal of Psychology, XXIX (1950), 3-33.

326. Radke, Marian J., Troger, H. G., and Davis, H. "Social Perceptions and Attitudes of Children," Genetic Psychology Monographs, XL (1949), 327-447. 
327. Radke-Yarrow, Marian, Thoger, H. G., and Milleer, J. "The Role of Parents in the Development of Children's Ethnic Attitudes," Child Development, XXIII (1952), 3-53.

328. Rappapont, D. "Freudian Mechanisms and Frustration Experiments," Psychoanalytic Quarterly, XI (1942), 503-11.

329. Read, C. S. "The Problem of Suicide," British Medical Joumal, I (1936), 631-34.

330. Reckless, W. C. The Crime Problem, New York: Appleton-Century-Crofts, Inc., 1950.

331. Reckless, W. C., Dinitz, S., and Murray, ELLEN. "Self-Concept as an Insulator against Delinquency," American Sociological Review, XXI (1956), 744-46.

332. ReDL, F., and Wineman, D. Children Who Hate: The Disorganization and Breakdown of Behavior Controls. Glencoe, Ill.: Free Press, 1951.

333. ---. Controls from Within: Techniques for the Treatment of the Aggressive Child. Glencoe, Ill.: Free Press, 1952.

334. Reichard, Suzanne, and Tillman, C. "Murder and Suicide as Defenses against Schizophrenic Psychosis," Journal of Clinical Psychopathology, XI (1950), 149-63.

335. ReIK, T. Masochism in Modern Man. New York: Farrar \& Rinehart, 1941.

336. -- . "Aggression from Anxiety," International Journal of Psychoanalysis, XXII (1941), 7-16.

337. ReIss, A. J., Jr. "Delinquency as the Failure of Personal and Social Controls," American Sociological Review, XVI (1951), 196-207.

338. - - . "Social Correlates of Psychological Types of Delinquency," ibid., XVII (1952), 710-18.

339. Ricketrs, A. F. "A Study of the Behavior of Young Children in Anger." In L. M. JaCk, E. M. ManWell, and I. G. Mengert, Behavior of the Preschool Child. ("University of Iowa Studies in Child Welfare," Vol. IX, No. 3.) Iowa City: University of Iowa Press, 1934.

340. Rittwagen, Marjorie. Sins of Their Fathers. Boston: Houghton Mifflin Co., 1958.

341. Rosenzweig, S. "An Outline of Frustration Theory." In J. McV. Hunt (ed.), Psychology and the Behavior Disorders. New York: Ronald Press Co., 1944.

342. Rowland, L. W. "Will Hypnotized Persons
Try To Harm Themselves or Others?" Journal of Abnormal and Social Psychology, XXXIV (1939), 114-17.

343. SADLER, W. S. "Juvenile Manic Activity," Nervous Child, IX (1952), 363-68.

344. Sakmeim, G. A. "Suicidal Responses on the Rorschach Test: A Validation Study," Journal of Nervous and Mental Disease, CXXII (1955), 332-44.

345. Sanford, R. N., Adkins, Margaret M., MUller, R. B., and Cobs, Elizabeth A. "Physique, Personality, and Scholarship," Monographs of the Society for Research in Child Development, XIII (1943), 1-105.

346. Saprenfield, B. R. Personality Dynamics. New York: Alfred A. Knopf, 1954.

347. SaUl, L. J. "Hostility in Cases of Essential Hypertension," Psychosomatic Medicine, I. (1939), 153-61.

348. Schachter, M. “The Cyclothymic States in the Prepubescent Child," Nervous Child, IX (1952), 357-62.

349. Schilder, P., and Wechsler, D. "The Attitude of Children toward Death," Journal of Genetic Psychology, LV (1934), 406-51.

350. SchMid, C. F. "A Study of Homicides in Seattle, 1914-1924," Social Forces, IV (1926), 745-56.

351. -- . "Suicide in Minneapolis, Minnesota, 1928-1932," American Journal of Sociology, XXXIX (1933), 30-48.

352. Schmid, C. F., and VAN Arsdol, M. D., Jr. "Completed and Attempted Suicides: A Comparative Analysis," American Sociological Review, XX (1955), 273-83.

353. SchNeck, J. M. “A Military Offense Induced by Hypnosis," Journal of Nervous and Mental Disease, CVI (1947), 186-89.

354. Scrur, M. "Comments on the Metapsychology of Somatization," Psychoanalytic Study of the Child, X (1955), 119-64.

355. Scotr, J. P. "The Effects of Selection and Domestication on the Behavior of the Dog," Journal of the National Cancer Institute, XV (1954), 739-58.

356. ---. Aggression. Chicago: University of Chicago Press, 1958.

357. Scott, J. P., and Marston, M. V. "Nonadaptive Behavior Resulting from a Series of Defeats in Fighting Mice," Journal of Abnormal and Social Psychology, XLVIII (1953), 417-28.

358. Sears, Pauline S. Doll Play Aggression 
in Normal Young Children: Influence of Sex, Age, Sibling Status, Father's Absence. ("Psychological Monographs," Vol. LXV.) 1951 .

359. Sears, R. R. "II. Non-Aggressive Reactions to Frustration," Psychological Review, XLVIII (1941), 343-46.

360. Sears, R. R., Maccoby, Eleanor E., and Levin H. Patterns of Child Rearing. Evanston, Ill.: Row, Peterson \& Co., 1957.

361. Sears, R. R., Pintleh, Marganet H., and Sears, Pauline S. "Effect of Father Separation on Preschool Children's Doll Play Aggression," Child Development, XVII (1946), 219-43.

362. Seaps, R. R., Whiting, J. W. M., Nowlis, V., and Sears, Pauline S. "Some Childrearing Antecedents of Aggression and Dependency in Young Children," Genetic Psychology Monographs, XLVII (1953), 135236.

363. Seib, C. B., and Otten, A. L. "The Case of the Furious Children," Harper's Magazine, January, 1958.

364. Seward, J. P. "Aggressive Behavior in the Rat," Journal of Comparative Psychology, XXXVIII (1945), 175-97.

365. -- . "Aggressive Behavior in the Rat," ibid., XXXIX (1946), 51-76.

366. Seweld, W. H., Mussen, P. H., and HarRIs, C. W. "Relationships among Child Training Practices," American Sociological Review, XX (1955), 137-48.

367. Shaw, C. R. Delinquency Areas. Chicago: University of Chicago Press, 1929.

368. Shaw, C. R., et al. Juvenile Delinquency and Urban Areas. Chicago: University of Chicago Press, 1942.

369. Siegel, Alberta E. "Aggressive Behavior of Young Children in the Absence of an Adult," Child Development, XXVIII (1957), 371-78.

370. SIEGEL, S. M. "The Relationship of Hostility to Authoritarianism," Journal of $A b$ normal and Social Psychology, LII (1956), 368-72.

371. Silverberg, W. V. Childhood Experience and Personal Destiny. New York: Springer Pub. Co., 1952.

372. Stmpson, G. "Methodological Problems in Determining the Aetiology of Suicide," American Sociological Review, XV (1950), 658-63.

373. SoBEL, R. "Treatment of Character-con- ditioned Hostility in Adolescents," Nervous Child, VIII (1949), 301-10.

374. Sperry, Bessie M., Staver, Nancy, and ManN, H. E. "Destructive Fantasies in Certain Learning Difficulties," American Journal of Orthopsychiatry, XXII (1952), 35665.

375. Stagner, R. "Studies of Aggressive Social Attitudes. I. Measurement and Interrelation of Selected Attitudes," Journal of Social Psychology, XX (1944), 109-20.

376. Stagnen, R., and Congdon, C. S. "Another Failure To Demonstrate Displacement of Aggression," Journal of Abnormal and Social Psychology, LI (1955), 695-96.

377. Stone, H. "The TAT Aggressive Content Scale," Journal of Projective Techniques, XX (1956), 445-52.

378. Sutherland, E. H. Principles of Criminology. Philadelphia: J. B. Lippincott Co., 1947.

379. Symonds, P. M. The Dynamics of Human Adjustment. New York: Appleton-CenturyCrofts, Inc., 1946.

380. Teicher, J. D. "A Study in Attempted Suicide," Journal of Nervous and Mental Disease, CV (1947), 283-98.

381. Thibaut, J. "An Experimental Study of the Cohesiveness of Underprivileged Groups," Human Relations, III (1950), 251-78.

382. Thibaut, J. W., and Coules, J. "The Role of Communication in the Reduction of Interpersonal Hostility," Journal of Abnormal and Social Psychology, XLVII (1952), 770-77.

383. Тном, D. A. "Juvenile Delinquency and Criminal Homicide," Journal of Maine Medical Association, XL (1949), 176-80.

384. Thonndixe, E. L. The Original Nature of Man. New York: Bureau of Publications, Teachers College, Columbia University, 1913.

385. ThonNe, F. C. "The Frustration-AngerHostility States: A New Diagnostic Classification," Journal of Clinical Psychology, IX (1953), 334-39.

386. Tolsma, F. J. "Some Considerations on the Phenomenon of Aggression," Journal of Mental Science, CI (1953), 473-82.

387. Vollmer, H. "Jealousy in Children," American Journal of Orthopsychiatry, XVI (1946), 660-71.

388. WALL, J. H. "The Psychiatric Problem of 
Suicide," American Journal of Psychiatry, CI (1944), 404-6.

389. Walters, J., Pearce, D., and Dahms, L. "Affectional and Aggressive Behavior of Preschool Children," Child Development, XXVIII (1957), 15-26.

390. Watkins, J. G. "Antisocial Compulsions Induced under Hypnotic Trance," Journal of Abnormal and Social Psychology, XLII (1947), 256-59.

391. Watson, J. P. Psychology from the Standpoint of a Behaviorist. Philadelphia: J. B. Lippincott Co., 1919.

392. Watson, R. E., Pritzker, L., and Madison, P. "Hostility in Neurotics and Normals," Journal of Abnormal and Social Psychology, L (1955), 36-40.

393. WeCHSLER, D. "The Incidence and Significance of Fingernail Biting in Children," Psychoanalytic Review, XVIII (1931), 201-9.

394. Weinberg, S. K., and Arond, H. "The Occupational Culture of the Boxer," American Journal of Sociology, LVII (1952), 460-69.

395. Weiss, J. M. A. “Suicide: An Epidemiologic Analysis," Psychiatric Quarterly, XXVIII (1954), 225-52,

396. Weitzenhoffer, A. M. "The Production of Antisocial Acts under Hypnosis," Journal of Abnormal and Social Psychology, XLIV (1949), 420-22.

397. - - Hypnotism: An Objective Study in Suggestibility. New York: John Wiley \& Sons, Inc., 1953.

398. Weich, L. "What Is Need Reduction," Journal of Psychology, XXXIII (1952), 153-57.

399. Welissch, E. "A Colony for Maladjusted Children," Mental Health, X (1950), 6-9.

400. WELLS, W. R. "Experiments in the Hypnotic Production of Crimes," Journal of Psychology, XI (1941), 63-102.

401. White, Mary Alice, and Schrember, HanNa. "Diagnosing 'Suicidal Risks' on the Rorschach," Psychiatric Quarterly Supplement, XXVI (1952), 161-89.
402. Whiting, J. W. M., and Chind, I. L. Child Training and Personality. New Haven: Yale University Press, 1953.

403. Whitman, H. Terror in the Streets. New York: Dial Press, 1951.

404. Williams, E. Y. "Some Observations on the Psychological Aspects of Suicide," Journal of Abnormal and Social Psychology, XXXI (1936), 260-65.

405. WIRT, R. D. "Ideational Expression of Hostile Impulses," Journal of Consulting Psychology, XX (1956), 185-89.

406. Wittman, Mary P., and Huffman, A. V. "A Comparative Study of Developmental Adjustment, and Personality Characteristics of Psychotic, Psychoneurotic, Delinquent, and Normally Adjusted Teen Aged Youths," Journal of Genetic Psychology, LXVI (1945), 167-82.

407. Wolberg, L. R. “A Note on the Treatment of Aggression in Emotionally Disturbed Children," Psychiatric Quarterly, XVIII (1944), 667-73.

408. WORCHEL, P. "Catharsis and the Relief of Hostility," Journal of Abnormal and Social Psychology, LV (1957), 238-43.

409. Wricht, M. E. "Constructiveness of Play as Affected by Group Organization and Frustration," Character and Personality, XI (1942), 40-49.

410. --_. "The Influence of Frustration upon Social Relations of Young Children," ibid., XII (1943), 111-22.

411. Young, P. C. "Experimental Hypnotism: A Review," Psychological Bulletin, XXXVIII (1941), 92-104.

412. ZANDER, A. F. A Study of Experimental Frustration. ("Psychological Monographs," Vol. LVI, No. 256.) 1944.

413. Zilboorg, G. "Considerations on Suicide, with Particular Reference to That of the Young," American Journal of Orthopsychiatry, VII (1937), 15-31.

414. Zuckermann, S. The Social Life of Monkeys and Apes. London: Kegan, Paul; New York: Harcourt, Brace \& Co., 1932. 